\author{
UNIVERSIDADE DE SÃO PAULO \\ ESCOLA DE ARTES, CIÊNCIAS E HUMANIDADES \\ PROGRAMA DE PÓS-GRADUAÇÃO EM SISTEMAS DE INFORMAÇÃO
}

JOZIAS ROLIM DE ARAÚJO JÚNIOR

Reconhecimento Multibiométrico Baseado em Imagens de Face Parcialmente Ocluídas

São Paulo

2019 


\section{Reconhecimento Multibiométrico Baseado em Imagens de Face Parcialmente Ocluídas}

Dissertação apresentada à Escola de Artes, Ciências e Humanidades da Universidade de São Paulo para obtenção do título de Mestre em Ciências pelo Programa de Pós-graduação em Sistemas de Informação.

Área de concentração: Metodologia e Técnicas da Computação

Versão corrigida contendo as alterações solicitadas pela comissão julgadora em 28 de maio de 2018. A versão original encontra-se em acervo reservado na Biblioteca da EACH-USP e na Biblioteca Digital de Teses e Dissertações da USP (BDTD), de acordo com a Resolução CoPGr 6018, de 13 de outubro de 2011.

Orientador: Prof. Dr. Clodoaldo Aparecido de Moraes Lima

Coorientador: Profa. Dra. Sarajane Marques Peres

São Paulo 
Autorizo a reprodução e divulgação total ou parcial deste trabalho, por qualquer meio convencional ou eletrônico, para fins de estudo e pesquisa, desde que citada a fonte.

CATALOGAÇÃO-NA-PUBLICAÇÃO

(Universidade de São Paulo. Escola de Artes, Ciências e Humanidades. Biblioteca) CRB-8 4936

Araújo Júnior, Jozias Rolim de

Reconhecimento multibiométrico baseado em imagens de face parcialmente ocluídas / Jozias Rolim de Araújo Júnior ; Clodoaldo Aparecido de Moraes Lima, orientador, ; coorientadora, Sarajane Marques Peres. - 2019.

$120 \mathrm{f}$ : : il.

Dissertação (Mestrado em Ciências) - Programa de PósGraduação em Sistemas de Informação, Escola de Artes, Ciências e Humanidades, Universidade de São Paulo, em 2018..

Versão corrigida

1. Reconhecimento de padrões. 2. Interface homem computador. 3. Percepção da face. 4. Face - Análise. I. Lima, Clodoaldo Aparecido de Moraes, orient. II. Peres, Sarajane Marques, coorient. III. Tìtulo.

CDD 22.ed.- 006.4 
Dissertação de autoria de Jozias Rolim de Araújo Júnior, sob o título "Reconhecimento Multibiométrico Baseado em Imagens de Face Parcialmente Ocluídas", apresentada à Escola de Artes, Ciências e Humanidades da Universidade de São Paulo, para obtenção do título de Mestre em Ciências pelo Programa de Pós-graduação em Sistemas de Informação, na área de concentração Metodologia e Técnicas da Computação, aprovada em 29 de março de 2018 pela comissão julgadora constituída pelos doutores:

Prof. Dr.Clodoaldo Aparecido de Moraes Lima

Escola de Artes, Ciências e Humanidades - Universidade de São Paulo

Presidente

Prof. Dr. Alessando Zimmer

Departamento de Engenharia Elétrica - Universidade Federal do Paraná

Prof. Dr. Odemir Martinez Bruno

Departamento de Física e Ciência Interdisciplinar - Universidade de São Paulo

Profa. Dra. Fátima de Lourdes dos Santos Nunes Marques

Escola de Artes, Ciências e Humanidades - Universidade de São Paulo 
Dedico este trabalho primeiramente a Deus, por ser essencial em minha vida, por ter traçado o caminho do qual percorri, por ter me dado forças e energia até o fim dessa trajetória. A minha esposa Kédyma Rolim, que com muito carinho e apoio não mediu esforços para que eu chegasse até aqui. 


\section{Agradecimentos}

Agradeço, primeiramente, à Deus, que me deu forças e energia para concluir todo esse trabalho. Durante toda minha trajetória guiou meus passos foi socorro bem presente nas horas de angústias, fraquejei diversas vezes, por muitas pensei em desistir, mas Deus sempre usou pessoas e situações que me levassem a continuar e persistir até o fim. A bíblia cita em Gálatas cap. 6 versículo 9: "E não nos cansemos de fazer o bem, pois no tempo próprio colheremos, se não desanimarmos.". Tentei sempre fazer o bem, ajudar a quem precisava e cooperar com tudo, muitas vezes a pesquisa é muito intensa, difícil e a caminhada é muito complicada, as montanhas parecem altas demais para escalar, e são, mas cada lasca na montanha, cada apoio, cada técnica utilizada, foi de grande aprendizado e Deus permitiu que chegasse bem alto, para que eu pudesse olhasse para trás e falar que "essa montanha me ensinou demais, muito obrigado por ser tão dura".

Aos meus pais, que mesmo distantes e em situação dificil, não pararam de me ajudar e me incentivar para que eu concluísse com êxito essa etapa da minha vida. Sempre me deram oportunidade de estudar, sempre me deram incentivos, passei por dias difíceis, e eles sempre estavam lá. Minha mãe, uma guerreira, foi a minha fortaleza. Meu pai, independente do resultado, sempre com bom humor e orgulhoso em cada passo.

Aos Prof. Dr. Clodoaldo Aparecido de Moraes Lima e a Profa. Dra. Sarajane Marques Peres, pelas orientação, seu grande desprendimento em ajudar e amizade sincera. Cada um com seu perfil, foram extremamente importantes, me ajudaram muito, por conta disso, me considero uma nova pessoa, novo homem, um novo pesquisador. Demostraram o caminho da pesquisa, a vida acadêmica, compartilharam diversas experiências e acima de tudo foram atenciosos, dedicaram grande, do que para mim é a coisa mais valiosa no mundo, seu tempo em me orientar e mostrar o caminho a qual deveria traçar. Escrevendo esse agradecimento, vejo que palavras não conseguem descrever tudo que fizeram por mim, só agradeço e confirmo que levarei para toda a vida a grande experiência que me proporcionaram.

Aos colegas do Grupo de Inteligência Artificial (GrIA), que por diversos dias, noites e madrugadas, compartilharam experiências, dividiram tarefas e compartilhamos conhecimento e experiências. Foram amigos, companheiros e irmãos. Lutaram junto dia a dia sem fraqueja com o objetivo de alcançar o topo, foram um equipe incrível, pessoas 
de diversos lugares com culturas e experiências maravilhosas para compartilhar, cada um com habilidades incríveis que combinadas tornaram o GrIA um dos melhores ambientes para se trabalhar e pesquisar, obrigado por tudo.

Ao Programa de Pós-graduação em Sistemas de Informação (PPgSI) da Escola de Artes, Ciências e Humanidades da Universidade de São Paulo, por ter me proporcionado a oportunidade de fazer parte desse grupo seleto de pesquisadores e fornecer o incrível corpo docente do qual é formado. Pela atenção com que atendeu prontamente todos os chamados e dúvidas. Pelas oportunidades de apoio e tutoria em processo. 
"Se você tiver que escolher entre ser gentil e estar certo, escolha ser gentil e estará sempre certo!"

(Richard Carlson) 


\title{
Resumo
}

\author{
ARAÚJO JÚNIOR, Jozias Rolim de. Reconhecimento Multibiométrico Baseado \\ em Imagens de Face Parcialmente Ocluídas. 2019. 121 f. Dissertação (Mestrado em \\ Ciências) - Escola de Artes, Ciências e Humanidades, Universidade de São Paulo, São \\ Paulo, 2018.
}

Com o avanço da tecnologia, as estratégias tradicionais para identificação de pessoas se tornaram mais suscetíveis a falhas. De forma a superar essas dificuldades algumas abordagens vêm sendo propostas na literatura. Dentre estas abordagens destaca-se a Biometria. O campo da Biometria abarca uma grande variedade de tecnologias usadas para identificar ou verificar a identidade de uma pessoa por meio da mensuração e análise de aspectos físicos e/ou comportamentais do ser humano. Em função disso, a biometria tem um amplo campo de aplicações em sistemas que exigem uma identificação segura de seus usuários. Os sistemas biométricos mais populares são baseados em reconhecimento facial ou em impressões digitais. Entretanto, existem sistemas biométricos que utilizam a íris, varredura de retina, voz, geometria da mão e termogramas faciais. Atualmente, tem havido progresso significativo em reconhecimento automático de face em condições controladas. Em aplicações do mundo real, o reconhecimento facial sofre de uma série de problemas nos cenários não controlados. Esses problemas são devidos, principalmente, a diferentes variações faciais que podem mudar muito a aparência da face, incluindo variações de expressão, de iluminação, alterações da pose, assim como oclusões parciais. Em comparação com o grande número de trabalhos na literatura em relação aos problemas de variação de expressão/iluminação/pose, o problema de oclusão é relativamente negligenciado pela comunidade científica. Embora tenha sido dada pouca atenção ao problema de oclusão na literatura de reconhecimento facial, a importância deste problema deve ser enfatizada, pois a presença de oclusão é muito comum em cenários não controlados e pode estar associada a várias questões de segurança. Por outro lado, a Multibiométria é uma abordagem relativamente nova para representação de conhecimento biométrico que visa consolida múltiplas fontes de informação visando melhorar a performance do sistema biométrico. Multibiométria é baseada no conceito de que informações obtidas a partir de diferentes modalidades ou da mesma modalidade capturada de diversas formas se complementam. Consequentemente, uma combinação adequada dessas informações pode ser mais útil que o uso de informações obtidas a partir de qualquer uma das modalidades individualmente. A fim de melhorar a performance dos sistemas biométricos faciais na presença de oclusão parciais será investigado o emprego de diferentes técnicas de reconstrução de oclusões parciais de forma a gerar diferentes imagens de face, as quais serão combinadas no nível de extração de característica e utilizadas como entrada para um classificador neural. Os resultados demonstram que a abordagem proposta é capaz de melhorar a performance dos sistemas biométricos baseados em face parcialmente ocluídas.

Palavras-chaves: Sistemas Multibiométricos. Reconhecimento facial. Detecção de oclusão facial. Reconstrução de face parcialmente ocluída. Fusão de dados. Extração de características. Ambiente não controlado. 


\begin{abstract}
ARAÚJO JÚNIOR, Jozias Rolim de. Multibiometric Recognition Based on Partially Occluded Face Images. 2019. 121 p. Dissertation (Master of Science) School of Arts, Sciences and Humanities, University of São Paulo, São Paulo, 2018.

With the advancement of technology, traditional strategies for identifying people have become more susceptible to failures. In order to overcome these difficulties, some approaches have been proposed in the literature. Among these approaches, Biometrics stands out. The field of biometrics covers a wide range of technologies used to identify or verify a person's identity by measuring and analyzing physical and / or behavioral aspects of the human being. As a result, a biometry has a wide field of applications in systems that require a secure identification of its users. The most popular biometric systems are based on facial recognition or fingerprints. However, there are biometric systems that use the iris, retinal scan, voice, hand geometry, and facial thermograms. Currently, there has been significant progress in automatic face recognition under controlled conditions. In real world applications, facial recognition suffers from a number of problems in uncontrolled scenarios. These problems are mainly due to different facial variations that can greatly change the appearance of the face, including variations in expression, illumination, posture, as well as partial occlusions. Compared with the large number of papers in the literature regarding problems of expression / illumination / pose variation, the occlusion problem is relatively neglected by the research community. Although attention has been paid to the occlusion problem in the facial recognition literature, the importance of this problem should be emphasized, since the presence of occlusion is very common in uncontrolled scenarios and may be associated with several safety issues. On the other hand, multibiometry is a relatively new approach to biometric knowledge representation that aims to consolidate multiple sources of information to improve the performance of the biometric system. Multibiometry is based on the concept that information obtained from different modalities or from the same modalities captured in different ways complement each other. Accordingly, a suitable combination of such information may be more useful than the use of information obtained from any of the individuals modalities. In order to improve the performance of facial biometric systems in the presence of partial occlusion, the use of different partial occlusion reconstruction techniques was investigated in order to generate different face images, which were combined at the feature extraction level and used as input for a neural classifier. The results demonstrate that the proposed approach is capable of improving the performance of biometric systems based on partially occluded faces.
\end{abstract}

Keywords: Multibiometric systems. Facial recognition. Face occlusion detection. Reconstruction of partially occluded face. Fusion of data. Feature extraction. Uncontrolled environment. 


\section{Lista de figuras}

Figura 1 - Sistema biométrico integrado de forma serial . . . . . . . . . . . . . 35

Figura 2 - Sistema biométrico integrado de forma paralela . . . . . . . . . . . 36

Figura 3 - Sistema biométrico ntegrado de forma hierárquica . . . . . . . . . . . . 37

Figura 4 - Integração no nível sensorial . . . . . . . . . . . . . . 38

Figura 5 - Fusão no nível da extração de caracteristica . . . . . . . . . . . . . . . 39

Figura 6 - Fusão da pontuação obtida no nível de comparação . . . . . . . . . . . 39

Figura 7 - Fusão no nível da decisão . . . . . . . . . . . . . . . . . . . . 40

Figura 8 - Estrutura de Sistema biométrico baseado em faces parcialmente ocluídas 41

Figura 9 - Exemplo da geração de uma imagem integral . . . . . . . . . . . . . . 43

Figura 10 - Exemplo do cálculo da soma de um retângulo . . . . . . . . . . . . . . 43

Figura 11 - Exemplo de características de Haar . . . . . . . . . . . . . . . . . . . . 44

Figura 12 - Arquitetura do classificador cascata . . . . . . . . . . . . . . 45

Figura 13 - Skin Color - imagem original, máscara, imagem segmentada . . . . . . 48

Figura 14 - Eigenfaces . . . . . . . . . . . . . . . . . . 50

Figura 15 - Imagem da face original e reconstruída . . . . . . . . . . . . . . . 50

Figura 16 - Máscara de remoção de oclusão . . . . . . . . . . . . . . . . . . . . . 51

Figura 17 - Possíveis máscaras $O^{\prime} \ldots \ldots \ldots$. . . . . . . . . . . 61

Figura 18 - Reconstrução com regressão baseada em KNN . . . . . . . . . . . . . . 62

Figura 19 - Exemplo regressão baseada em KNN, com $\mathrm{k}=5$. . . . . . . . . . . . 63

Figura 20 - Reconstrução com regressão linear . . . . . . . . . . . . . . . . . 64

Figura 21 - Reconstrução com Regressão Ridge . . . . . . . . . . . . . . . . . . 65

Figura 22 - Reconstrução - regressão baseada em árvores extremamente aleatórias 66

Figura 23 - Decomposição Wavelet 2-D . . . . . . . . . . . . . . . 68

Figura 24 - Rede Neural MLP . . . . . . . . . . . . . . . . . . . . . 69

Figura 25 - Sistema de reconhecimento biométrico usando imagens de fase com oclusão no treinamento . . . . . . . . . . . . . . . . . . . . 71

Figura 26 - Sistema de reconhecimento biométrico baseado em imagens com oclusão, com reconstrução da parte ocluída . . . . . . . . . . . . . . . 72

Figura 27 - Arquitetura da Abordagem proposta . . . . . . . . . . . . . 78

Figura 28 - Imagens de face detectadas na base de dados AR . . . . . . . . . . . 81 
Figura 29 - Preprocessamento das imagens . . . . . . . . . . . . . . . . 82

Figura 30 - Remoção parte ocluída - Eigenfaces . . . . . . . . . . . . . . . 84

Figura 31 - Decomposição em três níveis - Wavelet - Coiflet . . . . . . . . . . . 87

Figura 32 - Evolução da taxa de reconhecimento variando os parãmetros da Rede

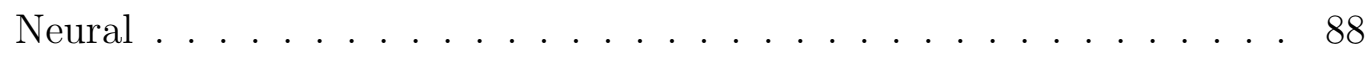

Figura 33 - Matriz de confusão . . . . . . . . . . . . . . . . . . . . . . . 89

Figura 34 - Exemplo de matriz de confusão . . . . . . . . . . . . . . . . . . . . . . 90

Figura 35 - Estrutura de um processo de reconhecimento facial sem tratamento da oclusão . . . . . . . . . . . . . . . . . . . 92

Figura 36 - Matriz de confusão para um sistema de reconhecimento biométrico sem treinamento da oclusão . . . . . . . . . . . . . . . . . . . . . . . . 93

Figura 37 - Estrutura de um processo de reconhecimento facial com tratamento da oclusão . . . . . . . . . . . . . . . . . . . . . . . 994

Figura 38 - Matriz de confusão para um sistema de reconhecimento biométrico com reconstrução facial baseada em RPCA . . . . . . . . . . . . . 95

Figura 39 - Exemplos de reconstrução facial baseada em Eigenfaces . . . . . . . . . 95

Figura 40 - Exemplos de reconstrução facial baseada em Fisherfaces . . . . . . . . 96

Figura 41 - Exemplos de reconstrução facial baseada em RPCA . . . . . . . . . . . 96

Figura 42 - Exemplos de reconstrução facial baseada em FRPCA . . . . . . . . . . 97

Figura 43 - Exemplos de reconstrução facial baseada em APCA . . . . . . . . . . . 97

Figura 44 - Exemplos de reconstrução facial baseada em GPCA . . . . . . . . . . . 98

Figura 45 - Matriz de confusão (para fold igual a 6) para um sistema de reconhecimento biométrico com reconstrução facial baseada Eigenfaces . . . . 100

Figura 46 - Matriz de confusão (para fold igual a 6) para um sistema de reconhecimento biométrico com reconstrução facial baseada em Fisherface . . . . 101

Figura 47 - Matriz de confusão (para fold igual a 6) para um sistema de reconhecimento biométrico com reconstrução facial baseada em RPCA . . . . 102

Figura 48 - Matriz de confusão (para fold igual a 6) para um sistema de reconhecimento biométrico com reconstrução facial baseada em FRPCA . . . . . 103

Figura 49 - Matriz de confusão (para fold igual a 6) para um sistema de reconhecimento biométrico com reconstrução facial baseada em APCA . . . . 104

Figura 50 - Matriz de confusão (para fold igual a 6) para um sistema de reconhecimento biométrico com reconstrução facial baseada em GPCA . . . . 105 


\section{Lista de algoritmos}

Algoritmo 1 - Algoritmo Skin Tone Detection . . . . . . . . . . . . . . . . . . 47

Algoritmo 2 - Algoritmo proposto por Erdogmus (ERDOGMUS et al., 2004) para calcular o PCA de forma recursiva, aplicado em imagens de face . . . . . . . . . . 58

Algoritmo 3 - Algoritmo de regressão baseada em árvores extremamante aleatórias . . . 67 


\section{Lista de tabelas}

Tabela 1 - Métricas de desempenho para um sistema de reconhecimento biométrico sem treinamento da oclusão . . . . . . . . . . . . . . . . . . . . . . . . 92

Tabela 2 - Métricas de desempenho para um sistema de reconhecimento biométrico com tratamento da oclusão . . . . . . . . . . . . . . . . . . . 94

Tabela 3 - Métricas de desempenho para um sistema de reconhecimento multibiométrico com tratamento da oclusão . . . . . . . . . . . . . . . . . 98

Tabela 4 - Resultados médios individuais de acurácia por técnica . . . . . . . . 99

Tabela 5 - Métricas de desempenho para um sistema de reconhecimento biométrico com reconstrução facial via Eigenfaces com validação cruzada 10-folds . 100

Tabela 6 - Métricas de desempenho para um sistema de reconhecimento biométrico com reconstrução facial via Fisherfaces com validação cruzada 10-folds 101

Tabela 7 - Métricas de desempenho para um sistema de reconhecimento biométrico com reconstrução facial via RPCA com validação cruzada 10-folds . . . 102

Tabela 8 - Métricas de desempenho para um sistema de reconhecimento biométrico com reconstrução facial via FRPCA com validação cruzada 10-folds . . 103

Tabela 9 - Métricas de desempenho para um sistema de reconhecimento biométrico com reconstrução facial via APCA e validação cruzada 10-folds ... 104

Tabela 10 - Métricas de desempenho para um sistema de reconhecimento biométrico com reconstrução facial via GPCA com validação cruzada 10-folds . . . 105

Tabela 11 - Métricas de desempenho para um sistema de reconhecimento biométrico com reconstrução facial via árvore extremamente aleatórias com validação cruzada 10-folds . . . . . . . . . . . . . . . . 106

Tabela 12 - Métricas de desempenho para um sistema de reconhecimento biométrico com reconstrução facial via regressão linear e validação cruzada 10-folds 106

Tabela 13 - Métricas de desempenho para um sistema de reconhecimento biométrico com reconstrução facial via regressão ridge com validação cruzada 10-folds107

Tabela 14 - Métricas de desempenho para um sistema de reconhecimento biométrico com reconstrução facial via regressão com KNN com validação cruzada 10 -folds . . . . . . . . . . . . . . . . . 107 
Tabela 15 - Métricas de desempenho para um sistema de reconhecimento biométrico sem reconstrução facial com validação cruzada 10-folds . . . . . . . . . 108

Tabela 16 - Métricas de desempenho para um sistema de reconhecimento multibiométrico com reconstrução facial baseada em subespaço com validação cruzada 10 -folds . . . . . . . . . . . . . . . . . . . 108

Tabela 17 - Métricas de desempenho para um sistema de reconhecimento multibiométrico com reconstrução facial baseada em subespaço e baseadas em regressões e validação cruzada 10-folds . . . . . . . . . . . . . 109

Tabela 18 - Resumo das Métricas de desempenho alcançadas no Experimento \#1, $\# 2$ e $\# 3$. . . . . . . . . . . . . . . . . . . . . . . . . . 110

Tabela 19 - Resumo das Métricas de desempenho alcançadas no Experimento \#4 . 111 


\section{Lista de abreviaturas e siglas}

APCA Análise dos componentes principais, do inglês, Asymmetrical Principal Component Analysis, é uma técnica de reconstrução facial baseada e subespaço que, a partir de uma imagem de entrada ocluída, projetando-a em um espaço de faces não ocluídas permite que seja possível reconstruila.

DFFS Distância do espaço de faces, do inglês, Distance From Face Space, é uma medida que ajuda a determinar a presença ou não de oclusão na imagem. Usada na técnica de detecção e remoção de oclusão Eigenfaces.

FRPCA Análise de componentes principais recursiva rápida, do inglês, Fast Recursive Principal Component Analysis, é uma técnica de reconstrução baseada em subespaços que permite, com poucas iterações, encontrar os coeficientes de combinação para reconstrução da imagem ocluída.

GPCA Gappy Principal Component Analysis, ou simplesmente GPCA, é uma técnica de reconstrução facial baseada em norma Gappy, onde a imagem de face ocluída é reconstruída de modo a minimizar o erro de reconstrução em relação a imagens não ocluídas, tratando apenas a região ocluída.

KNN K-Nearest Neighbors, ou simplesmente KNN, como costuma ser conhecida, é uma técnica que leva em consideração o comportamento de $k$ (quantidade) vizinhos para determinar o comportamento da amostra apresentada, leva em consideração medidas de distâncias para determinar a proximidade dos $k$ vizinhos.

LDA Análise de discriminante linear, do inglês, Linear Discriminant Analysis, é um método para redução da dimensionalidade que permite reduzir a dimensionalidade do espaço mantendo o máximo possível de informações.

PCA Análise de componentes principais, do inglês, Principal Component Analysis, é um método para redução de dimensionalide que permite reduzir a dimensionalidade do espaço projentando as características em 
menores dimensões de modo que as dimensões sejam mais representativas possível.

RGB Do inglês, Red, Green, and Blue, é a notação para representar imagem coloridas através da representação em combinação das cores vermelho, verde e azul.

RPCA Análise de componentes principais recursivo, do inglês, Recursive Principal Component Analysis, é uma técnica de reconstrução facial baseada em subespaços que permite que a imagem seja reconstruída encontrando os coeficientes de combinação da imagem de forma recursiva, ou seja, levando em consideração valores anteriores. 


\section{Lista de símbolos}

ii

$k$

$w$

$h$

I

$\psi$

$\hat{\mathrm{I}}$

E

$\Gamma$

$M$

$n$

$\Theta$

$\Psi$

$l$

A

C

V

$U$

$\|e\|$

$x$

Pixel da imagem integral (Viola Jones)

Contador (Viola Jones, Eigenface, GPCA)

Tamanho da imagem na dimensão x (Skin color)

Tamanho da imagem na dimensão y (Skin color)

Imagem em escala de cinza (Skin color)

Multiplicação pixels RGB (Skin color)

Resultante maior pixel entre G e B da imagem RGB (Skin color)

Erro de sinal (Skin color)

Representa uma matriz linha (Eigenfaces)

Representa w x h (Eigenfaces, RPCA)

Numero de imagens (Eigenfaces, Fisherfaces, APCA, RPCA, FRPCA, FWPCA, Completar faces)

Vetor de imagens sem a média (Eigenfaces)

Vetor de imagens média (Eigenfaces)

Valor muito menor que $\mathrm{w} x \mathrm{~h}$ (Eigenfaces)

Imagens sem a média (Eigenfaces)

Matriz de covariancia (Eigenfaces)

Combinação linear entre as imagens e o espaço tipo n x n (Eigenfaces)

Espaço de faces (Eigenfaces, Fisherface)

DFFS (Eigenfaces)

Imagem de entrada convertida em matriz coluna (Eigenfaces, Fisherfaces, APCA, RPCA, FRPCA, FWPCA, Completar faces) 
Imagem média (Eigenfaces, Fisherface, FRPCA)

Quantidade de eigenfaces (Eigenfaces, GPCA)

Coeficiente de combinação linear (Eigenfaces, GPCA, FRPCA)

Vetor no espaço de faces (Eigenfaces, GPCA, FRPCA)

Matrizes de dispersão dentro da própria classe (Fisherface)

Matrizes de dispersão entre classes (Fisherface)

Número de classes (Fisherface)

Vetor no espaço de face diferente de $v$ (GPCA)

Parte não ocluída da imagem I (APCA)

Vetor de face não ocluída (APCA)

Espaço de faces não ocluídas (APCA)

Pseudo autovetor (APCA)

coeficiente do vetor de imagem não ocluida (APCA)

Autovetor da matriz de covariância (APCA)

Autovetor da matriz de covariância (APCA)

Vetor ortogonal (RPCA)

Autovalor (RPCA)

Peso (FRPCA, Regressão linear, Regressão Ridge)

Constante de compensação (FRPCA)

Desvio padrão do erro de reconstrução (FWPCA)

Erro entre a imagem reconstruída e a imagem original (FWPCA)

Imagem reconstruída (FWPCA)

Mascara de oclusão (Completar faces) 
$O$

$O^{\prime}$

$y^{\prime}$

$Y^{\prime}$

Vetor de máscaras de oclusão (Completar faces)

Máscara resultante (Completar faces)

Classe das imagens (Completar faces)

Vetor das classes das imagens (Completar faces) 


\section{Sumário}

Introdução . . . . . . . . . . . . . . . . . 23

1.1 Contextualização e motivação . . . . . . . . . . . . 25

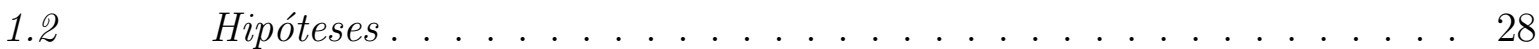

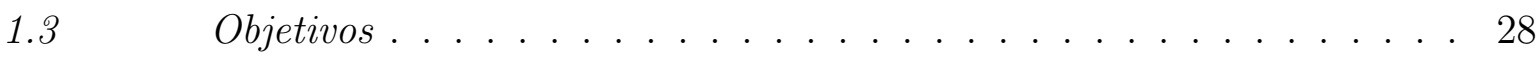

1.3.1 Objetivos gerais . . . . . . . . . . . . . . 29

1.3.2 Objetivos específicos . . . . . . . . . . . . . . 29

1.4 Estutura do trabalho. . . . . . . . . . . . . . . 29

2

Sistemas Biométricos ................ 31

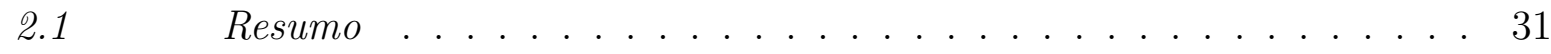

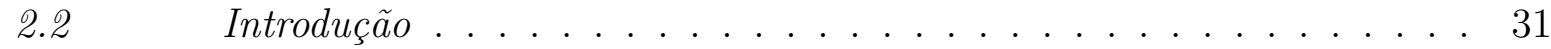

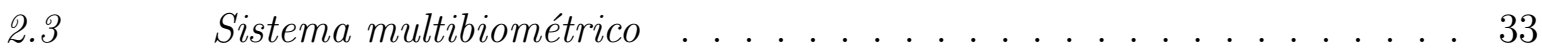

2.4 Estratégias de integração . . . . . . . . . . . . . 35

2.4.1 Integração baseada na arquitetura . . . . . . . . . . . . 35

2.4.2 Integração baseada no nível da fusão . . . . . . . . . . . . . . . . 36

$3 \quad$ Sistema de reconhecimento biométrico baseado em faces com

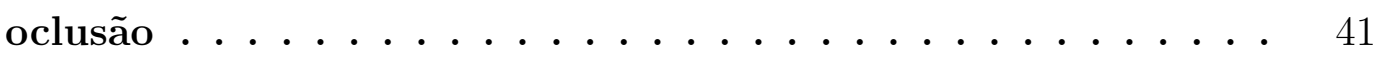

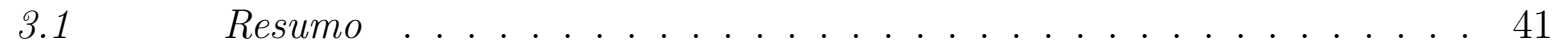

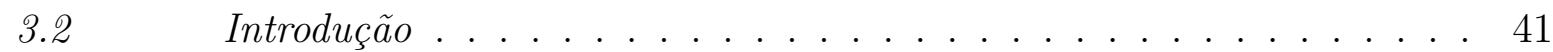

3.3 Detecção da Face . . . . . . . . . . . . . . . . 42

3.3.1 Algoritmo de detecção de fase baseado em Adaboost . . . . . . . . 42

3.3.2 Baseada em pigmentação da pele . . . . . . . . . . . . . . . 46

3.4 Técnica de detecção de oclusão . . . . . . . . . . . . . . 48

3.5 Técnicas de reconstrução de face baseadas em subespaços . . . . . . . 48

3.5.1 Eigenfaces . . . . . . . . . . . . . . . . . . 48

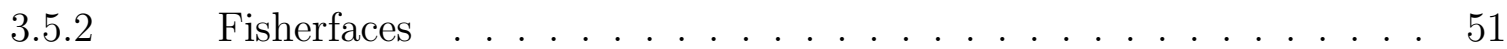

3.5.3 Análise de componentes principais Gappy . . . . . . . . . . . 52

3.5.4 Análise de componentes principais assimétricos . . . . . . . . . 53

3.5.5 Análise recursiva de componentes principais . . . . . . . . . . . 54

3.5.6 Análise recursiva rápida de componentes principais . . . . . . . . 58 
3.6.1 Regressão baseada em vizinhança . . . . . . . . . . . . . 62

3.6.2 Regressão linear . . . . . . . . . . . . . . . . . 63

3.6.3 Regressão Ridge . . . . . . . . . . . . . . . . . . . 64

3.6.4 Regressão baseada em árvores extremamente aleatórias . . . . . . . 65

3.7 Técnica de extração de característica - Transformadas Wavelets . . . 67

3.8 Técnica de comparação e decisão - Rede Neural MultiLayer Perceptron 68

Abordagem proposta ...................... 71

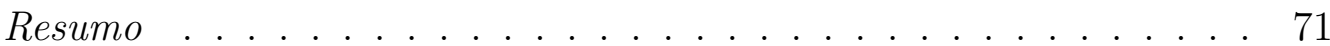

Trabalhos relacionados

Combinação de técnicas de reconstrução em nível de extração de características . . . . . . . . . . . . . . 76

Introdução . . . . . . . . . . . . . . . . . . . . . . . . . . . 79

5.3.3 Pré-processamento das imagens . . . . . . . . . . . . . . 80

5.3.4 Detecção da oclusão e remoção da parte ocluída . . . . . . . . . . . 82

5.3.5 Reconstrução baseada em sub-espaços . . . . . . . . . . . . 83

5.3.6 Reconstrução facial baseada em regressões . . . . . . . . . . . . . 85

5.3.7 Avaliação das imagens reconstruídas . . . . . . . . . . . 85

5.3.8 Extração de características . . . . . . . . . . . . . 86

5.3.9 Etapa de Fusão . . . . . . . . . . . . . . . . . . . 86

5.3.10 Classificador . . . . . . . . . . . . . . . . . 87

5.3.11 Métricas de avalição usadas nos experimentos . . . . . . . . . 88

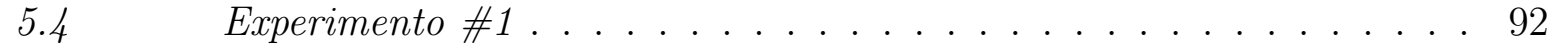

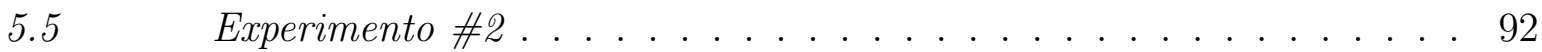

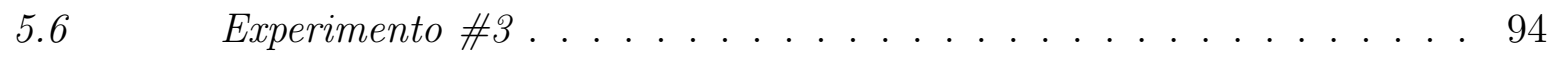


5.7.1 Técnicas baseadas em subespaço . . . . . . . . . . . . 99

5.7.2 Técnicas baseadas em regressão . . . . . . . . . . . . 106

5.7.3 Reconhecimento sem tratamento da oclusão . . . . . . . . . . . . 107

5.7.4 Fusão de técnicas de reconstrução baseadas em subespaço . . . . . 108

5.7.5 Fusão de técnicas de reconstrução baseadas em subespaço e baseadas em regressões . . . . . . . . . . . . . . . . . . . . 109

5.8 Discussão dos Resultados . . . . . . . . . . . . . . . 109

5.9 Considerações Finais . . . . . . . . . . . . . . . . 111

$6 \quad$ Conclusão e Perspectivas Futuras ～. . . . . . . . . . . 113

6.1 O enfoque da pesquisa . . . . . . . . . . . . . . 113

6.2 Contribuições e resultados obtidos . . . . . . . . . . . . . . . . 114

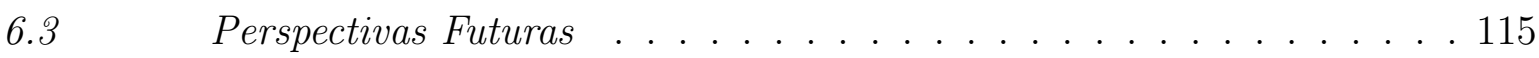

Referências $^{1} \ldots \ldots \ldots \ldots \ldots$ 


\section{Introdução}

Um problema fundamental em inteligência artificial é compreender e imitar a capacidade do sistema visual humano para processar e reconhecer faces, o qual tem atraído a atenção de diferentes comunidades, como neurociência, ciência da computação, estatística e psicologia. Reconhecimento biométrico facial, como um tema de pesquisa interdisciplinar, tem sido estudado por parte da comunidade de ciência da computação desde o início dos anos 90 (BUREL; CAREL, 1994; CHELLAPPA; WILSON; SIROHEY, 1995; DAUGMAN, 1997; LI; JAIN, 2011). Junto com o avanço tecnológico, o reconhecimento facial automático passou de filmes de ficção científica para a vida diária e se tornou uma técnica essencial para inúmeras aplicações de mundo real. Aplicações envolvendo reconhecimento facial podem ser encontradas em sistemas inteligentes, interação homem computador, gerenciamento de segurança, sistema de controle de acesso, vigilância por vídeo, computação ubíqua, indexação de multimídia, telefones inteligentes e motores de busca.

O campo da Biometria refere-se a uma grande variedade de tecnologias usadas para identificar e verificar a identidade de uma pessoa por meio da mensuração e análise de vários aspectos físicos e comportamentais do ser humano (AL-RAISI; AL-KHOURI, 2008). Modalidades biométricas são características extraídas do corpo humano, que são únicas para cada indivíduo e que podem ser usadas para estabelecer a identidade de um indivíduo em uma população. Dentre as principais modalidades biométricas empregadas temos: impressão digital (JAIN; FLYNN; ROSS, 2007), face (PHILLIPS et al., 2000), palma da mão (JAIN; FLYNN; ROSS, 2007), e íris (ZIAUDDIN; DAILEY, 2009). O fato das modalidades biométricas estarem ligadas diretamente a alguma característica dos usuários consiste em uma possibilidade extraordinária para superar os gaps de segurança causados pelas estratégias tradicionais de reconhecimento. Modalidades biométricas são mais difíceis de serem roubadas ou falsificadas quando comparadas aos números PIN ou senhas.

Dentre as modalidades biométricas, a face é a mais comumente vista e usada em nossa vida diária. Desde o advento da fotografia, tanto órgãos governamentais e organizações privadas têm mantido banco de dados de fotografias de pessoas contendo a face (por exemplo, para identificação pessoal, passaportes, cartões de sócio). Reconhecimento facial é um dos tópicos de pesquisa na área interdisciplinar de biometria, reconhecimento de padrão, 
visão computacional e aprendizado de máquina. A face é uma característica universal, única para cada pessoa e possui boa aceitabilidade em ambientes de captura. Reconhecimento automático facial em condições controladas tem alcançado um progresso significativo nos últimos anos. Entretanto, a performance em condições não controladas é ainda insatisfatória. Sistemas de reconhecimento facial em ambientes de mundo real, freqüentemente, lidam com condições não controladas e não previsíveis tais como grande mudança na iluminação, pose, expressão e oclusão, as quais introduzem variações intraclasse e degradam a performance de reconhecimento. Comparada com problemas de pose, iluminação e expressão, o problema relacionado à oclusão é relativamente pouco estudado na área.

De um modo geral, faces podem ser ocluídas de forma passiva ou ativa. Oclusões faciais são difíceis de serem evitadas completamente em ambientes de mundo real. Faces são usualmente ocluídas pelos próprios indivíduos. Por exemplo, na vida diária é comum as pessoas usarem acessórios faciais, tais como, óculos de sol, cachecóis, chapéus, máscaras e véus por razões culturais ou pessoais. Nos cenários envolvendo reconhecimento facial, pode-se pedir aos indivíduos para retirarem estes acessórios quando a cooperação do sujeito é aplicável (por exemplo, controle de fronteira), mas isto pode gerar alguns incômodos. Nos cenários relacionados à segurança, as pessoas tendem a usar a oclusão para esconder sua identidade e a cooperação do indivíduo não é aplicável a tudo (por exemplo, em sistemas de vigilância). O desenvolvimento de técnicas capazes de realizar o reconhecimento de faces ocluídas é muito importante, uma vez que isto ocorre em nossa vida diária e em cenários relacionados à segurança.

Há vários algoritmos de reconhecimento facial que são projetados para lidar com problemas como variação pose, iluminação e expressão facial. No entanto, há poucos trabalhos que tratam do problema da oclusão. As variações de pose podem ser reduzidas usando imagens de faces com múltiplas vistas de poses ou modelos de face em 3D. Uma espécie específica de oclusão (por exemplo, óculos de sol) não pode ser produzida por outros tipos de oclusões (por exemplo, lenço). Os tipos de oclusões são imprevisíveis em cenários práticos e nenhum conhecimento prévio está disponível. Todas estas características fazem com que seja difícil para os algoritmos que tratam com outros fatores, tais como variação de iluminação, sejam aplicados diretamente para lidar com as oclusões. A investigação sobre o reconhecimento facial envolvendo oclusão é muito importante, pois é um problema negligenciado em reconhecimento facial. 


\subsection{Contextualização e motivação}

Embora tenha sido dada pouca atenção ao problema de oclusão na literatura de reconhecimento facial, a importância deste problema deve ser enfatizada, pois a presença de oclusão é muito comum em cenários não controlados e pode estar associada a várias questões de segurança. Do ponto de vista do usuário, as oclusões faciais podem ocorrer por várias razões intencionais ou não. Em primeiro lugar, acessórios faciais como óculos de sol, cachecol, maquiagem facial e chapéu / boné são bastante comuns na vida diária das pessoas. Algumas pessoas também usam véus por convicções religiosas ou hábitos culturais. Nos aplicativos de vigilância, a facilidade de uso é a propriedade mais importante que deve ser considerada, onde nenhuma cooperação do usuário pode ser esperada. O sistema deve ser capaz de reconhecer as pessoas, não importa quão grande esse ruído se apresente. Em segundo lugar, a oclusão também aparece em cenários que envolve segurança. Por exemplo, a máscara cirúrgica, cujo procedimento é necessário nas áreas restritas do hospital, e é freqüentemente usada por pessoas na Ásia Oriental (por exemplo, China, Japão) para evitar a exposição à poluição do ar, doenças respiratórias ou alergia ao pólen. Também nas áreas de construção, capacete de segurança é vital para seres humanos em tais áreas. Por último, mas não menos importante, as oclusões faciais são muitas vezes relacionadas a várias questões de segurança graves. Os hooligans do futebol inglês e os ladrões de caixas eletrônicos tendem a usar cachecóis e / ou óculos de sol para impedir que suas faces sejam reconhecidas. Ladrões de banco e ladrões de loja geralmente usam um boné ao entrar em lugares onde cometem ações ilegais.

Atacar todas as oclusões mencionadas acima no reconhecimento facial é essencial para fins de segurança e aplicação da lei. Conforme mencionado anteriormente, identificar as pessoas sem qualquer cooperação na remoção de oclusão devido a acessórios faciais traz grande conveniência e confortabilidade para os usuários em inúmeros cenários. Por outro lado, identificar a presença de oclusões em locais restritos (por exemplo, hospital, área de construção) e revelar a identidade das pessoas nessas áreas garantem a segurança no ambiente. Da mesma forma, a detecção da presença de oclusão pode identificar pessoas suspeitas em certas áreas (por exemplo, estádio de futebol, caixa eletrônico, lojas, aeroporto) e o reconhecimento facial (apesar da presença de oclusão) nessas áreas pode ajudar a polícia a encontrar criminosos / fugitivos. Em suma, o reconhecimento robusto de faces 
ocluídas parcialmente é muito importante e tem muitos usos potenciais no mundo da vigilância.

Há três categorias principais de abordagens empregadas para atacar o problema de reconhecimento facial na presença da oclusão: i) abordagens baseadas em reconstrução, que formulam o reconhecimento de faces ocluídas como um problema de reconstrução. Uma face ocluída é reconstruída por meio de uma combinação linear das imagens de face de treinamento. Em seguida a imagem reconstruída é atribuída para a classe que possui menor erro de reconstrução. ii) Abordagens baseadas em correspondência local, as quais extraem características locais da face, tais que as partes afetadas e não afetadas da face possam ser analisadas separadamente. iii) Abordagens baseadas em características insensíveis, as quais extraem características da face que são robustas a oclusão, tais como, segmentos lineares, diferença da orientação do gradiente, diferença da fase da função Gabor.

Um problema comum dos métodos baseado em reconstrução, é que estes usualmente requerem um número grande de exemplos por individuo para representar uma imagem de teste. Muitos métodos baseado em reconstrução assumem que as imagens do treinamento são capturadas em condições controladas. Entretanto, esta suposição geralmente não acontece em cenários de mundo real. Outro problema relacionado com esta categoria é que esta pode incorrer em um alto custo computacional. A idéia por trás das abordagens baseadas em correspondência local é que as alterações da aparência facial causadas por oclusões são de natureza local. Somente partes de uma face são distorcidas por oclusões, enquanto outras são menos afetadas e podem ser usadas para o reconhecimento. Portanto, em comparação com os métodos baseados em reconstrução, os métodos baseados em correspondência local são menos propensos atacar a situação em que mais de metade da face esteja ocluída. Por outro lado, as abordagens baseada em características insensíveis a oclusão assumem que as características extraídas localmente são menos prováveis de serem afetadas pela oclusão. No entanto, a forma da oclusão em cenários de mundo real são imprevisíveis, logo é difícil encontrar uma representação conveniente que seja insensível a vários tipos de oclusão.

Esta dissertação irá focar em métodos baseados em reconstrução. Neste caso, há dois problemas distintos relacionados com o reconhecimento facial com oclusões: detecção da face ocluída e a recuperação da face ocluída. A primeira tarefa consiste em determinar se uma imagem de face está ou não ocluída, e pode ser utilizada para rejeitar automaticamente as imagens ocluídas em aplicações, tais como imagens de face para passaporte. Este 
mecanismo de rejeição nem sempre é adequado para reconhecimento facial em alguns cenários (por exemplo, vigilância), onde nenhuma outra imagem pode ser obtida devido à falta de cooperação do indivíduo. A segunda tarefa consiste em restaurar as regiões ocluídas das imagens faciais. Esta tarefa pode recuperar as áreas obstruídas, mas esta pode não contribuir diretamente para o reconhecimento, já que as informações da identidade do indivíduo podem estar contaminadas por algum ruído durante a recuperação.

Biometria multibiométrica é uma abordagem relativamente nova para representação do conhecimento biométrico, que visa consolidar as informações apresentadas pelas múltiplas modalidades biométricas ou por uma única modalidade capturada por diversos sensores. Sistemas biométricos multibiométrico apresentam as seguintes vantagens: i) melhora significativa no desempenho de reconhecimento - diferentes modalidades medem informações complementares e por esta virtude podem encontrar melhor desempenho; ii) melhora na qualidade do sistema, frente a variações do ambiente - todas as modalidades biométricas sofrem com algum tipo de interferência do ambiente, por exemplo, o reconhecimento facial é seriamente afetado pelas condições de iluminação, energia, etc, por outro lado reconhecimento por impressão digital pode ser afetado pela umidade, logo ao realizarmos a fusão destas duas modalidades, espera-se uma redução na nível de interferência do ambiente; iii) diminui o problema da não-universalidade, ao utilizarmos mais de uma modalidade biométrica existe uma maior probabilidade de cobertura da população; iv) garante uma boa defesa contra ataques por circunvenção e repetição - haverá um grau de dificuldade maior uma vez que mais de uma modalidade biométrica terá que ser falsificada ao mesmo tempo e como as modalidade biométricas a serem captadas podem ser escolhidas aleatoriamente na etapa de reconhecimento, haverá uma maior necessidade da presença do indivíduo na captação, por exemplo, o sistema pode pedir uma certa combinação de digitais. Embora as necessidades de armazenamento, tempo de processamento possam ser maiores no sistema biométrico multimodal quando comparado a um sistema biométrico unimodal, as vantagens mencionadas representam um argumento convincente para a implantação desses sistemas em aplicações de mundo real (BALA, 2008).

Para a construção de um sistema multimodal é necessário realizar a combinação de duas, ou mais, modalidades biométricas. Essa união pode ser realizada de diferentes maneiras e são categorizadas de acordo com a sua arquitetura, nível de fusão e estratégia de fusão. Esta divisão leva em consideração os módulos que compõem um sistema biométrico. 
A decisão da estratégia de combinação das modalidades trata-se de um dos principais pontos a serem considerados no projeto de um sistema biométrico multimodal.

Como o desempenho das técnicas de detecção e reconstrução de oclusão propostas na literatura depende do tipo de oclusão e estas influenciam diretamente no reconhecimento, pode-se utilizar a idéia de Biometria multibiométrica de forma a torna o processo de identificação mais robusto a oclusão. Neste caso, dado uma imagem de face ocluída pode-se aplicar várias de técnicas de detecção e reconstrução e produzir várias imagens de face. Com base nestas imagens, pode-se produzir uma única imagem ou aplicar técnicas de técnicas de extração de características a cada imagem e empregar estas características como entrada para um classificador. Esta dissertação visa investigar o emprego da Biometria Multibiométrica para melhorar o desempenho de reconhecimento.

\subsection{Hipóteses}

Esta dissertação pressupõe as seguintes hipóteses:

- Diferentes técnicas de detecção e reconstrução de oclusões parciais produzem imagens de face com diferentes níveis de ruído, logo espera-se que com a combinação dessas imagens seja possível extrair características mais discriminantes visando o reconhecimento facial;

- As imagens produzidas pelas técnicas de detecção e reconstrução de oclusões parciais possuem características complementares;

- A combinação das características extraídas de cada imagem pode produzir um conjunto de característica mais discriminativa;

- A fusão das imagens produzidas pelas técnicas de detecção e reconstrução de oclusões pode reduzir o nível de ruído.

\subsection{Objetivos}

Nesta seção serão apresentados os objetivos gerais e específicos desta dissertação. 


\subsubsection{Objetivos gerais}

O objetivo desta dissertação é empregar o conceito de biometria multibiométrica para reconhecimento facial na presença de oclusões. Para alcançar este objetivo diferentes técnicas de detecção e reconstrução de oclusões faciais foram empregadas para reconstruir a imagens de face ocluídas, as quais produziram diferentes imagens de faces. Com base nisto, foi investigada a combinação das diferentes imagens (fusão no nível sensorial) e a combinação das características extraídas (fusão no nível de característica) cada imagem para o reconhecimento de faces ocluídas.

\subsubsection{Objetivos específicos}

- Implementar diferentes técnicas de detecção de oclusão;

- Implementar diferentes técnicas de reconstrução facial;

- Implementar diferentes estratégias de fusão para o nível sensorial.

- Implementar diferentes técnicas de fusão no nível sensorial e de característica;

- Investigar o desempenho das diferentes estratégias de detecção de oclusão, reconstrução e sua fusão para reconhecimento biométrico facial.

\subsection{Estutura do trabalho}

Os capítulos desta dissertação descrevem a teoria necessária para que cada um dos objetivos listados acima fossem alcançados. A seguir é apresentado uma descrição sucinta de cada capítulo:

- Capítulo 1, o atual, apresenta uma breve introdução, motivação, justificativa, hipóteses, objetivos e organização do texto;

- Capítulo 2 apresenta a teoria sobre sistemas biométricos, as etapas do processo de reconhecimento, uma descrição sucinta sobre algumas modalidades biométricas, definição e características dos sistemas multibiométricos e as estratégias de combinação;

- Capítulo 3 apresenta a teoria sobre reconstrução facial, as técnicas mais utilizadas para segmentação da face, detecção de oclusão e reconstrução facial; 
- Capítulo 4 apresenta uma descrição da abordagem proposta e como as hipóteses levantadas foram verificadas;

- Capítulo 5 descreve a configuração dos experimentos, as bases de dados utilizadas, pré-processamento das imagens e a extração de característica. Apresenta também, os resultados obtidos usando a abordagem proposta e a abordagem tradicional, visando validar as hipóteses levantadas.

- Capítulo 6 descreve os comentários finais sobre os resultados obtidos e as questões em aberto que poderão ser tratadas por outros trabalhos. 


\section{Sistemas Biométricos}

\subsection{Resumo}

Neste capítulo foram apresentadas as definições de biometria. Foram apresentados os conceitos de sistemas biométricos e multibiométricos, suas vantagens, desvantagens e limitações. As etapas de cadastramento e autenticação / reconhecimento. Foram apresentados os módulos de um sistema biométrico tradicional. Por fim, foram apresentadas as estratégias de integração.

\subsection{Introdução}

Um fator importante no projeto de um sistema biométrico é determinar como um indivíduo é identificado. Dependendo do contexto, um sistema biométrico pode ser um sistema de verificação (autenticação) ou um sistema de identificação (reconhecimento). A identificação tenta estabelecer a identidade de uma determinada pessoa a partir de uma lista de pessoas cadastradas (um para muitos), ou seja, o sistema é projetado para responder a questão: "Quem é esta pessoa?". Já a autenticação visa confirmar ou negar a identidade reivindicada por uma pessoa (um para um), o sistema visa responder a seguinte questão: "Esta pessoa é quem ela diz ser?". Esta dissertação irá focar principalmente na identificação.

O reconhecimento biométrico de um indivíduo é realizado a partir de características extraídas do mesmo. As características podem ser comportamentais, tais como: forma de andar, assinatura, forma de digitação, ou até, de maneira mais comum, características físicas, como: face, íris, palma da mão, impressão digital, formato da orelha, entre outras. Para que os sistemas biométricos sejam construídos, as características extraídas devem ser armazenadas para servir de modelo (template), posteriormente. Assim, os sistemas são constituídos de duas etapas: (i) cadastramento e (ii) autenticação ou reconhecimento.

- Cadastramento - na etapa de cadastramento, as características biométricas extraídas dos indivíduos são capturadas. Assim, as características mais importantes para classificar o indivíduo (características únicas, ou suficientemente descriminante) são compactadas na forma de um template, que é armazenado na base de dados para posterior comparação na fase de autenticação. 
- Autenticação / Reconhecimento - nesta etapa, o novo template criado a partir das características extraídas é comparado com os templates armazenados anteriormente, a decisão do sistema é tomada a partir das comparações. Contanto, existem dois modos distinto para realizar esta tarefa, são eles:(i) identificação, neste modo o indivíduo não se identifica ao sistema e fica a par do mesmo identificar o indivíduo (essa tarefa é $1: \mathrm{N}$, onde $\mathrm{N}$ é a quantidade de templates armazenados na fase de cadastramento). Esse modo, dispensa uso de outro dispositivo ou mecanismo para identificação, utilizando apenas as características biométricas para a autentificação do indivíduo; (ii) verificação, neste modo o indivíduo necessita informar o seu id, além de sua fornecer as características biométricas (tarefa 1:1, onde apenas o template do id do indivíduo informado é utilizado para a comparação).

Um sistema biométrico tradicional é composto por quatro módulos: (i) Módulo sensorial - neste os dados biométricos de um usuário são adquiridos, como por exemplo, uma câmera que captura a imagem de face de um indivíduo; (ii) Módulo de extração de característica - neste módulo, os dados adquiridos pelo modulo sensorial são processados pela técnicas de extração das características visando a extração de informções relevantes para o reconhecimento, como por exemplo, a distância entre os dois olhos, angulo formado entre o ponto central da boca e o ponto central dos dois olhos, distância entre boca e nariz, tamanho do rosto correspondem a algumas das características extraídas da face; (iii) Módulo de comparação - as características são comparadas contra os valores do(s)template(s) armazenado(s) no banco de dados, gerando uma pontuação, como por exemplo, no caso do reconhecimento baseado em impressão digital, a quantidade de minúcias coincidentes entre o template gerado e o template armazenado é computado e tratado como pontuação;(iv) Módulo de tomada de decisão - neste a identidade do indivíduo é estabelecida ou a identidade identificada é aceita ou rejeitada baseada na pontuação gerada pelo modulo de comparação.

No reconhecimento facial, a imagem da face do usuário é capturada por uma câmera, em seguida, é realizado a segmentação, que consiste em encontrar na imagem capturada a região da face, eliminando, por exemplo, o fundo e algumas interferências do ambiente. Após essa segmentação, características são extraídas da imagem segmentada e armazenadas para posterior comparação. Dentre as características extraídas destaca-se aquelas obtidas diretamente da imagem de face, como por exemplo, distâncias entre orelhas, distância 
entre nariz e boca e aquelas obtidas após algum tipo de processamento, como por exemplo, coeficientes da transformada wavelet aplicada a imagem da face, etc. Uma desvantagem de utilização da imagem de face como modalidade biométrica é que as imagens coletadas podem sofrer variações devido a expressão, luminosidade no ambiente, rotação da face na captura, presença de óculos, barba, marcas da idade, maquiagem, lenços, etc.

\subsection{Sistema multibiométrico}

A identificação de pessoas com base em características biométricas tem atraído muito atenção de vários pesquisadores para a concepção de sistemas de segurança. No entanto, nenhuma modalidade biométrica atende a todos os requisitos de desempenho necessários nos sistemas práticos.

Sistemas unibiométricos, também chamado de unimodais, usam uma modalidade biométrica para realizar o reconhecimento dos indivíduos. Estes sistemas estão longe de serem perfeitos e sofrem de vários problemas, tais como, ruído na captura, não-universidade, falta de individualidade e sensibilidade a ataque por pessoas não autorizadas. Por outro lado, os sistemas multibiométricos são aqueles que utilizam múltiplas fontes de informação biométrica. Estes sistemas visam superar as limitações que surgem quando se usa uma única modalidade biométrica para reconhecer os indivíduos.

Os sistemas multibiométricos são classificados em cinco abordagens de acordo com a fonte de informação biométrica, a saber, i) Sistemas multi-sensores - empregam múltiplos sensores para capturar uma única característica biométrica de um indivíduo; ii) Sistemas multi-algorítmicos - empregam múltiplas técnicas de extração características e / ou múltiplos algoritmos de classificação aplicados sobre a mesma modalidade biométrica para melhorar o desempenho no reconhecimento; iii) Sistemas multi-instância - usam várias instâncias da mesma característica biométrica, um exemplo é o uso de múltiplos dedos empregado no reconhecimento por meio de impressões digitais; iv) Sistemas de múltiplas amostras - o qual usa um único sensor para adquirir múltiplas amostras da mesma modalidade biométrica, o qual visa explicar as variações que podem ocorrer na captura da característica biométrica; v) Sistemas multimodais - estabelecem a identidade com base na evidência de múltiplas modalidades biométricas. 
Os sistemas multibiométricos apresentam algumas vantagens sobre os sistemas unibiométricos:

- a combinação das evidências obtidas de diferentes fontes, se for utilizado uma estratégia de fusão adequada pode-se melhorar significativamente a performance dos sistemas biométricos.

- a presença de múltiplas fontes aumenta efetivamente a quantidade de informação disponível.

- se for utilizado múltiplas fontes de informação, tendem a resolver o problema da não universalidade, como por exemplo, uma pessoa que não possui a impressão digital, pode fazer uso da face e/ ou íris para sua identificação.

- permitem que o indivíduo possa se identificar com a modalidade biométrica mais adequada no momento, por exemplo, se a fonte de informação do sistema biométrico for face, voz, íris e impressão digital, o indivíduo pode ser identificado por face e voz usando seu dispositivo móvel, ou via impressão digital e íris em um acesso físico.

- reduz o efeito de dados ruidosos, dada a disponibilidade de múltiplas fontes de informação. Se a amostra biométrica obtida de uma das fontes tiver baixa qualidade durante uma determinada aquisição, as outras informações ainda podem ser discriminatórias suficientes para permitir a tomada de decisão correta.

- podem permitir a busca em uma grande base de dados de forma computacionalmente eficiente, isto é, pode-se inicialmente usar uma fonte de informação relativamente simples, mas com pouca capacidade discriminatória, para realizar a busca. Com isto iremos reduzir o tamaho da base de dados, em seguida pode-se usar uma fonte de informação mais complexa para realizar uma busca mais precisa.

- maior dificuldade de ser fraudado, pois haverá necessidade de fraudar múltiplas fontes de informação. No caso das fontes de informação serem mais de uma modalidade biométrica, pode-se facilmente incorporar um mecanismo de aquisição biométrica das modalidades em ordem aleatória. Esse mecanismo garantirá que o sistema está interagindo com um usuário.

Os sistemas multibiométricos também apresentam algumas desvantagens quando comparados com sistemas unibiométricos. Eles são mais caros e requerem mais recursos computacionais e maior capacidade de armazenamento. Os sistemas multibiométricos geralmente requerem um maior tempo de cadastro dos usuários, quando utilizado múltiplas 
modalidades biometrias, podendo causar algum inconveniente ao usuário. Finalmente, o desempenho de um sistema multibiométrico pode ser, na verdade, menor que a de um sistema unibiométrico, caso não seja utilizado uma técnica adequada para fusão das diferentes fontes de informação. Apesar dessas vantagens, sistemas multibiométricos oferecem alguns atrativos e, conseqüentemente vem sendo cada vez mais implantados.

Há uma variedade de fatores que devem ser considerados quando se projeta um sistema multibiométrico. Estes fatores incluem: (i) a escolha e o número de fontes de informação; (ii) o nível de integração na qual as informações podem ser agrupadas; (iii) a metodologia usada para integrar esta informação; (iv) o custo versus desempenho.

\subsection{Estratégias de integração}

De acordo com Jain et al. (ROSS; JAIN, 2004), as integrações podem ser realizadas de diversas formas, sendo que estas, geralmente, são categorizadas de acordo com a sua arquitetura, nível da fusão e estratégia de fusão.

\subsubsection{Integração baseada na arquitetura}

Considerando que cada fonte de alimentação seja utilizada para gerar um sistema biométrico, logo estes podem ser agrupados da seguinte forma:

- serial - neste $n$ sistemas biométricos são agrupados em série, conforme ilustrado na figura 1. Este tipo de arquitetura pode diminuir o custo computacional em sistemas de grande escala que operam no modo de identificação, já que os sistemas biométricos mais rápidos (e não tão precisos) podem ser utilizados nos primeiros estágios da integração, diminuindo progressivamente o número de possíveis identidades que serão checadas pelos sistemas mais precisos e computacionalmente mais custosos.

Figura 1 - Sistema biométrico integrado de forma serial

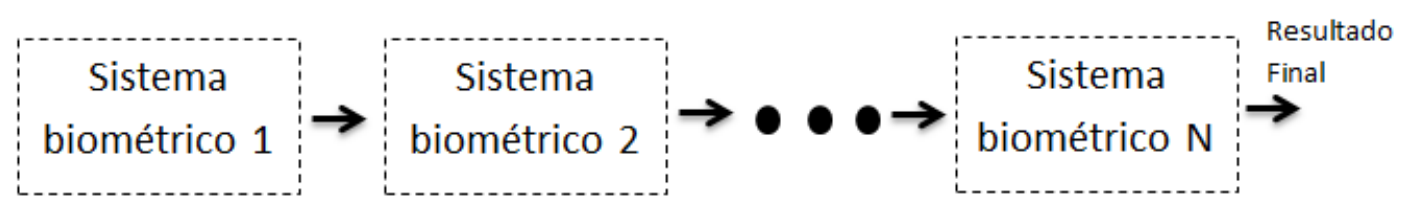


- paralela - neste cada sistema biométrico funciona de forma independente e os dados fornecidos por eles são combinados por um módulo de fusão, conforme ilustrado na Figura 2.

Figura 2 - Sistema biométrico integrado de forma paralela

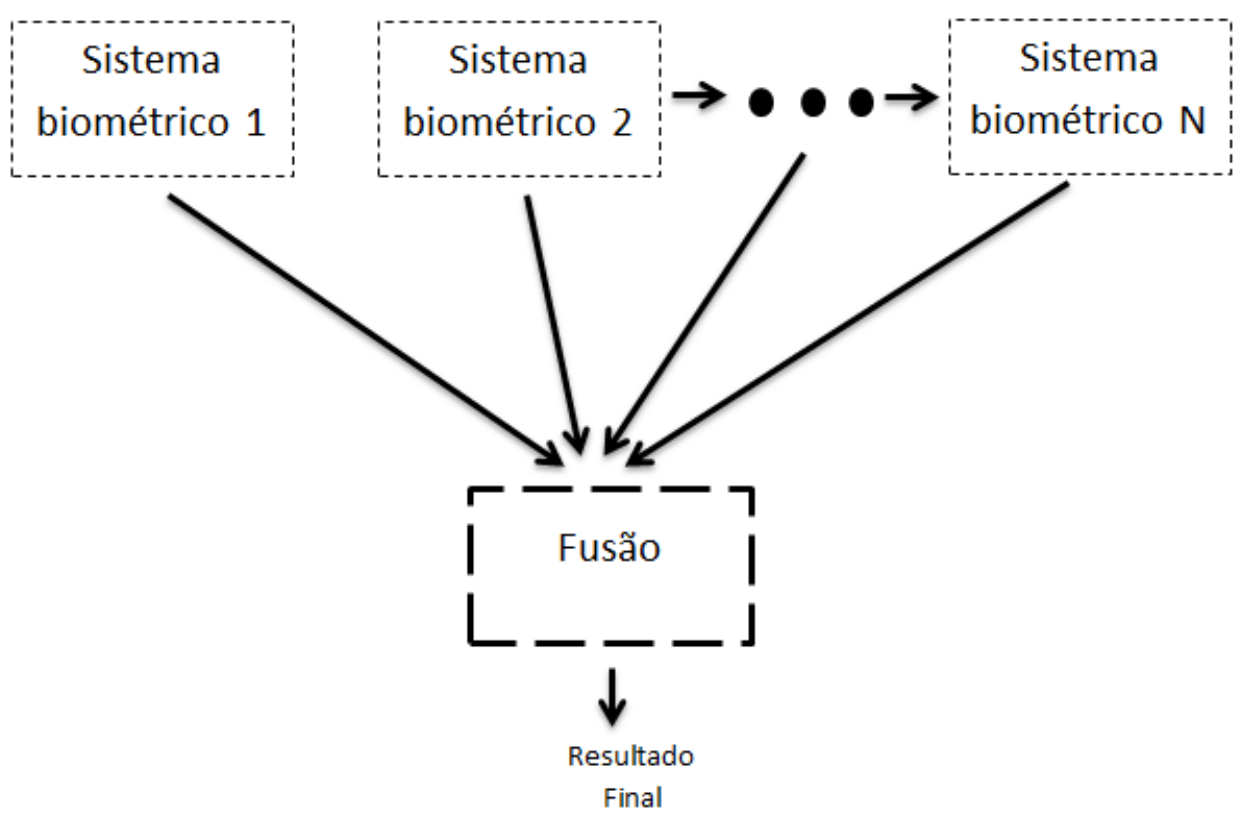

Fonte: Jozias Rolim, 2018

- hierárquica - neste os sistemas biométricos são combinados de acordo com alguma estratégia de fusão, gerando uma formação semelhante a uma árvore, conforme ilustrado na Figura 3.

\subsubsection{Integração baseada no nível da fusão}

Baseados nos módulos que compõem um sistema biométrico, podemos realizar a fusão nos seguintes níveis: sensorial, extração de característica, comparação e tomada de decisão. De acordo com Monwar (MONWAR; GAVRILOVA, 2009), podemos subdividir estes níveis em duas categorias principais: (i) fusão anterior a comparação e (ii) fusão posterior a comparação.

- Fusão anterior à comparação: neste caso, a fusão da informação ocorre antes da comparação. Esta categoria combina as informações do sistema biométrico multibiométrico nos seguintes subníveis. 
Figura 3 - Sistema biométrico ntegrado de forma hierárquica

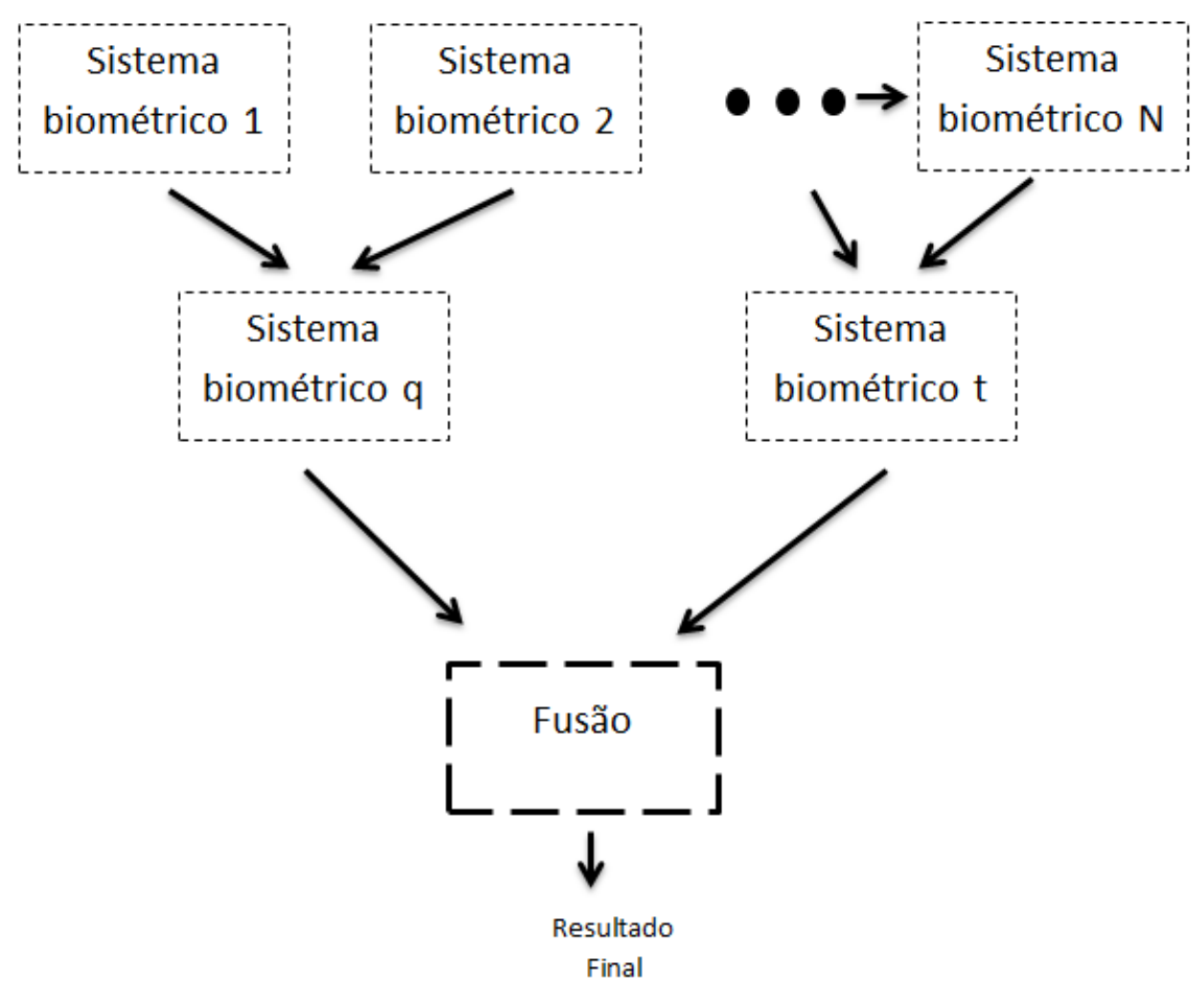

Fonte: Jozias Rolim, 2018

- Nivel sensorial: Os dados brutos adquiridos podem ser processados e integrados para gerar novo dado a partir do qual as características são extraídas, conforme por ser visto na Figura 4. Por exemplo, (RAGHAVENDRA; RAO; KUMAR, 2010) propôs uma estratégia de fusão para imagens da face e palma da mão usando Otimização por Enxame de Partículas (do inglês Particle Swarm Optimisation - PSO). O método consiste nos seguintes passos. Primeiro, as imagens da face e palma da mão obtidas a partir de diferentes sensores são processados pela transformada wavelet, em seguida o PSO é empregado para selecionar os coeficientes de wavelet mais discriminativos da face e palma da mão para produzir uma imagem integrada. Análise Discriminante Direta com Kernel (do inglês Kernel Direct Discrimination Analysis - KDDA) foi aplicado para extração de caracteristica e a decisão a respeito de aceitação/rejeição foi realizada usando o classificador K-Vizinhos mais Próximos (do inglês Nearest Neighbour - K-NN).

- Nível de extração de característica: as características extraídas das múltiplas fontes de dados é usado para criar um conjunto de características para repre- 
Figura 4 - Integração no nível sensorial

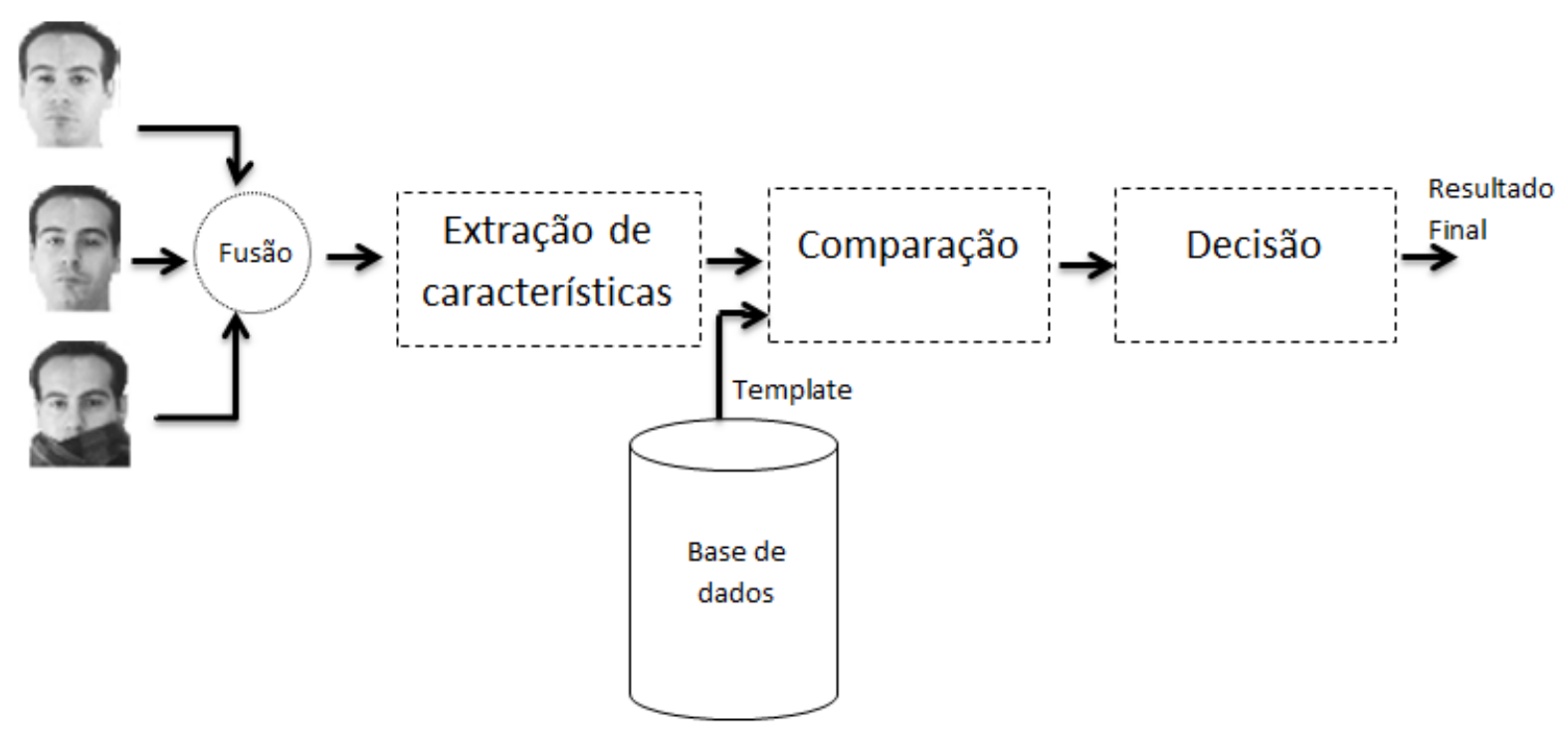

Fonte: Jozias Rolim, 2018

sentar o individuo. Por exemplo, a localização e ângulo das minúcias em uma impressão digital, podem ser concatenadas com os autovalores da face e com a textura da íris a fim de construir um vetor de características de alta dimensionalidade(ROSS; GOVINDARAJAN, 2005), para mais detalhes veja figura 5. Geralmente, um procedimento seleção de característica pode ser adotado para gerar um subconjunto de característica mais discriminante a partir do vetor de característica de alta dimensionalidade (CHANG et al., 2003).

- Fusão posterior à comparação: nesta categoria ocorre a integração da informação após a comparação. Esta categoria combina as informações do sistema biométrico multibiométrico nos seguintes subníveis.

- Nível comparação baseada na pontuação : neste caso, cada sistema biométrico fornece um vetor contendo com as pontuações que indica a proximidade do vetor de característica com cada template armazenado. As pontuações de cada sistema podem ser combinadas gerando um valor escalar (MARCIALIS; ROLI, 2004). Técnicas tais como regressão logística pode ser usada para combinar o vetor de pontuação oriundo de diferentes sistemas e gerar um novo vetor. Como exemplo, a pontuação gerada pelos sistemas biométricos usando face e mão de um usuário pode ser combinada via media aritmética a fim de obter uma nova 
Figura 5 - Fusão no nível da extração de caracteristica

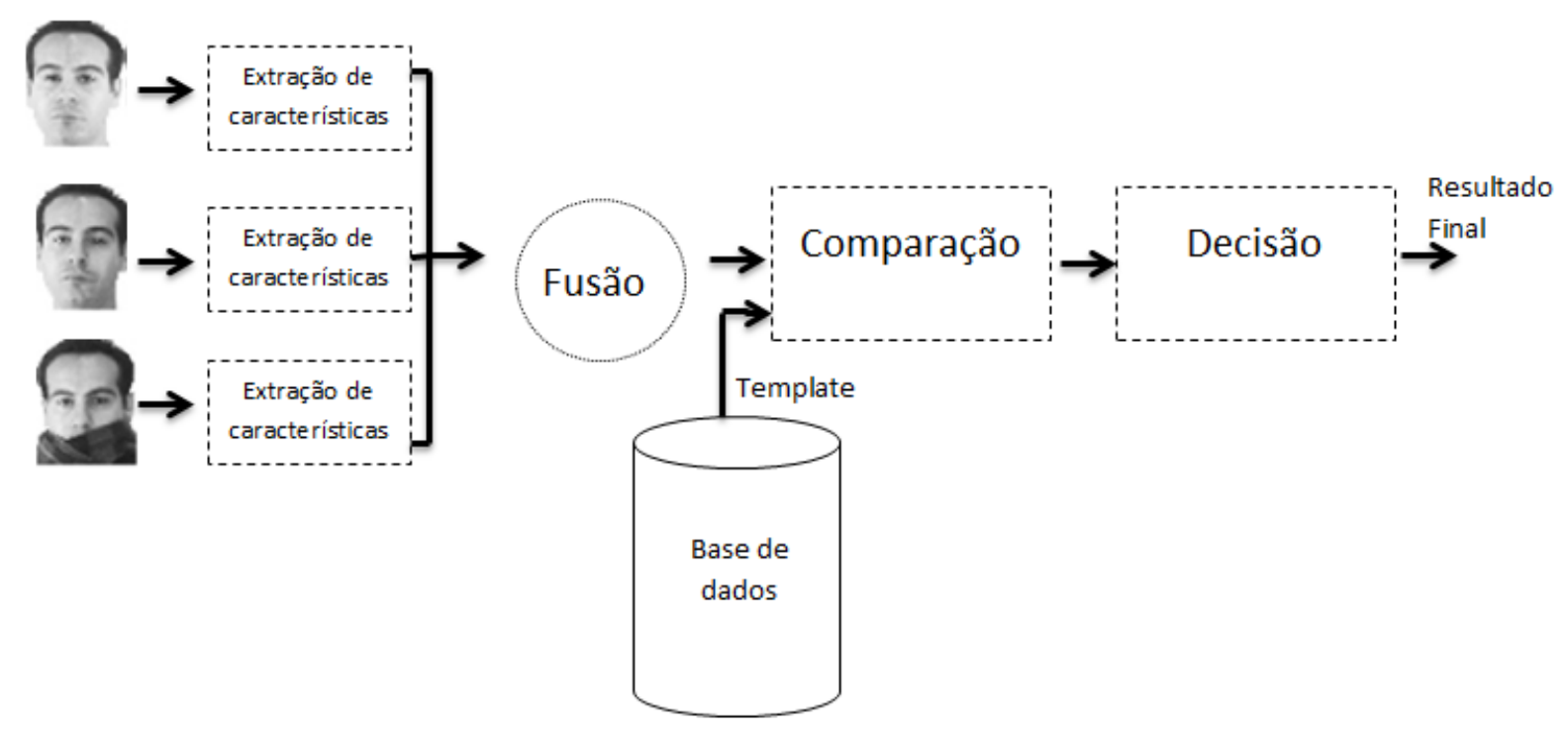

Fonte: Jozias Rolim, 2018

pontuação. Com base no novo vetor de pontuação pode-se tomar decisão final (ROSS; JAIN, 2003). A figura 6 ilustra este processo.

Figura 6 - Fusão da pontuação obtida no nível de comparação

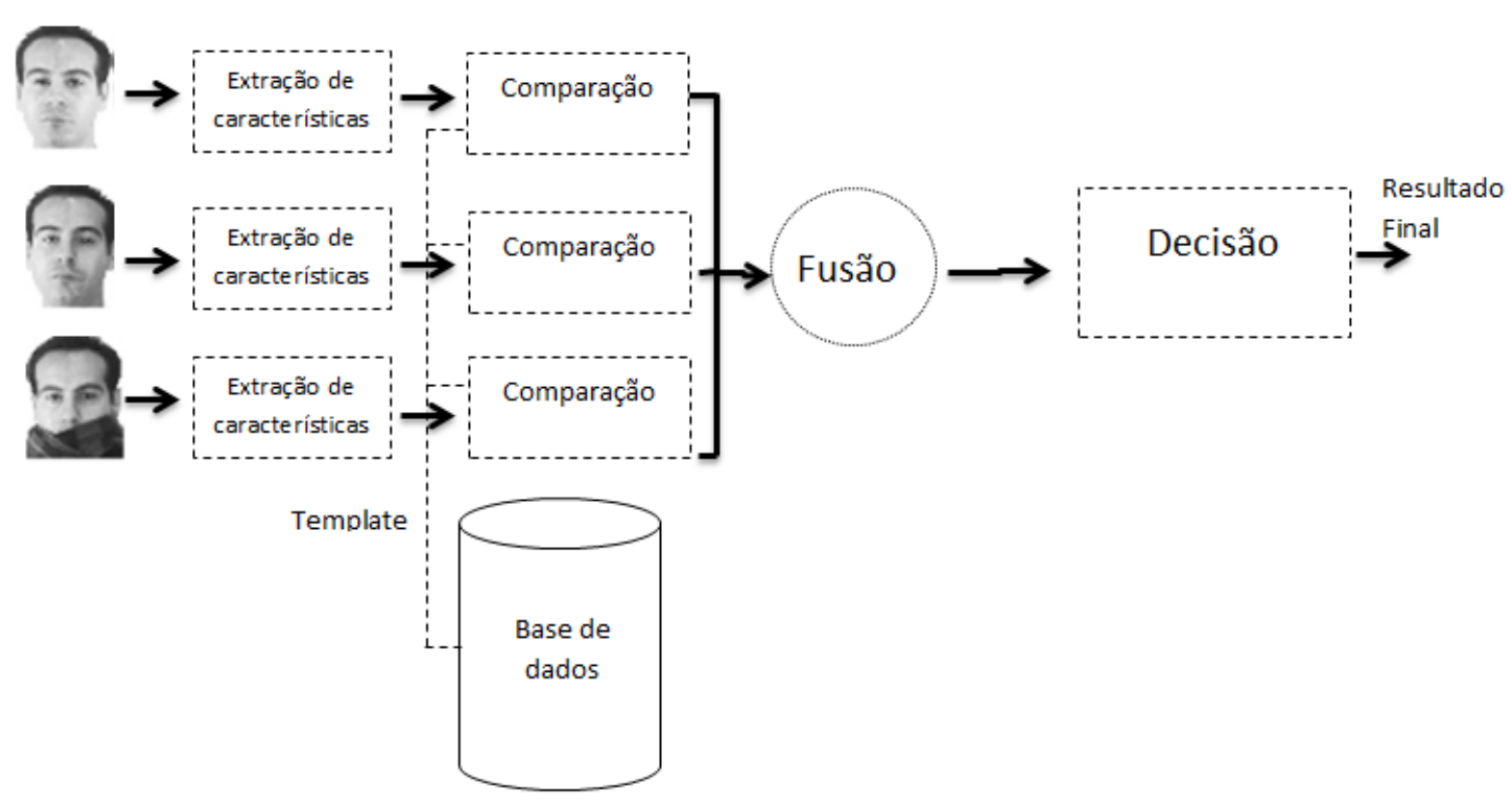

Fonte: Jozias Rolim, 2018

- Nível de comparação baseada no rank: Este tipo de fusão é relevante em sistemas de identificação onde cada classificador associa um rank a todos as 
identidades cadastradas (um rank alto indica uma alta similaridade entre o vetor de característica e o template armazenado). Assim a fusão realiza a consolidação de vários ranks associados com uma identidade e determina um novo rank que será utilizado na decisão final (ROSS; JAIN, 2003).

- Nível de Decisão: Quando cada comparador (por exemplo, classificador) produz seu próprio rótulo de classe (isto é, aceita ou rejeita no caso de verificação, ou a identidade de um usuário no caso de um sistema de identificação), um único rótulo de classe pode ser obtido obtido utilizando por exemplo voto majoritário (KINNUNEN; HAUTAMäKI; FRäNTI, 2004). A figura 7 ilustra este processo.

Figura 7 - Fusão no nível da decisão

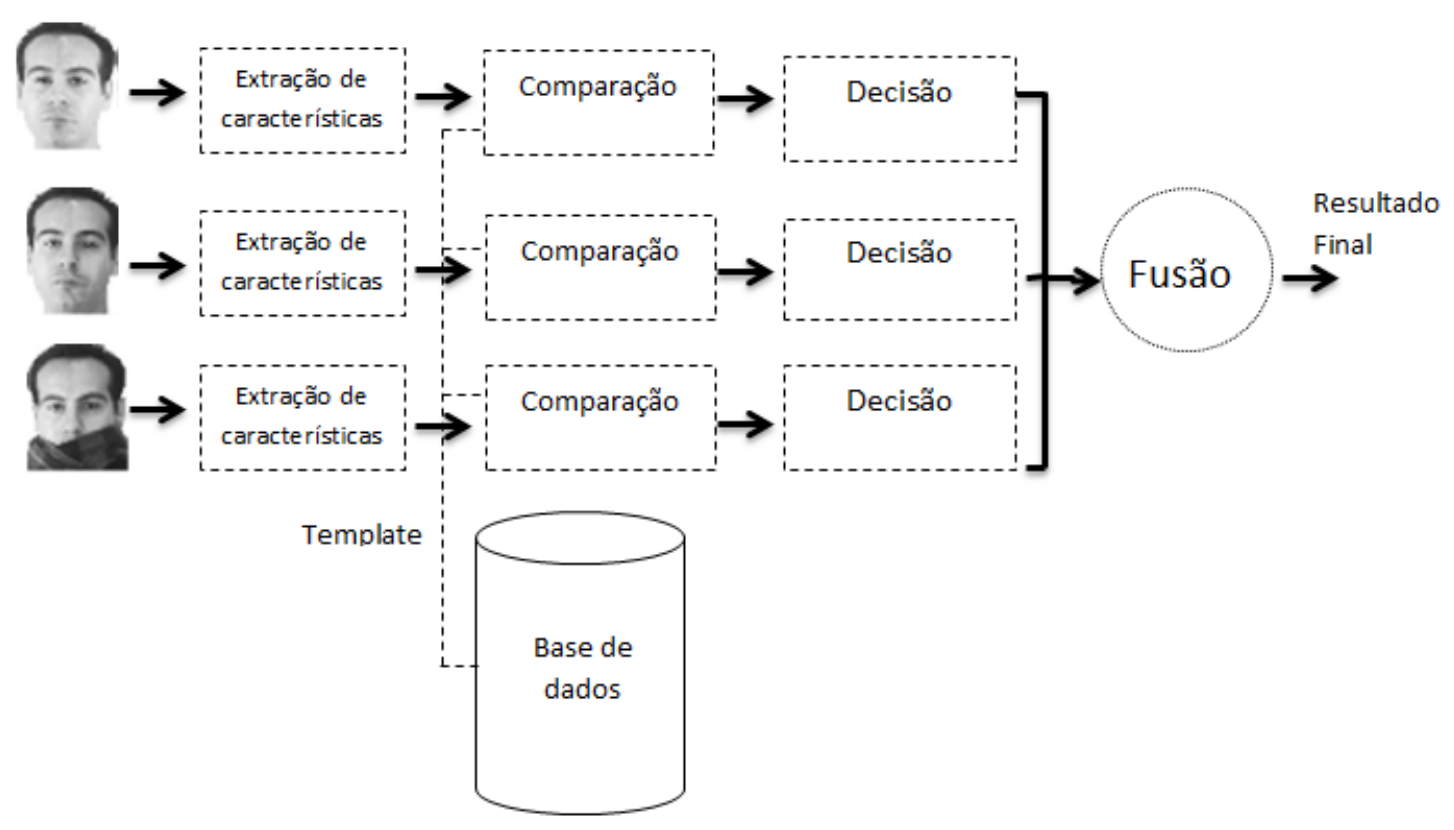

Fonte: Jozias Rolim, 2018 


\section{Sistema de reconhecimento biométrico baseado em faces com oclusão}

\subsection{Resumo}

Neste capítulo serão apresentadas todas as etapas do sistema de reconhecimento biométrico baseado em faces com oclusão. Para cada etapa foram descritas as técnicas pesquisadas, comentando com detalhes seus funcionamentos, vantagens, desvantagens e limitações. Foram apresentadas técnicas de deteç̧ão de face, detecção de oclusão, remoção da oclusão, reconstrução facial, extração de características, comparação e decisão. As técnicas de reconstrução facial foram segmentadas em baseadas em subespaços e baseadas em regressões.

\subsection{Introdução}

Antes de serem apresentadas as técnicas de reconstrução de face parcialmente ocluídas, é necessário descrever as etapas que compõem um sistemas de reconhecimento baseado em imagens de face parcialmente ocluídas, as quais são descritas na Figura 8.

Figura 8 - Estrutura de Sistema biométrico baseado em faces parcialmente ocluídas

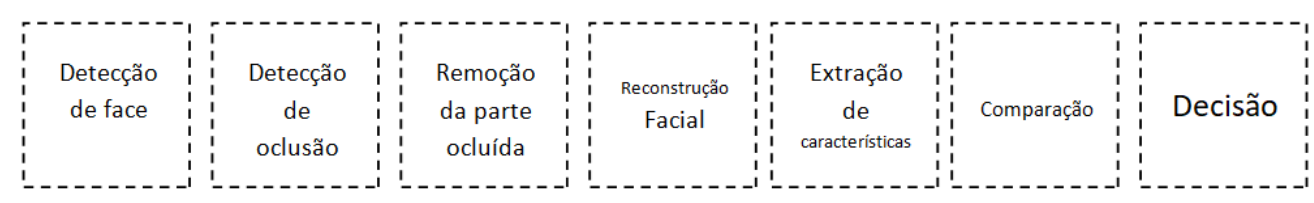

Fonte: Jozias Rolim, 2018

O processo de reconhecimento biométrico baseado em faces com oclusão se dá por meio das seguintes etapas: (i) detecção de face, nesta etapa a imagem capturada no sensor é analisada para verificar a presença ou não de face humana; (ii) detecção de oclusão, nesta etapa é verificada a ocorrência de oclusão na imagem de face apresentada (caso a imagem de face apresentada não contenha oclusão, o processo é avançado para a etapa v); (iii) na etapa de remoção da oclusão, a oclusão é removida da imagem de face; (iv) reconstrução facial, nesta etapa a parte removida é reconstruída, de modo a possibilitar a extração de características com alto poder discriminatório; (v) extração de características, nesta etapa as características da imagem de face são extraídas e preparadas para a fase de comparação; (vi) nesta fase, comparação, os vetores de características formados na fase anterior são comparados aos já presentes na base de dados (ou utilizados no treinamento 
de classificador); (vi) na camada de decisão é onde o modelo informa a classe do indivíduo calculada pelo sistema.

Nesta secção serão descritas as técnicas dos processos de detecção de faces,detecção de oclusão, remoção da oclusão e reconstrução facial, de maneira conceitual e com exemplos, de modo que seja possível uma maior compreensão das mesmas.

\subsection{Detecção da Face}

A detecção de face consiste de uma abordagem de processamento de imagem para verificar a existência de uma face em determinada imagem e determinar a sua localização espacial. Esta abordagem é utilizada na maioria dos sistemas de reconhecimento facial. Detectar a face antes da extração de características é uma forma de minimizar que outros elementos presentes na imagem, mas que não são relevantes para o reconhecimento, sejam detectados durante o procedimento de extração de características.

De forma geral, a face é um objeto tridimensional que pode receber iluminação de diferentes fontes e pode estar em inúmeras direções. A detecção de face, se realizada por seres humanos, é uma tarefa trivial por ser considerada uma atividade natural do cérebro. Em contra partida, ao ser realizado por uma máquina como um computador, estará sujeita a determinados problemas. Alguns desses problemas são as diversas variações que uma imagem de face pode apresentar: variação de pose, iluminação, expressão e oclusões parciais. Estas variações dificultam a detecção correta da face

\subsubsection{Algoritmo de detecção de fase baseado em Adaboost}

Um dos possíveis algoritmos utilizados para detecção de face é o algoritmo ViolaJones (VIOLA; JONES, 2004). O primeiro passo desse algoritmo consiste em transformar a imagem de entrada em uma imagem integral. Cada pixel da imagem integral é a soma dos pixels presentes acima e a esquerda na imagem de entrada. A equação 1 é empregada para obter a imagem integral.

$$
i i\left(i^{\prime}, j^{\prime}\right)=\sum_{i \leq i^{\prime}, j \leq j^{\prime}} i(i, j)
$$


em que $i i\left(i^{\prime}, j^{\prime}\right)$ define um pixel da imagem integral e $i(i, j)$ define um pixel da imagem de entrada. A figura 9 apresenta um exemplo desse procedimento.

Figura 9 - Exemplo da geração de uma imagem integral
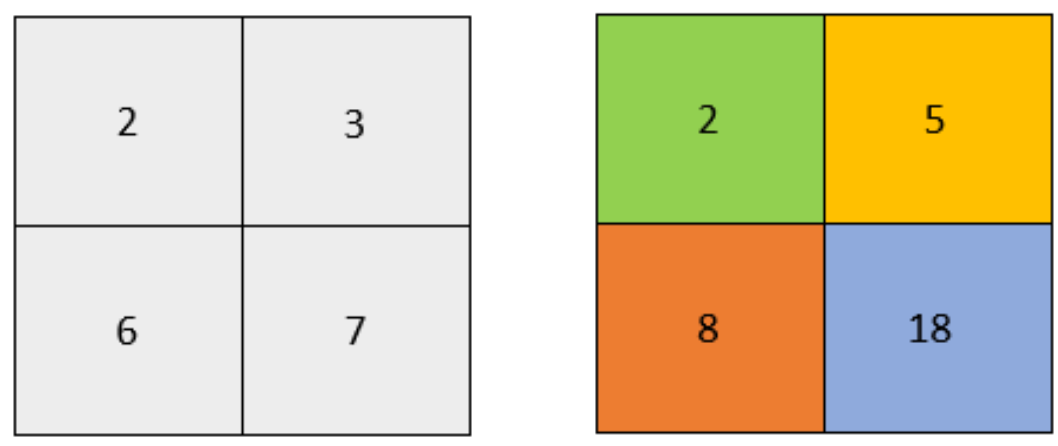

Fonte: Jozias Rolim, 2018

Com esse procedimento é possível calcular a soma de todos os pixels internos a um retângulo qualquer utilizando apenas os quatro valores do vértice. A figura 10 mostra como é possível descobrir o valor do retângulo $W$ na imagem de entrada utilizando a equação 2 .

Figura 10 - Exemplo do cálculo da soma de um retângulo

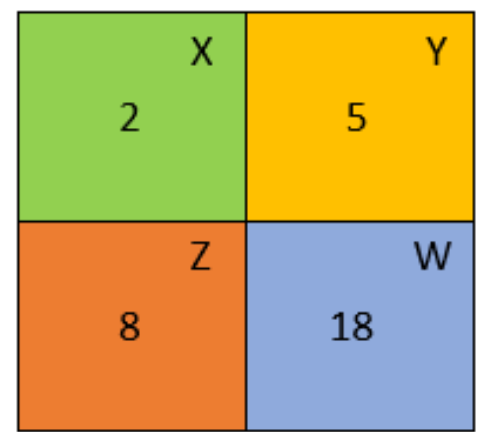

Fonte: Jozias Rolim, 2018

$$
I(W)=W-Y-Z+X
$$

Considerando que o retângulo $X$ está contido nos retângulos $Y$ e $Z$, faz-se necessário adicionar o valor de $X$. Realizando a expansão dessa abordagem em imagens de dimensões maiores, é possível analisar que a soma dos pixels de uma região pode ser assintoticamente realizado em um tempo linear.

De maneira geral, o algoritmo Viola-Jones analisa determinada região de uma imagem utilizando dois ou mais desses retângulos, chamada característica de Haar. A figura 11 mostra esse procedimento. 
Figura 11 - Exemplo de características de Haar

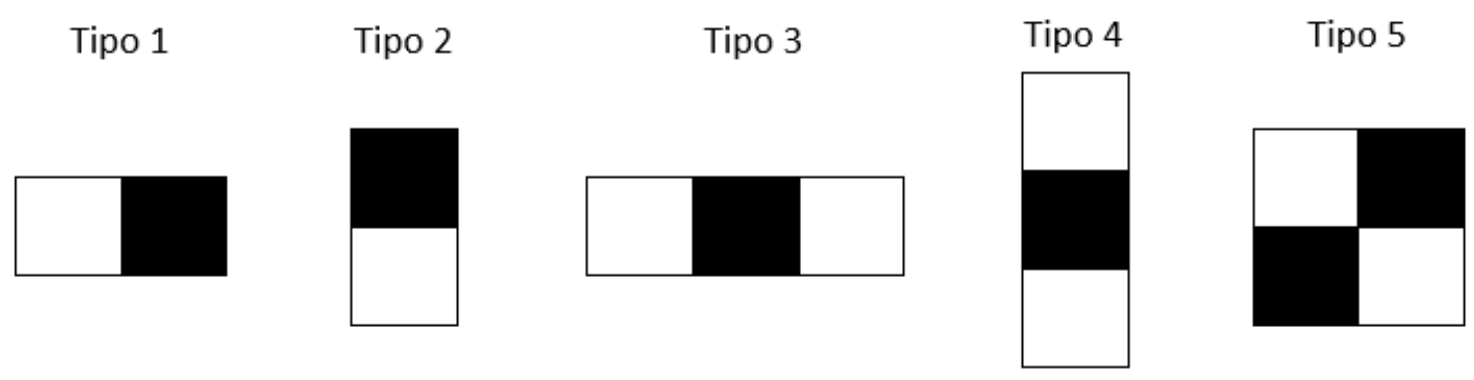

Fonte: Adaptada de (VIOLA; JONES, 2004), 2018

O Algoritmo de Viola-Jones foi construído baseado em imagens de resolução de $24 \times 24$ pixels e com um total de 6060 características de Haar diferentes. Apesar do conjunto de características utilizado ser baseado nas imagens de resolução $24 \times 24$ e serem consideradas simples, elas possuem alta eficiência computacional e mesmo que uma característica de Haar seja analisada em uma imagem com resolução maior é esperado que ela apresente valor próximo ao valor obtido com essa característica nas imagens bases.

O principio básico do Algoritmo Viola-Jones é varrer a mesma imagem várias vezes, cada vez com um novo tamanho de janelas, visando localizar as faces nessa imagem. Pode-se verificar que uma grande quantidade das janelas analisadas produzirá resultados negativo, ou seja, não será uma face. Com isso, ao invés de confirmar que uma janela trata-se de uma face, este busca descartar as regiões de não faces.

Devido à natureza do problema foi verificado que a construção de um único classificador não seria capaz de alcançar o desempenho esperado. Em função disso, foi realizada a construção de um classificador em cascata baseado em uma modificação do Algoritmo Adaboost proposto por (FREUND; SCHAPIRE; ABE, 1999). Através da combinação de um conjunto de classificadores, chamados de fracos, realiza a construção de um sistema com uma alta taxa de confiabilidade. A figura 12 apresenta um exemplo desse algoritmo.

O classificador em cascata foi treinado com diferentes quantidades de classificadores por nível, onde cada nível visa verificar se uma determinada janela trata-se de uma não face, de forma definitiva, ou de uma face. Quando uma dessas janelas é classificada, em algum dos níveis como não face, esta é automaticamente descartada. Por outro lado, 
quando esta é classificada como uma possível face, esta é enviada para o próximo nível da cascata. Esse procedimento é ilustrado na Figura 12.

Figura 12 - Arquitetura do classificador cascata

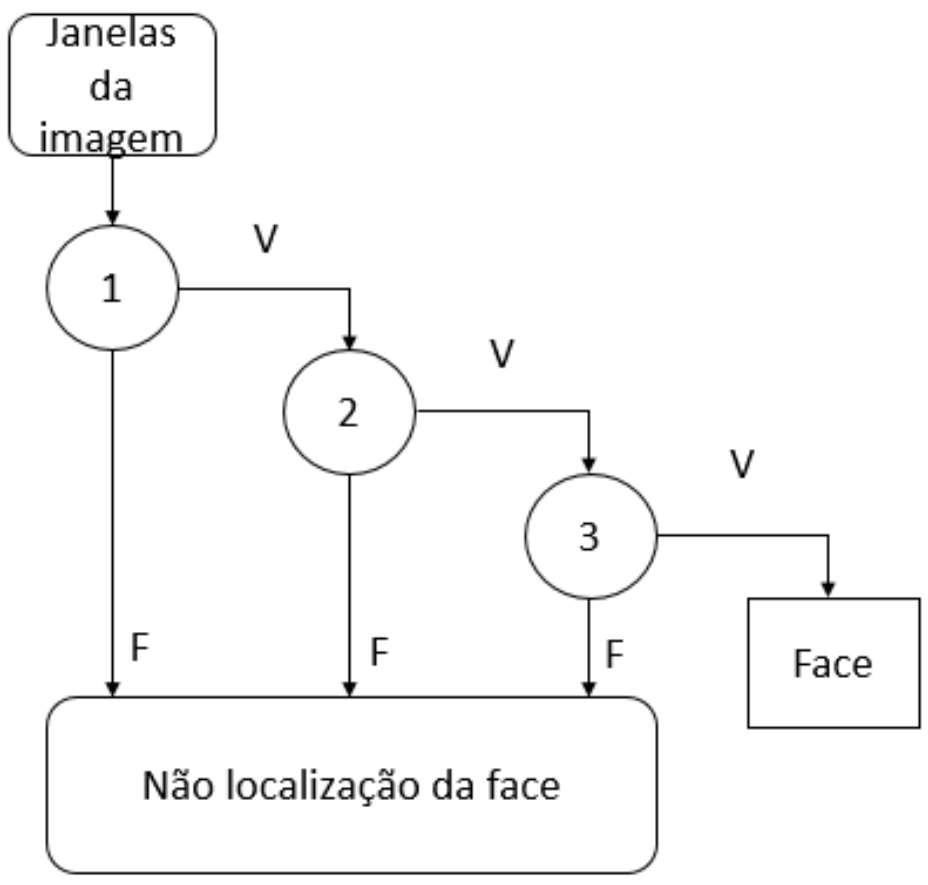

Fonte: Adaptada de (VIOLA; JONES, 2004), 2018

Uma das características desse classificador é que são esperados que regiões de não face fossem aceitas como face ao longo dos primeiros níveis do classificador. Entretanto, isto não deve ser um problema, já que os próximos níveis devem ser capazes de classificá-los como não face. Portanto, o algoritmo Viola-Jones produz a aceitação de muitas regiões de não face no estágio inicial. Conseqüentemente, a quantidade de não faces no estagio final de classificação deve ser muito menor.

Outra forma de classificar o Algoritmo de Viola-Jones é através do termo cascata de atenção, isto indica que uma análise com maior atenção é realizada nas regiões onde tem a maior possibilidade de conter um face, para isso um determinado estágio $k$ devem ser treinados com as não faces que foram aceitas pelo estágio $k-1$.

Apesar do algoritmo Viola-Jones apresentar dificuldade na localização da face quando a imagem apresenta alguma variação em relação à pose do usuário e a iluminação do ambiente, este algoritmo apresenta um bom desempenho na detecção da face em sistemas biométricos baseados em face, visto que esses sistemas geralmente são utilizados em ambientes controlados. 
Os sistemas biométricos baseados em face apresentaram um grande avanço, porém algumas dificuldades ainda são enfrentadas, tais como as dificuldades da localização da face em ambientes não controlados (DHARAVATH; TALUKDAR; LASKAR, 2013). Além das possíveis formas de falsificação que podem ser realizadas através do uso de fotografias, vídeos, máscaras, desenho, engenharia reversa baseada na face do usuário, maquiagem ou cirurgias plásticas (AKHTAR; MICHELONI; FORESTI, 2015), sendo algumas dessas possibilidades podem ser combatidas através das técnicas de detecção de presença de vida.

\subsubsection{Baseada em pigmentação da pele}

Cheddad (CHEDDAD et al., 2009) propôs um método baseado em detecção de texturas de cores de peles humanas para detectar faces humanas. O modelo é dado por cinco fases:

- Na primeira fase, a imagem de tamanho $(w, h, 3)$, onde o $w$ é a quantidade de pixel em $x, h$ a quantidade de pixel em $y$ e 3 os valores nos canais de cores RGB (Red, Green, Blue), possui seus pixels normalizados entre 0 e 1;

- Na segunda fase, cada pixel RGB é multiplicado por escalares (0.298, 0.587 e 0.140, valores apresentados pelo autor, relativos na média da percepção do olho humano) e somados, gerando assim a imagem em escala de cinza $I$ de tamanho $(w, h)$, a operação pode ser vista na equação 3 , onde $\oplus$ representa uma multiplicação matricial;

$$
I(i, j)=\left(\psi(r(i, j), g(i, j), b(i, j)) \oplus(0.298,0.587,0.140)^{T}\right)
$$

- Na terceira fase, com o propósito de obter a informação de matiz e saturação da imagem, eliminadas ao converter a imagem RGB para escala de cinza na primeira fase, é calculado o $\hat{I}$ de tamanho $(w, h)$, extraindo o maior valor dos canais $\mathrm{G}$ e $\mathrm{B}$ de cada pixel da imagem, apresentado na equação 4. O valor de $\mathrm{R}$ é ignorado nesta etapa, dado que a maior parte das cores de pele se apresentam de forma mais significativas no canal de cor R, que será crucial no momento do cálculo do erro (apresentado adiante);

$$
\hat{I}(i, j)=\max (g(i, j), b(i, j))
$$


- Na quarta fase do processo é calculado o erro de sinal, denotado por $E(i, j)$, onde o $E$ resultante é uma imagem de tamanho $(w, h)$, subtraindo as imagens resultantes obtidas através das equações 3 e 4, a operação pode ser visualizada na equação 5;

$$
E=I-\hat{I}
$$

- Na quinta e última fase, é calculada uma imagem binária, onde cada pixel em $E$ é submetido à equação 6 , onde os valores 0 representam ausência de cor e os valores 1 presença de cor, neste caso, 1 representa a face humana;

$$
f(i, j)=\left\{\begin{array}{l}
1, \text { se } 0.02511<=E(i, j)<=0.1177 \\
0, \text { senão }
\end{array}\right.
$$

O algoritmo proposto pode ser observado no algoritmo 1.

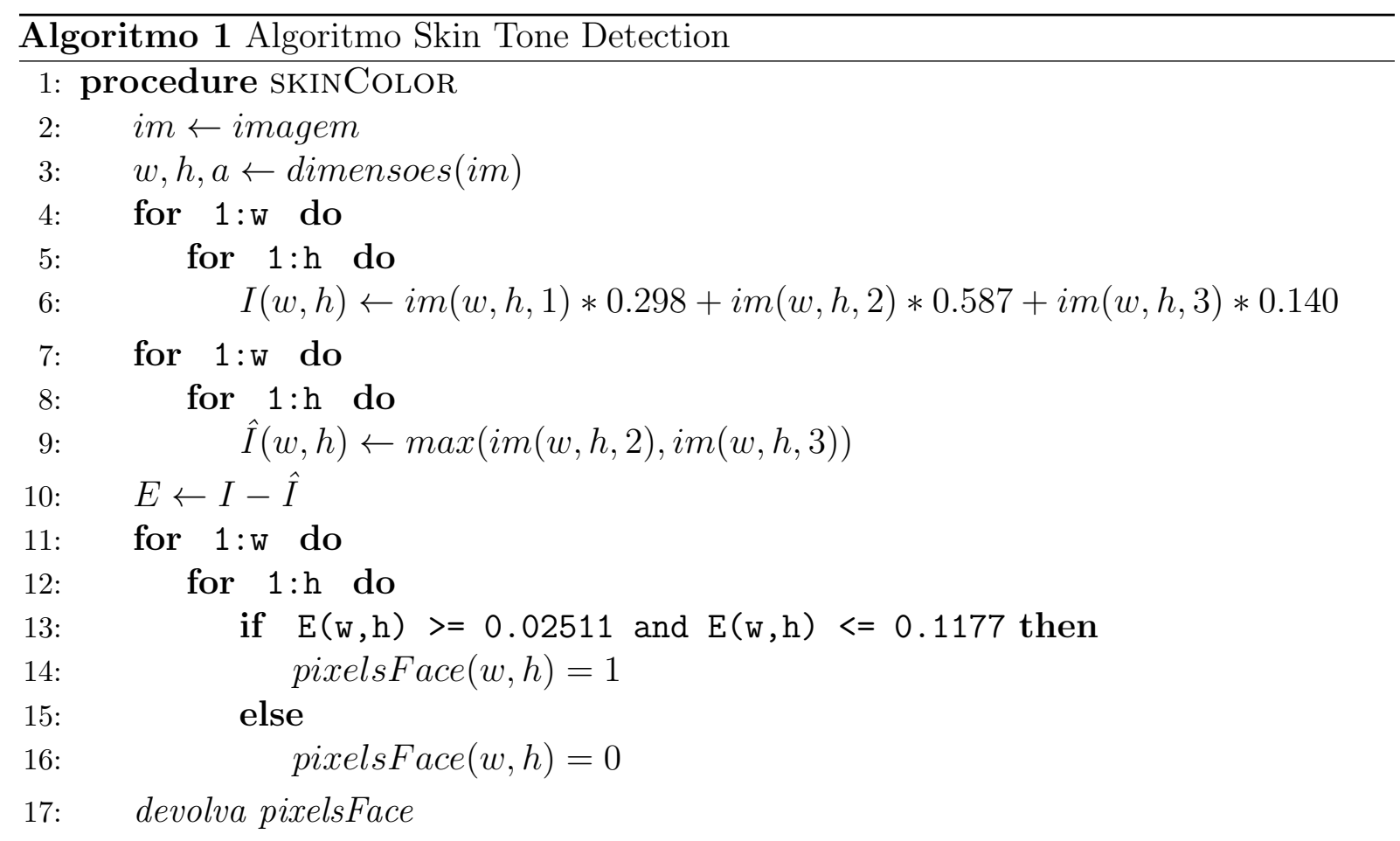

Fonte: Abbas Cheddad, 2009

Dado a máscara contendo os valores de presença de face humana, é possível segmentar a face humana da imagem de entrada, permitindo assim, que outras partes da imagem, como fundo, sejam removidas, aprimorando as técnicas de reconstrução de faces ocluídas. Um exemplo pode ser observado na Figura 13. 
Figura 13 - Skin Color - imagem original, máscara, imagem segmentada

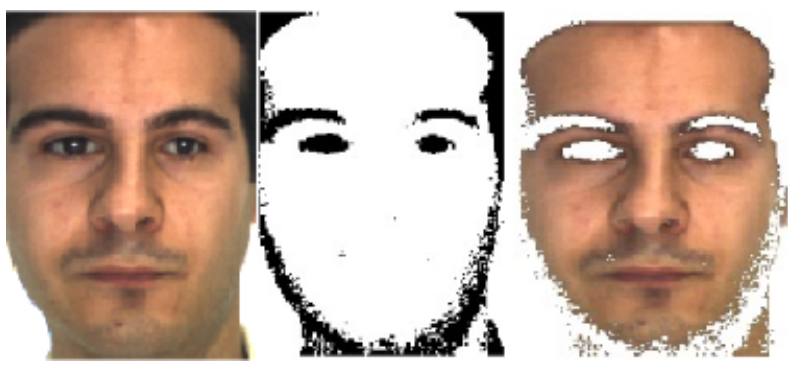

Fonte: Jozias Rolim, 2018

\subsection{Técnica de detecção de oclusão}

A detecção de oclusão em imagens de face baseia-se em encontrar deformações que se apresentam em regiões locais da face. As deformações podem se dar por diversos fatores, sejam eles acessórios (óculos, turbante, véu, etc.), mudanças físicas dos indivíduos (barba, queimaduras, etc.) ou outros quaisquer motivos (mão na face, iluminação que distorce a captura e aparenta oclusão, etc.). A seguir será apresentada a técnica de detecção utilizada por esse trabalho, chamada de Eigenfaces, por se tratar também de uma técnica utilizada para reconstrução, será apresenta na seção 3.5.1.

\subsection{Técnicas de reconstrução de face baseadas em subespaços}

A reconstrução da face é uma das fases importantes para o reconhecimento de indivíduos, quando se trata de faces ocluídas, muitas vezes a parte ocluída é extraída e prejudica de forma acentuada o processo de reconhecimento biométrico. Nesta seção serão apresentadas, com detalhes, as técnicas e procedimentos adotados, no que diz respeito as técnicas de reconstrução de face baseadas em subespaços. Todas as técnicas fazem uso de imagens em escala de cinza, representadas em forma de matriz coluna, onde cada linha é concatenada com a subsequente, $x$ é a variável que representa a imagem neste estado. A imagem $x$ é adquirida concatenando cada coluna da imagem original.

\subsubsection{Eigenfaces}

Proposto por Turk (TURK; PENTLAND, 1991a), também chamado de "PCA para faces" é o nome dado ao conjunto de autovalores que são utilizados para reconhecimento 
de faces humanas na computação visual. Sua técnica parte do princípio que as imagens são interpretadas como vetores em uma matriz, sendo $w$ o número de linhas de uma imagem e o $h$ o número de colunas, podemos afirmar que uma imagem é um vetor no espaço ( $w x$ h)-dimensional. No eigenfaces, as imagens de face são representadas por uma matriz $\Gamma$, de tamanho $M x n$, onde $M=w x h$ e $n$ o número de imagens $x$ a serem utilizadas durante a fase de treinamento. Assim, o eigenfaces representa a projeção das faces em sub-espaços vetoriais. A principal idéia do eigenfaces é representar $\Gamma$ em uma dimensão menor, onde temos $\Theta=\Gamma-$ média da face (representado por $\Psi$ ), assim $\Theta-\Psi=w 1 u 1+w 2 u 2+\ldots+$ wlul, onde $l<<w x h$.

Tendo um conjunto de imagens $n$ para treinamento, é criada a matriz de $n$ cópias da média das imagens, ilustrado na equação 7.

$$
\Psi[M x n]=1 / n \sum_{i=1}^{N} \Gamma[M x i]
$$

Dado que a média das imagens de face foi calculada, é necessário calcular a diferença entre cada imagem de face $\Gamma_{i}$ e a média gravada em $\Psi$, como apresentado na equação 8.

$$
\Theta_{i}[M x n]=\Gamma_{i}[M x n]-\Psi[M x n], \text { sendo } A[M x n]=\left[\Theta_{1}, \Theta_{2}, \ldots, \Theta_{n}\right]
$$

Assim a partir dos valores encontrados os autovalores e autovetores podem ser extraídos, da matriz de covariância das imagens de treinamento, apresentado na equação 9 .

$$
C[M x n]=A[M x n] A^{T}[M x n]
$$

No entanto, encontrar autovetores de uma matriz [MxM] é uma tarefa custosa para o tamanho das imagens utilizadas, assim uma maneira simplificada será adotada (TURK; PENTLAND, 1991b). Dada a matriz de covariância os primeiros $n$ auto-vetores podem ser apresentados como uma combinação linear entre os auto-vetores de $A^{T}[n x M] A[M x n]$ (aqui representado por $V$ ) e as imagens contidas em $A$, conforme apresentado em na equação 10 .

$$
U[M x n]=A[M x n] V[n x n]
$$


Dados os eigenfaces representados por $\mathrm{U}$, temos a representação das imagens ressaltando as principais características das imagens de face utilizadas, conforme pode ser observado na Figura 14.

Figura 14 - Eigenfaces

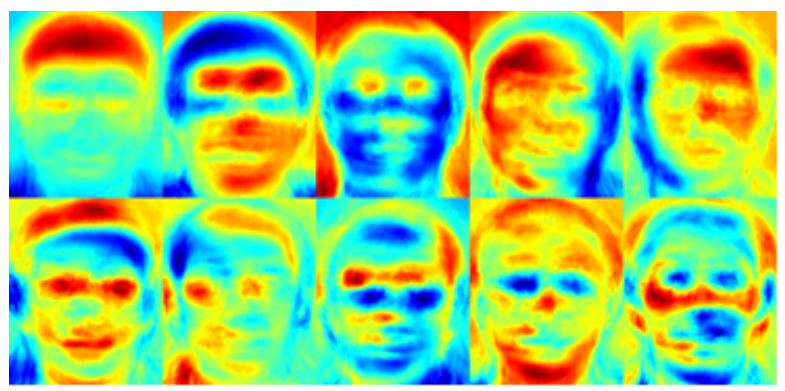

Fonte: OpenCV, 2016

A partir do eigenfaces, podemos agora obter o $\|e\|$, chamado de DFFS (Distance From Face Space), conforme apresentado na equação 11.

$$
\|e\|=-x+m+\sum_{i=1}^{N} y_{i} v_{i}
$$

Onde $x$ é a imagem de entrada, $\|e\|$ é o DFFS, $m$ é a imagem média das faces apresentadas ao modelo, $v_{i}$ são os $N$ eigenfaces considerados e $y_{i}$ são os coeficientes de combinação linear. Assim a média da face e os eigenfaces são selecionados de modo a minimizar a variação da imagem da face. Cada coeficiente $y_{i}$ é obtido projetando o vetor $(x-m)$ no eigenfaces correspondente $v_{i}$.

O DFFS de uma imagem de face ocluída é bem maior que o de uma imagem de face não ocluída. De fato, faces ocluídas não podem combinar linearmente com eigenfaces calculados com exemplos de imagens não ocluídas. Assim, quando uma imagem é reconstruída a partir do eigenfaces, a parte ocluída tende a ser mais evidenciada, conforme pode ser visualizado na Figura 15, em um exemplo de oclusão por uso de óculos.

Figura 15 - Imagem da face original e reconstruída
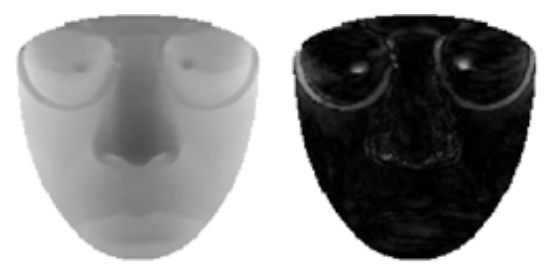

Fonte: Adaptado de Colombo, 2006 
Assim, quanto maior for a diferença entre o pixel original e o pixel reconstruído, maior é a probabilidade do pixel original está ocluído. Deste modo, um limiar pode ser definido para remover a suposta parte ocluída, vale salientar que o limiar é definido empiricamente, o que pode não ser tão preciso, apresentado um modelo na Figura 16.

Figura 16 - Máscara de remoção de oclusão

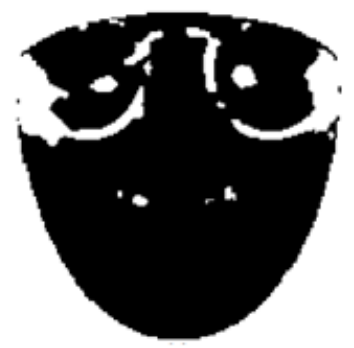

Fonte: Adaptado de Colombo, 2006

Por fim, filtros morfológicos são aplicados de modo a preparar a imagem para a fase de reconstrução da mesma. Esses filtros são aplicados em dois passos, sendo o primeiro responsável por preencher os espaços vazios deixados pela eliminação das partes ocluídas e o segundo descartar pequenas regiões que não aparentam ser regiões ocluídas, por exemplo, regiões que possuem uma área ocluída muito pequena, como as regiões próximas ao nariz apresentadas na Figura 16.

\subsubsection{Fisherfaces}

O Fisherfaces, inicialmente proposto por Fisher (FISHER, 1938), baseado em análise de discriminante linear (Linear Discriminant Analysis ou LDA), é um método capaz de reduzir dimensionalidade do espaço, enquanto preserva o máximo possível de informações discriminatórias. Essa técnica procura direções no espaço, onde as classes são melhores separadas. O Fisherface, quando faz uso de várias imagens de cada uma das classes, é capaz de definir melhor as classes, mesmo com variação de luminosidade e expressão. No Fisherface, dois conceitos são apresentados:(i) dispersão dentro da própria imagem e (ii) dispersão entre classes, dado por:

- (i) dispersão dentro da própria classe, se refere às características intrapessoais e representa variações de aparência na mesma pessoa, devido à diferença na iluminação do ambiente, expressões faciais e obstruções na face; 
- (ii) a dispersão entre classes, representa a diferença na aparência relacionada à diferença de identidade.

A matriz de dispersão $S_{w}$, e a matriz de dispersão $S_{b}$, se baseiam nos dois conceitos apresentados anteriormente, respectivamente, dadas por:

$$
\begin{gathered}
S_{w}=\sum_{q=1}^{c} \sum_{p=1}^{n_{q}}\left(x_{p}^{q}-m_{q}\right)\left(x_{p}^{q}-m_{q}\right)^{T}, \\
S_{b}=\sum_{q=1}^{c}\left(m_{q}-m\right)\left(m_{q}-m\right)^{T},
\end{gathered}
$$

onde, $x_{p}^{q}$ é a $p$-ésima amostra (imagem) da classe $q, m_{q}$ é a média da classe $q, c$ é o número de classes, $n_{p}$ é o número de amostras da classe $q$ e $m$ é a média de todas as classes. O subespaço criado pelo Fisherface é formado pelo conjunto de vetores discriminantes $U=\left[U_{1} U_{2} \ldots U_{k}\right]$ que satisfaça a Equação 14 .

$$
U=\operatorname{argmax}\left|\begin{array}{l}
U^{T} S_{b} U \\
U^{T} S_{w} U
\end{array}\right|
$$

Assim, quando as imagens de face forem projetadas no espaço U, as faces de mesma classe serão distribuídas próximas umas das outras, e esse espaço, deverá ser projetado o mais distante possível do espaço obtido ao projetarmos as imagens de outras classes, obtendo assim um alto poder discriminatório. Isso é possível devido a minimização de $U^{T} S_{b} U$ e maximização de $U^{T} S_{w} U$. No entanto, na maioria das vezes a matriz $S_{w}$ não admite inversa, então, para solucionar esse problema é necessário fazer uso de artifícios matemáticos. Isso acontece porque geralmente o número de imagens é muito menor do que a quantidade de dimensões no espaço. Assim, é possível solucionar esse problema de pelo menos duas formas distintas, usar o método da pseudo-inversa, ou aplicar a análise de um subespaço, ao invés de aplicá-lo no espaço completo.

\subsubsection{Análise de componentes principais Gappy}

Uma vez que as oclusões foram detectadas a imagem da face deve ser reconstruída. Umas das estratégias de restauração da imagem da face é o GPCA (Gappy Principal Component Analysis). 
A estratégia baseia-se em um conjunto de faces sem oclusões $x_{1}, x_{2}, \ldots, x_{n}$ para determinar os componentes principais através da média das faces e os eigenfaces. Assim, uma imagem de face com oclusão $x$ pode ser restaurada realizando a combinação linear com o eigenfaces, conforme a equação 15.

$$
x+e=m+\sum_{i=1}^{N} y_{i} v_{i}
$$

Para calcular o coeficiente $y_{i}$, o DFFS $\|e\|^{2}$ deve ser minimizado. Contudo, o DFFS é calculado incluindo as partes excluídas da imagem (partes com oclusão removidas na fase de detecção e remoção de oclusão), enquanto apenas a informação disponível é considerada. Para ser realizada a restauração é necessário encontrar o produto Gappy dado por $(u, v)_{z}$, equação 16 , onde o valor de $z_{i}$ é 0 , se a o componente de $x$ na posição $i$ for vazio, ou seja, foi removido na fase de detecção de oclusão, caso contrário $z_{i}=1$.

$$
(u, v)_{z}=\sum_{i=1}^{d} u_{i} \cdot v_{i} \cdot z_{i}
$$

A norma Gappy correspondente $\|v\|_{z}$ é definida como $\sqrt{(v, v)_{z}}$. O coeficiente $y_{i}$ são definidos de modo a minimizar o $\|e\|_{z^{2}}$, conforme apresentado na equação 17.

$$
\|e\|_{z}^{2}=\left\|-x+m+\sum_{i=1}^{N} y_{i} v_{i}\right\|_{z}^{2}=\|x-m\|_{z}^{2}-2 \sum_{i=1}^{N} \sum_{j=1}^{N} y_{i} y_{j}\left(v_{j}, v_{i}\right)_{z}
$$

Calculando a derivada do $\|e\|_{z}^{2}$ em relação a cada $y_{i}$, considerando as derivadas parciais nulas, temos um sistema, que pode ser visualizado na equação 18.

$$
\frac{\partial\|e\|_{z}^{2}}{\partial y_{i}}=-2\left(x-m, v_{i}\right)_{z}+2 \sum_{j=1}^{N} y_{j}\left(v_{j}, v_{i}\right)_{z}=0, \text { para cada } i \text { em }\{1, \ldots, N\}
$$

Assim a imagem pode ser reconstruída usando a equação 15, onde os coeficientes são encontrados resolvendo o sistema 18. Em linhas gerais, a imagem é reconstruída de modo a diminuir o erro em relação a imagem média, onde apenas os pixels com oclusão são alterados.

\subsubsection{Análise de componentes principais assimétricos}

Baseado no PCA (Principal Component Analysis) (JOLLIFFE, 2002), com o APCA (Asymmetrical Principal Component Analysis), extensão do PCA, proposto por Söderström 
e Li (SÖDERSTRÖM; LI, 2011) é possível reconstruir regiões ocluídas em imagens de face, levando em consideração as regiões não ocluídas. A intensidade dos pixels não ocluídos é utilizada para estimar as partes ocluídas. No APCA dois autovetores são construídos, um a partir dos pixels não ocluídos da própria imagem ocluída onde os vetores são ortogonais entre si e o outro, chamado de pseudo autovetor, ou autovetor falso, é construído a partir das imagens não ocluídas. Dada a imagem $x$, podemos representar a parte não ocluída de $x$ como $x^{n o} . x^{n o}$ é modelado em um espaço vetorial $\Phi$, dado por $\Phi^{n o}=\left\{\phi_{1}^{n o}, \phi_{2}^{n o}, \phi_{3}^{n o}, \ldots, \phi_{n}^{n o}\right\}$, a equação 19 apresenta a função de mapeamento, onde $b_{i j}^{n o}$ são os autovetores da matriz de covariância $\left\{\left(x_{i}^{n o}-x_{\underline{0}}^{n o}\right)^{T}\left(x_{j}^{n o}-x_{\underline{0}}^{n o}\right)\right\}$ e $x_{\underline{0}}^{n o}$ é a média das regiões não ocluídas, pode ser visualizada na equação 20 o cálculo da média.

$$
\begin{gathered}
\phi_{j}^{n o}=\sum_{i} b_{i j}^{n o}\left(x_{i}^{n o}-x_{\underline{0}}^{n o}\right) \\
x_{\underline{0}}^{n o}=\frac{1}{N} \sum_{j=1}^{N}\left(x_{j}^{n o}\right)
\end{gathered}
$$

Os autovetores das partes não ocluídas são utilizados para torná-los ortogonais, enquanto as partes ocluídas são modeladas de acordo com as partes não ocluídas. Assim o pseudo auto vetor pode ser construído, conforme pode ser visto na equação 21 , onde $x_{i}$ é a imagem original e $x_{\underline{0}}$ é a média das imagens originais.

$$
\Phi_{j}^{P}=\sum_{i} b_{i j}^{n o}\left(x_{i}-x_{\underline{0}}\right)
$$

A projeção é usada para extrair coeficientes $\left\{\alpha_{j}^{n o}\right\}$ do autovetor $\Phi_{j}^{n o}$, conforme apresentado na equação 22 .

$$
\alpha_{j}^{n o}=\Phi_{j}^{n o}\left(x^{n o}-x_{\underline{0}}^{n o}\right)^{T}
$$

Por fim, a imagem é reconstruída utilizando a equação 23 , onde $M$ é a quantidade de pseudo auto vetores selecionados para a reconstrução.

$$
\hat{x}=x_{\underline{0}}+\sum_{j=1}^{M} \alpha_{j}^{M} \Phi_{j}^{P}
$$

3.5.5 Análise recursiva de componentes principais

O PCA (Principal Component Analysis) é um problema bem conhecido e estudado de forma extensiva na literatura. A maioria dos algoritmos propostos para solucionar o 
problema baseiam-se no gradiente descendente (KUNG; DIAMANTARAS; TAUR, 1994; MAO; JAIN, 1995; OJA, 1983; RAO; PRINCIPE; WONG, 2004), que são extremamente lentos para convergir, e seu desempenho depende fortemente do tamanho do passo utilizado, $\alpha$ (alpha). Para amenizar o problema, foram propostos métodos baseados em sub-espaço (YANG, 1995; HEGDE et al., 2006). No entanto, técnicas baseadas em sub-espaços são exaustivas (necessitam de grande tempo e poder computacional, para serem executadas). Foi apresentado por Rao (RAO; PRINCIPE, 2002), um método baseado em ponto fixo, que mostrou convergência rápida com complexidade bem próxima dos métodos baseados em gradiente. Contudo, o método baseado em ponto fixo depende do uso de técnicas de deflação (BURRAGE et al., 1998), que traz convergência sequencial, reduzindo assim a velocidade de convergência.

Proposto por Erdogmus (ERDOGMUS et al., 2004), o Recursive PCA (RPCA), se propõem a resolver o problema do PCA, de modo a evitar os problemas apresentados pelos algoritmos baseados em subespaço e gradiente. O RPCA também se apresenta como uma estratégia robusta para solucionar o PCA quando tratamos de processamento de sinal, permitindo que seja possível calcular a matriz de covariância estimada de forma recursiva, evitando todo o processamento quando um novo sinal (nova imagem) é apresentada ao modelo. Para facilitar a compreensão sobre o algoritmo, será apresentado o método utilizado para solucionar o PCA em seguida sua adaptação para o RPCA. Considere $\mathbf{x}$, um vetor, representando uma imagem, com valor de média zero, de dimensão $\mathbf{M}$ e $\mathbf{n}$ projeções $v_{1}, v_{2}, \ldots, v_{n}$ de tal modo que $v_{j}=w_{j}^{T} x$, onde os $w_{j}$ são vetores unitários que definem a dimensão de projeção no espaço. O primeiro autovetor (direção no espaço) é definido com a solução do problema de otimização descrito na equação 24 .

$$
w_{1}=\operatorname{argmax}\left(w^{T} C w\right), \text { sujeito a restrição } w^{T} w=1,
$$

onde $C$ é a matriz de covariança. Os próximos autovetores são definidos adicionandose restrições ao problema descrito na equação 24 , de modo a garantir a ortogonalidade do autovetor atual, com os encontrados anteriormente, conforme apresentado na equação 25.

$$
w_{j}=\operatorname{argmax}\left(w^{T} C w\right), \text { sujeito a restrição } w^{T} w=1, w^{T} w_{l}=0, l<j
$$

Em geral, a solução para este problema acaba sendo a matriz de covariância $C$, de tal modo que os principais autovetores são os vetores $x$ rearranjados em $C$ de acordo 
com seus respectivos autovalores correspondentes (maior para o menor) (GOLUB; LOAN, 1989).

Contudo, em aplicações de processamento de sinais, existem necessidades diferentes. As imagens são adquiridas de forma seqüencial, o que exige regras de atualização amostra por amostra para a matriz de covariância. Considere $\mathbf{x}_{k}$, um vetor, representando uma imagem, com média zero, de dimensão $\mathbf{M}$ e $\mathbf{k}$ o momento em que a o vetor é apresentado. A matriz de covariância estimada no tempo $k$ para o vetor $x$ pode ser calculada conforme demonstrado na equação 26:

$$
C_{k}=\frac{1}{k} \sum_{i=1}^{k} x_{i} x_{i}^{T}=\frac{(k-1)}{k} C_{k-1}+\frac{1}{k} x_{k} x_{k}^{T},
$$

com $C_{k}=Q_{k} \Lambda_{k} Q_{k}^{T}$ e $R_{k}=Q_{k-1} \Lambda_{k-1} Q_{k-1}^{T}$, onde $Q$ e $\Lambda$ denota o vetor ortogonal e o autovalor, respectivamente. Definindo também $\alpha_{k}=Q_{k-1}^{T} x_{k}$ e substituindo na equação 26, temos:

$$
Q_{k}\left(k \Lambda_{k}\right) Q_{k}^{T}=Q_{k-1}\left[(k-1) \Lambda_{k-1}+\alpha_{k} \alpha_{k}^{T}\right] Q_{k-1}^{T},
$$

dada a decomposição da matriz $\left[(k-1) \Lambda_{k-1}+\alpha_{k} \alpha_{k}^{T}\right]$, dada por $V_{k} D k V k^{T}$, onde $V$ é ortonormal e $D$ é diagonal, então

$$
Q_{k}\left(k \Lambda_{k}\right) Q_{k}^{T}=Q_{k-1} V_{k} D_{k} V_{k}^{T} Q_{k-1}^{T}
$$

Por comparação, as regras de atualização recursiva para os autovetores e autovalores são determinados como sendo:

$$
\begin{aligned}
Q_{k} & =Q_{k-1} V_{k}, \\
\Lambda_{k} & =\frac{D_{k}}{k}
\end{aligned}
$$

Apesar da matriz $\left[(k-1) \Lambda_{k-1}+\alpha_{k} \alpha_{k}^{T}\right]$ ter uma estrutura muito mais simples que a de uma matriz de covariância normal, determinar a decomposição dos autovetores $V_{k} D_{k} V_{k}^{T}$, ainda apresenta certa dificuldade, especialmente se $k$ for grande. Assim, o problema pode ser resolvido de forma mais simples usando uma abordagem de análise de perturbação da matriz (WANG et al., 2013).

Quando $k$ é grande, a matriz $\left[(k-1) \Lambda_{k-1}+\alpha_{k} \alpha_{k}^{T}\right]$ é diagonalmente dominante, de acordo com o teorema de Gershgorin, ou seja, seus autovalores são próximos da parte 
diagonal $\left((k-1) \Lambda_{k-1}\right)$ e o autovetores próximos da identidade. Em resumo, o problema de análise de perturbação da matriz, destina-se a encontrar a decomposição da matriz na forma $\Lambda+\alpha \alpha^{T}$, ou seja, uma atualização em uma matriz diagonal $\Lambda$, usando as aproximações: $D=\Lambda+P_{\Lambda}$ e $V=I+P_{V}$, onde $P_{\Lambda}$ e $P_{V}$ são pequenas matrizes de perturbação, com a matriz de perturbação $P_{\Lambda}$ sendo, naturalmente, diagonal. Com as definição propostas, a decomposição dos autovetores $V D V^{T}$ pode ser descrita conforme ilustrado na equação 30:

$$
\begin{aligned}
V D V^{T} & =\left(I+P_{V}\right)\left(\Lambda+P_{\Lambda}\right)\left(I+P_{V}^{T}\right) \\
& =\Lambda+\Lambda P_{V}^{T}+P_{\Lambda}+P_{\Lambda} P_{V}^{T}+P_{\Lambda} \Lambda+P_{V} \Lambda P_{V}^{T}+P_{V} P_{\Lambda}+P_{V} P_{\Lambda} P_{V}^{T} \\
& =\Lambda+P_{\Lambda}+D P_{V}^{T}+P_{V} D+P_{V} \Lambda P_{V}^{T}+P_{V} P_{\Lambda} P_{V}^{T}
\end{aligned}
$$

Decompondo a equação 30 para a forma $\Lambda+\alpha \alpha^{T}$, e assumindo que os termos $P_{V} \Lambda P_{V}^{T}$ e $P_{V} P_{\Lambda} P_{V}^{T}$ são insignificantes, temos:

$$
\alpha \alpha^{T}=P_{\Lambda}+D P_{V}^{T}+P_{V} D
$$

A ortonormalidade de $V$ trás uma equação adicional que caracteriza $P_{V}$. Substituindo assim, $V=I+P_{V}$ em $V V^{T}=I$ e assumindo que $P_{V} P_{V}^{T} \approx 0$, temos que $P_{V}=-P_{V}^{T}$. Combinando o fato que a matriz de perturbação do autovetor $P_{V}$ é anti-simétrica a $P_{\Lambda}$ e $D$ é diagonal, então a solução para as matrizes de perturbação encontradas na equação 31 se dar por: a i-ésima entrada diagonal de $P_{\Lambda}$ é $\alpha_{i}^{2}$ e a (i,j)-ésima entrada de $P_{V}$ é dada por:

$$
P_{V}(i, j)=\frac{\alpha_{i} \alpha_{j}}{\left(\lambda_{j}+\alpha_{j}^{2}-\lambda_{i}-\alpha_{i}^{2}\right)}, \text { se } j \neq i \text {, e } 0, \text { se } j=i
$$

Pode ser visto o pseudocódigo do RPCA no Algoritmo 2. Como pode ser observado, o algoritmo apresenta algumas variáveis que devem ser definidas, como o parâmetro de profundidade de memória e os autovalores e autovetores iniciais.

Para selecionarmos o parâmetro de profundidade de memória $\left(\lambda_{k}\right)$, devemos levar em consideração as seguintes situações:

- Em uma situação onde cada amostra tem o mesmo peso, o parâmetro deve ser devido como $\lambda_{k}=\frac{1}{k}$, neste caso, a atualização recursiva acontece conforme descrito na Equação 26;

- Em um ambiente estacionário, ou seja, as características do processo não são alteradas no tempo, o processo se desenvolve no tempo em torno da média, de modo que 


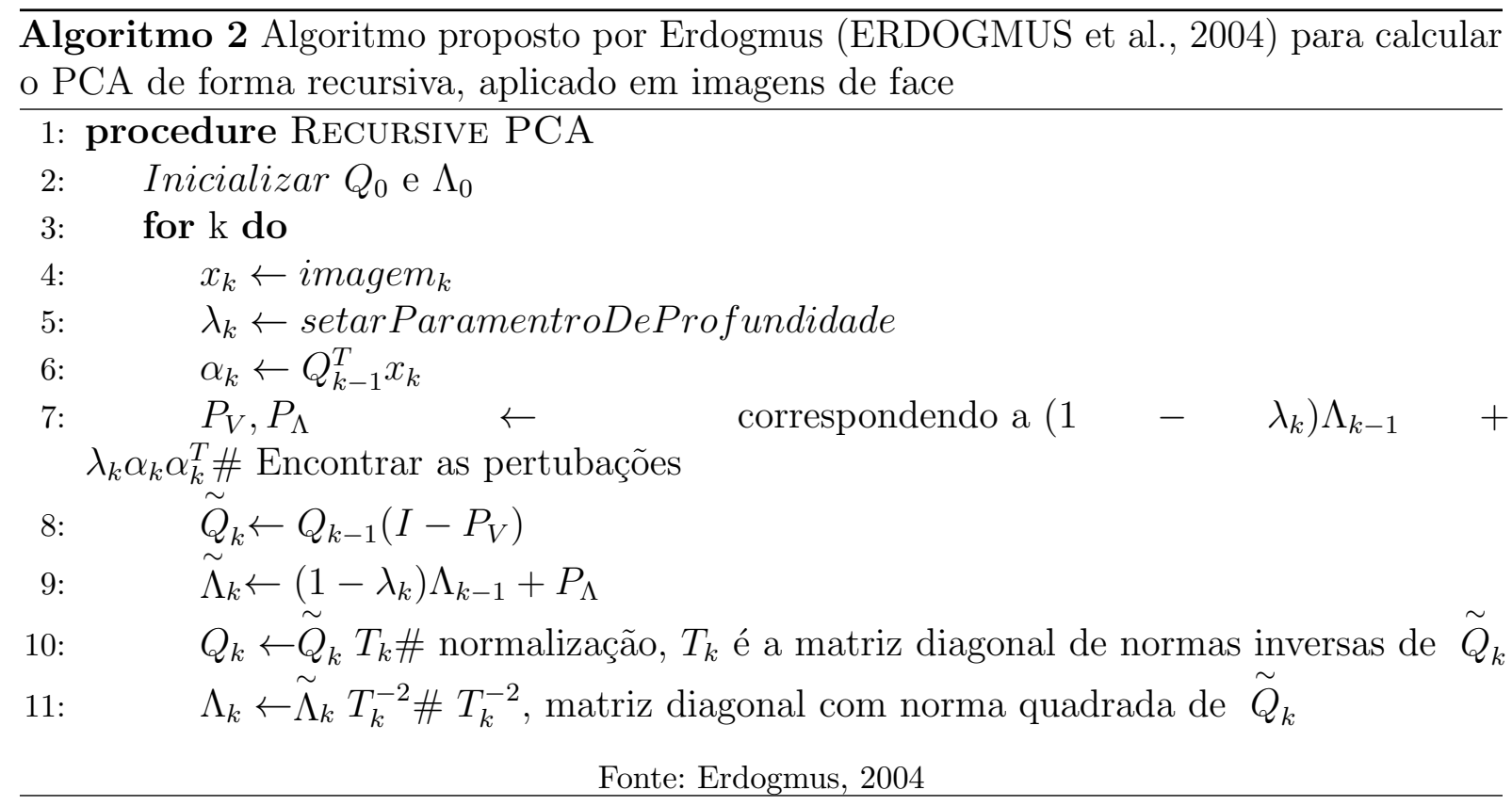

a escolha de uma origem dos tempos não é importante, pode ser empregada uma estratégia para selecionar uma taxa de decaimento fixa dada por:

$$
C_{k}=(1-\lambda) C_{k}+\lambda x_{k} x_{k}^{T}
$$

sendo $\lambda \in(0,1)$ e um valor muito pequeno. Considerando que a média da profundidade da memória é de $\frac{1}{\lambda}$ amostras, a seleção deste parâmetro é um trade-off entre capacidade de rastreamento e variância da estimativa.

No que diz respeito a definir os autovetores e autovalores, é necessário inicializar a matriz $Q_{0}$ e a matriz do autovalor $\Lambda_{0}$ com a primeira imagem de amostra para obter uma estimativa parcial da matriz de covariância e determinar a sua posição $\left(N_{0}>n\right)$.

\subsubsection{Análise recursiva rápida de componentes principais}

O Fast Recursive PCA, proposto por Wang (WANG; TAO, 2007), apresenta uma alternativa a abordagem para calcular o Recursive PCA, descrito na seção 3.5.5, possibilitando atuar com maior precisão e velocidade no que diz respeito à (1) conhecer a correspondência exata entre a imagem original e a imagem a ser reconstruída e (2) maior velocidade na convergência e diminuição na complexidade computacional. 
A idéia básica do PCA é:

$$
x+e=m+\sum_{i=1}^{N} y_{i} v_{i}
$$

onde, $x=\left[x_{1}, x_{2}, x_{3}, \ldots, x_{n}\right]^{T}$ é a imagem de entrada com $n$ pixels, $e$ é a aproximação do erro, $m$ a média das faces, $v_{i}$ é o i-ésimo eigenface (autovetor da matriz de covariância de $x$ ) e $y_{i}$ é o coeficiente de combinação linear, que pode ser estimado por:

$$
y^{0}=v^{T}\left(x^{0}-m\right)
$$

onde, '0' é usado para representar a imagem original de entrada. Assim, $x^{0}$ é a imagem de face original e $y^{0}$ é o coeficiente linear calculado de $x^{0}$. A imagem de face reconstruída pode ser obtida com:

$$
x^{1^{\prime}}=m+\sum_{i=1}^{N} y_{i}^{0} v_{i},
$$

onde $x^{1^{\prime}}$ é a imagem projetada, que pode ser reconstruída pela soma dos pesos da imagem original e a imagem projetada, conforme pode ser visto na equação 37 .

$$
x^{1}=\alpha x^{0}+(1-\alpha) x^{1^{\prime}},
$$

o valor do peso $\alpha$ se encontra no intervalo $(0,1)$. Se a região estiver ocluída, o peso pode ser estimado pelo DFFS. Caso a região ocluída seja conhecida, o peso na região da oclusão é 1 , caso contrário 0 . Assim, $x^{1}$ é o resultado após a primeira fase de análise.

No RPCA, a nova imagem reconstruída é aplicada novamente as equações 35, 36 e 37, para um novo ciclo de análise e síntese, até que as diferenças entre os dois coeficientes sucessivos sejam inferiores a um limiar predefinido, dado por:

$$
\begin{gathered}
y^{n}=\left(x^{n}-m\right) v \\
x^{n+1^{\prime}}=m+\sum_{i=1}^{N} y_{i}^{n} v_{i} \\
x^{n+1}=\alpha x^{n}+(1-\alpha) x^{n+1^{\prime}}
\end{gathered}
$$


As iterações finalizam-se quando a diferença entre as imagens é menor que um limiar, dado por:

$$
D=\max \left(\left|y_{i}^{n+1}-y_{i}^{n}\right|\right)<\epsilon
$$

O FRPCA, propõem a adicionar a diferença entre os coeficientes sucessivos para compensar o segundo passo (Equação 39), resultando em:

$$
x^{n+1^{\prime}}=m+\sum_{i=1}^{N}\left[y_{i}^{n}+\beta\left(y_{i}^{n}-y_{i}^{n-1}\right)\right] v_{i}
$$

onde, $0<\beta<1$ é uma constante de compensação, tipicamente utiliza-se $\beta=0.5$, se $\beta=0$ é realizado o algoritmo clássico de compensação do PCA.

\subsection{Técnias de reconstrução facial baseadas em regressões}

Um forma de reconstruir faces ocluídas é remover a parte ocluída e usar um algoritmo de regressão para determinar quais são os pixels faltantes. Basicamente, para cada imagem de treinamento $x$ é gerada uma máscara de oclusão, onde em cada pixel é verificada a presença ou ausência de oclusão. Caso o pixel apresente oclusão o valor da mascará será zero, caso contrário seu valor será um, dado por:

$$
o_{k_{i, j}}= \begin{cases}0 & , \text { caso ocluído } \\ 1 & , \text { caso contrário }\end{cases}
$$

onde, $o_{k_{i, j}}$ é a máscara de oclusão da imagem $k$ no pixel $i, j$. Cada imagem passa por esse processo, gerando o vetor $O$, dado por $\left\{o_{1}, o_{2}, o_{3}, \ldots, o_{n-1}, o_{n}\right\}$. A interseção entre as máscaras de colusão definem uma nova máscara resultante, que separa a imagem $x^{\prime}$ (pixels não ocluído), dos label $x^{\prime \prime}$ (pixels ocluídos), como pode ser visto na Equação 44.

$$
O^{\prime}=o_{1} \cap o_{2} \cap o_{3} \cap \ldots \cap o_{n-1} \cap o_{n}
$$

Dada a máscara de oclusão $O^{\prime}$, é verificada a maior presença de oclusão, de modo que $50 \%$ seja o percentual máximo de oclusão. Assim, a máscara resultante $O^{\prime}$ é reprocessada, criando duas possíveis máscaras de oclusão, conforme pode ser vista na Figura 17. 
Figura 17 - Possíveis máscaras $O^{\prime}$
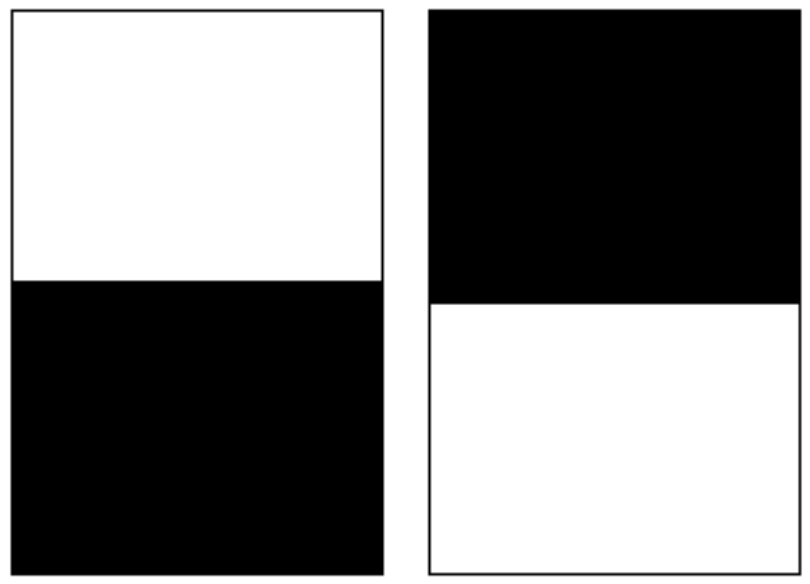

A parte ocluída é representada pela cor preta (0), enquanto a parte sem oclusão é representada pela cor branca (1).

Fonte: Jozias Rolim, 2018

Após esse processo, todas as imagem $x$ são multiplicados pela máscara, formando assim o conjunto de treinamento, conforme a Equação 45 e 46. Novas imagens que forem apresentadas ao modelo são aplicadas a mesma máscara definida no treinamento.

$$
\begin{gathered}
x_{k}^{\prime}=x_{k} * O^{\prime} \\
X^{\prime}=\left\{x_{1}^{\prime}, x_{2}^{\prime}, x_{3}^{\prime}, \ldots, x_{n-1}^{\prime}, x_{n}^{\prime}\right\}
\end{gathered}
$$

Para calcular o $Y^{\prime}$, que representa os labels das imagens de treinamento, o mesmo conjunto de imagens $x$ é multiplicado pela máscara oposta, dada por $O^{\prime \prime}=\left(O^{\prime}-1\right) *(-1)$, fazendo com que os valores que antes representavam a ausência de oclusão, passem a representar a presença. Assim, temos:

$$
\begin{gathered}
y_{k}^{\prime}=x_{k} * O^{\prime \prime} \\
Y^{\prime}=\left\{y_{1}^{\prime}, y_{2}^{\prime}, y_{3}^{\prime}, \ldots, y_{n-1}^{\prime}, y_{n}^{\prime}\right\}
\end{gathered}
$$

Para o treinamento foram usadas apenas imagens sem oclusão. Foram utilizadas regressões baseadas em KNN, Linear, Ridge e Árvores extremamente aleatórias, descritas nas secções seguintes. 
3.6.1 Regressão baseada em vizinhança

Regressão baseada em KNN (Nearest Neighbors Regression) (HAARA; KANGAS, 2012), utilizado quando os rótulos (labels) são contínuos, ao invés de variáveis discretas. Nesta estratégia, o rótulo é atribuído a um ponto que é calculado com base na média dos pontos vizinhos mais próximos, pode ser visto na Figura 18 uma exemplo da reconstrução com essa técnica.

Figura 18 - Reconstrução com regressão baseada em KNN

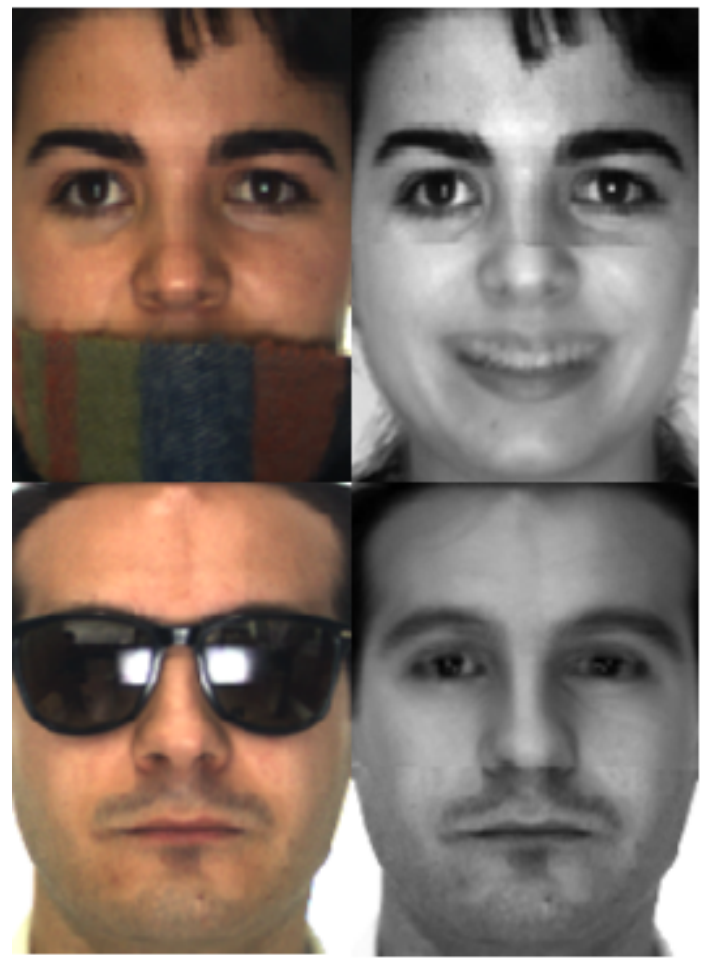

(i) Imagem original, (ii) Imagem reconstruída

Fonte: Jozias Rolim, 2018

A regressão baseada em vizinhos mais próximos usa pesos uniformes para cada vizinho, ou seja, os vizinhos mais próximos são encontrados por alguma função de distância, são somados e o resultado é dividido pela quantidade de vizinhos definida. Podem ser utilizadas diversas funções de distância com: distância Euclidiana, Manhattan, Minkowski, Chebychev. Na Figura 19, pode ser visto um exemplo de regressão utilizando a estratégia de vizinhos; 
Figura 19 - Exemplo regressão baseada em KNN, com $\mathrm{k}=5$

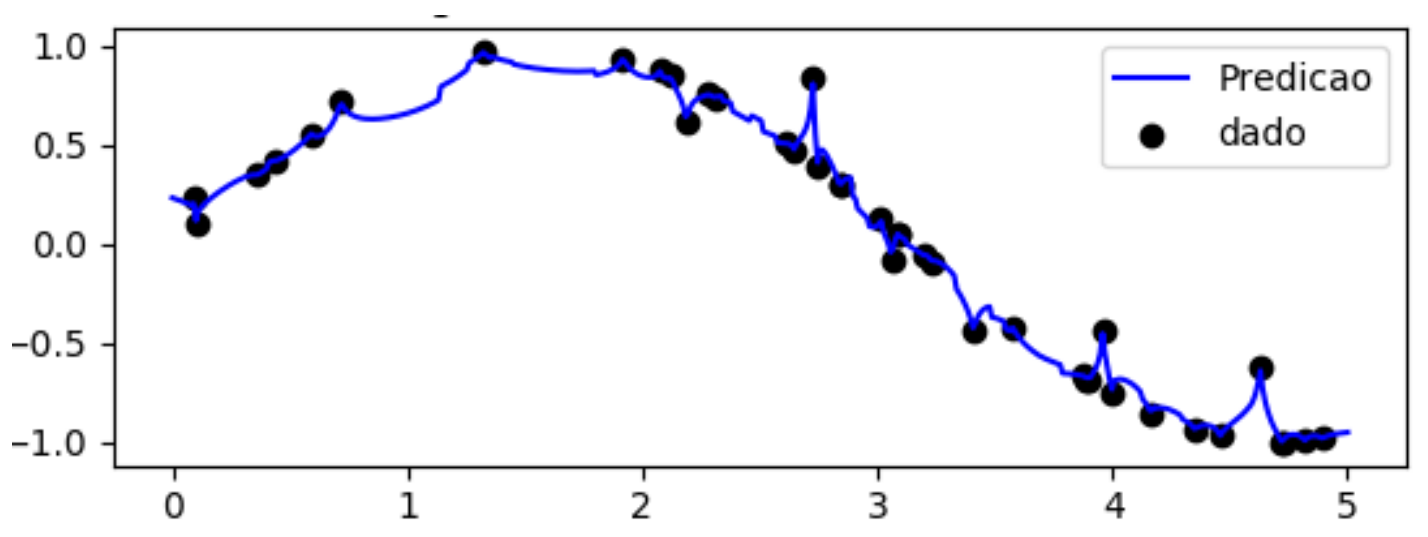

Fonte: Jozias Rolim, 2018

\subsubsection{Regressão linear}

Regressão linear (LARRABEE; SCOTT; BELLO, 2014) - a análise de regressão linear tem como resultado uma regressão matemática que descreve um relacionamento entre duas variáveis. A regressão se chama linear porque a equação da reta que ajusta os pontos é de primeiro grau. Ela é usada para estimar uma variável (variável dependente) com base em outra (variável independente). A equação da regressão linear é dada por:

$$
y_{k_{(i, j)}}^{\prime}=a x_{k_{\left(i^{\prime}, j^{\prime}\right)}}^{\prime}+b
$$

onde temos,

$$
\begin{gathered}
a=\frac{n \sum_{l=1}^{n} x_{l_{\left(i^{\prime}, j^{\prime}\right)}}^{\prime} y_{l_{(i, j)}}^{\prime}-\sum_{l=1}^{n} x_{l_{\left(i^{\prime}, j^{\prime}\right)}}^{\prime} \sum_{l=1}^{n} y_{l_{(i, j)}}^{\prime}}{n \sum_{l=1}^{n} x_{l_{\left(i^{\prime}, j^{\prime}\right)}}^{\prime 2}-\left(\sum_{l=1}^{n} x_{l_{\left(i^{\prime}, j^{\prime}\right)}}^{\prime}\right)^{2}} \\
b=\bar{y}^{\prime}-a \bar{x}^{\prime}
\end{gathered}
$$

sendo $y_{k_{(i, j)}}^{\prime}$ o valor que queremos descobrir da imagem $k$ no pixel $(i, j), x_{k_{\left(i^{\prime}, j\right)}}^{\prime} \mathrm{o}$ valor de referencia na imagem de entrada $k$ no pixel $\left(i^{\prime}, j\right.$ ) (informação da região não ocluída), $\bar{y}^{\prime}$ e $\bar{x}^{\prime}$ a média de valores de $y^{\prime}$ e $x^{\prime}$, respectivamente, calculados com base nas imagens de treinamento, pode ser visto na Figura 20 uma exemplo da reconstrução com essa técnica. Assim, podemos escrever o problema de regressão linear como sendo:

$$
y_{k}^{\prime}=a x_{k}^{\prime}+b+\epsilon_{i}
$$


onde $\epsilon_{k}$ é a variável que define o erro. Na fase de treinamento o objetivo é diminuir o erro residual, dado por:

$$
R S S=\sum_{i=1}^{n}\left(\epsilon_{i}\right)^{2}=\sum_{i=1}^{n}\left(y_{i}^{\prime}-\left(a x_{i}+b\right)\right)^{2}
$$

Figura 20 - Reconstrução com regressão linear

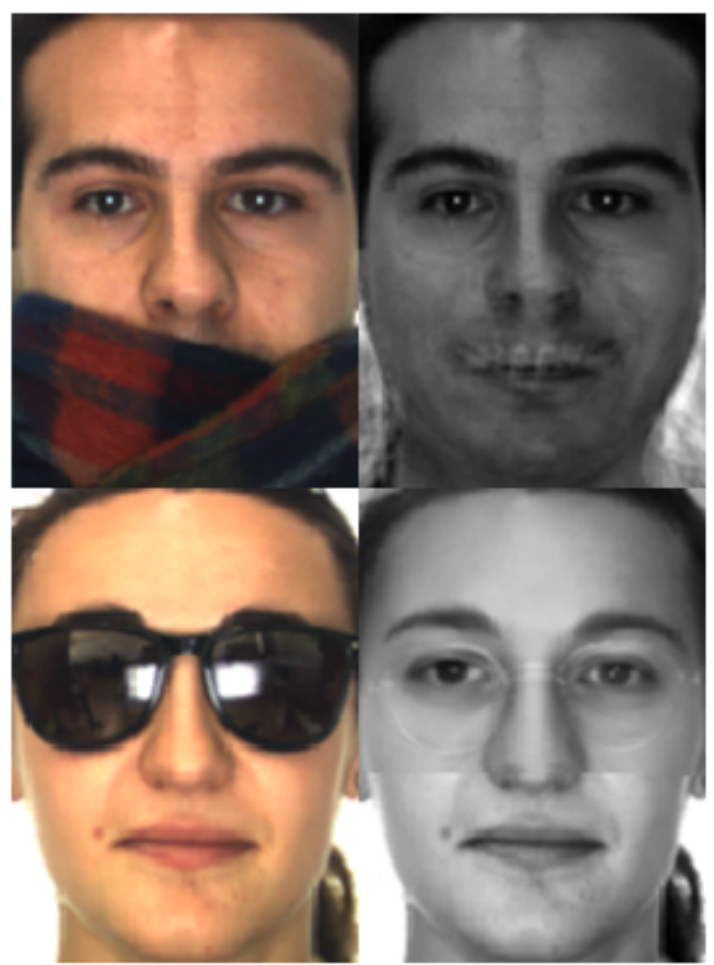

(i) Imagem original, (ii) Imagem reconstruída

Fonte: Jozias Rolim, 2018

\subsubsection{Regressão Ridge}

Regressão Ridge (HOERL; KENNARD, 1970) - na regressão ridge o principal objetivo é suavizar os atributos que sejam relacionados uns com os outros e que aumentam o ruído. Assim, o modelo converge para um resultado mais estável, mantendo a acurácia do modelo. Com isso, os atributos que menos contribuem para o modelo são penalizados de modo a minimizar seu valor. Um exemplo da regressão ridge aplicado a reconstrução facial pode ser vista na Figura 21. 
Figura 21 - Reconstrução com Regressão Ridge

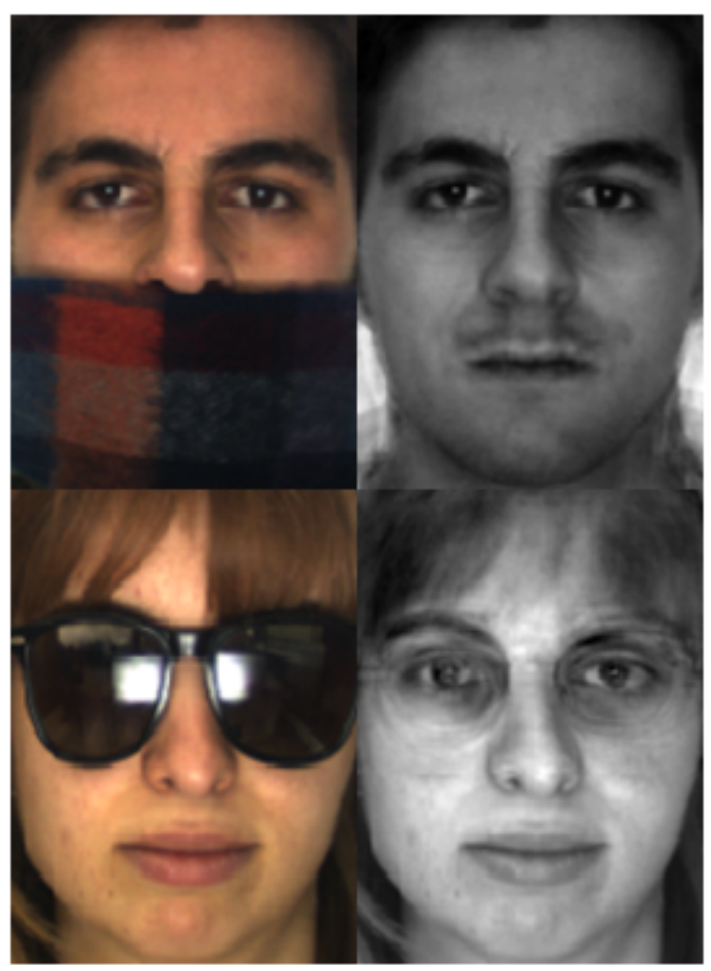

(i) Imagem original, (ii) Imagem reconstruída

Fonte: Jozias Rolim, 2018

Para conseguir realizar o que se propõem a regressão ridge adiciona uma penalidade no coeficiente de $\mathrm{x}$, dado por:

$$
R S S=\sum_{i=1}^{n}\left(\epsilon_{i}\right)^{2}+\alpha(a)^{2}=\sum_{i=1}^{n}\left(y_{i}^{\prime}-\left(a x_{i}+b\right)\right)^{2}+\alpha(a)^{2}
$$

onde, $\alpha$ é o parâmetro que controla a penalização dos valores. Observe que, se o valor de $\alpha$ é muito pequeno, tende a zero, temos a regressão linear. Neste modelo de regressão os valores outlier são minimizados devido a ação do $\alpha$, que controla as grande oscilações.

\subsubsection{Regressão baseada em árvores extremamente aleatórias}

Regressão baseada em árvores extremamente aleatórias, apresentada por Geurts (Extremely randomized trees) (GEURTS; ERNST; WEHENKEL, 2006), é um modelo baseado em árvores binárias, ou seja de ordem 2, onde cada nó pode possuir no máximo dois nós filhos, que utiliza um subconjunto aleatório de características, para definir um 
limiar de separação. No entanto, ao invés de procurar os limiares mais discriminatórios, os limiares são escolhidos de forma aleatória para cada característica e o melhor desses limiares gerados é escolhido como regra de divisão. Essa operação permite reduzir a variação do modelo. Pode ser visto na Figura 22, um exemplo de reconstrução com a técnica descrita.

Figura 22 - Reconstrução - regressão baseada em árvores extremamente aleatórias

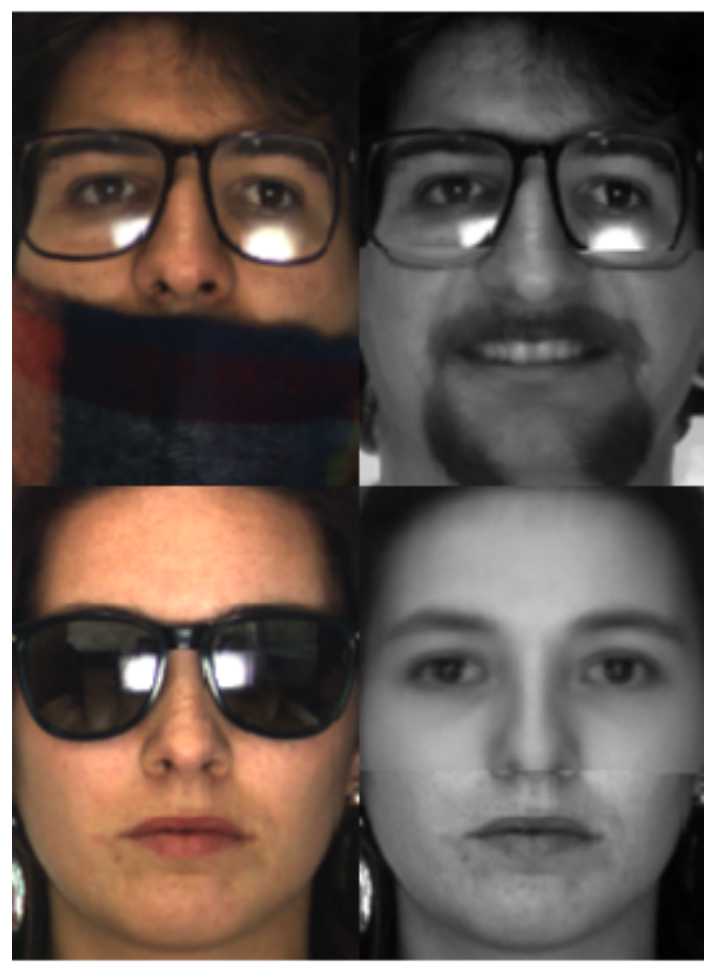

(i) Imagem original, (ii) Imagem reconstruída

Fonte: Jozias Rolim, 2018

As árvores extremamente aleatórias são similar as árvores aleatórias (Random forest ou Random Trees), no entanto se diferem, basicamente, por dois pontos: (i) não usam o procedimento de "bagging" para construir um conjunto de treino para cada árvore, o mesmo conjunto de treinamento é utilizado para treinar todas as árvores; (ii) escolhem um nó dividindo muito extremamente (tanto o índice como o valor da divisão são escolhidos de forma aleatória), enquanto a árvore aleatória encontra a melhor divisão entre o subconjunto aleatório de variáveis. O pseudo código da regressão baseada em árvores extremamente aleatórias pode ser visto no Algoritmo 3. O procedimento tem dois parâmetros, o $K$ que representa o numero de atributos aleatórios selecionados em cada nó e $n$, a quantidade mínima de exemplos para separar um nó. Esse procedimento é realizado $M$ vezes, de modo a gerar um "ensemble", onde cada execução gera uma árvore. Por fim, o "ensemble" decide por média aritmética o resultado.Os parâmetros $K, n_{\text {min }}$ e $M$, possuem diferentes efeitos, 
o $K$ determina a força do processo de seleção de atributos, enquanto $n_{\min }$, a média de ruído na saída e $M$ a redução da variância do modelo.

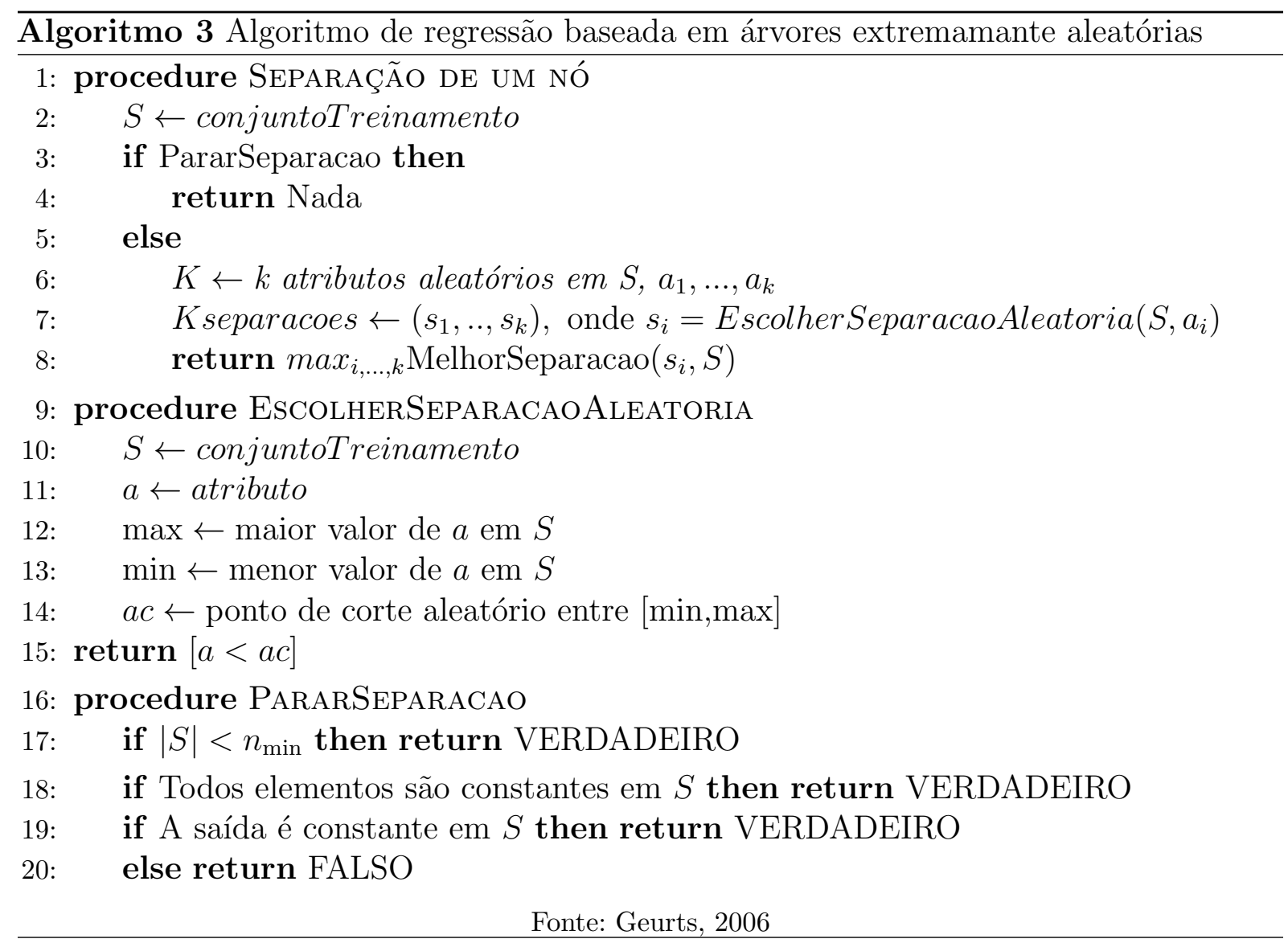

\subsection{Técnica de extração de característica - Transformadas Wavelets}

Mallat (MALLAT, 2008), define que a transformada Wavelet pode ser descrita como uma técnica de processamento de sinal, que realiza uma análise de determinado sinal nos domínios do tempo e freqüência. Uma função Wavelet pode ser descrita como uma função que apresenta média zero e obedece a Equação 55:

$$
\int_{-\infty}^{\infty} \Psi(t) d t=0
$$

A função Wavelet $\Psi$ pode sofrer dilatação por meio dos parâmetros $s$, representando a escala, e $u$, representando a translação, como pode ser visto na Equação 56.

$$
\Psi_{u, s}(t)=\frac{1}{\sqrt{s}} \Psi\left(\frac{t-u}{s}\right)
$$


Com isso pode-se definir a transformada Wavelet como sendo o seguinte produto interno:

$$
W T f(u, s)=\left\langle f, \Psi_{u, s}\right\rangle=\int_{-\infty}^{+\infty} f(t) \Psi_{u, s}(t) d t
$$

Além da utilização das funções Wavelet $\Psi$, conhecidas como função mãe, foi proposta em (MALLAT, 2008) uma outra forma de se realizar a transformada Wavelet. Essa nova abordagem utiliza um conjunto de filtros, sendo um filtro de passa-baixa $g$, que representa uma aproximação do sinal original, e um filtro de passa-alta $h$, representando os detalhes da imagem original. Para utilização da transformada Wavelet em sinais 2D, tal como as imagens, a idéia original foi expandida de forma a tratar as linhas e colunas da imagem como sinais independentes. Desta forma aplica-se a transformada Wavelet em seqüência, assim como ilustrado na Figura 23.

Figura 23 - Decomposição Wavelet 2-D

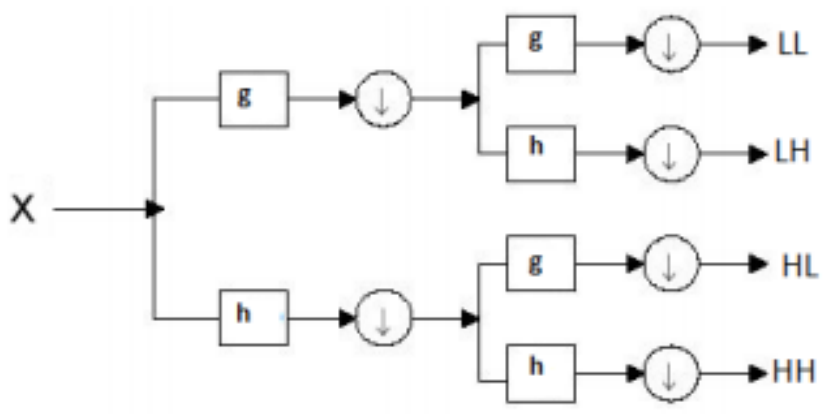

(A)

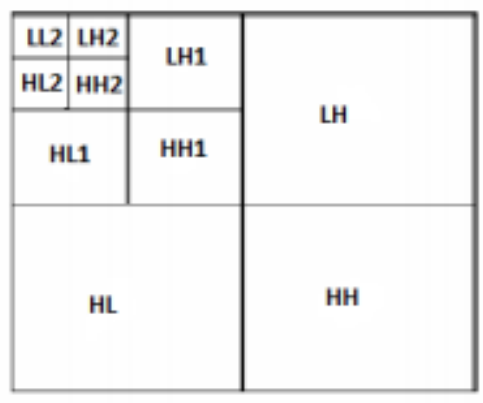

(B)

Fonte: Mallat, 2008

Ao final da decomposição Wavelet 2D são geradas 4 sub-imagens, onde cada uma delas apresenta resolução $(n / 2, n / 2)$, sendo as sub-imagens HL, LH e HH, representando as altas frequências em alguma das direções e podem ser descritas como contendo detalhes horizontais, verticais e diagonais da imagem original, enquanto que a imagem LL representa uma aproximação da imagem original. A transformada Wavelet gera ao final um conjunto de coeficientes que podem ser utilizados para representar a imagem original.

\subsection{Técnica de comparação e decisão - Rede Neural MultiLayer Perceptron}

A Rede Neural Multilayer Perceptron (MLP), proposta por (HAYKIN, 1998) é um sistema de processamento de informação que possui algumas características de desempenho 
em comum com as redes neurais biológicas. Uma rede neural pode ser caracterizada por três aspectos principais: (1) o padrão de conexões entre as unidades (arquitetura da rede), (2) o método de determinação dos pesos das conexões (treinamento ou aprendizado) e (3) sua função de ativação. Elas oferecem um paradigma de resolver problemas através de exemplos. A arquitetura de uma MLP consiste de um conjunto de unidades sensoriais que formam uma camada de entrada, uma ou mais camadas intermediárias (chamadas também de camadas escondidas) e uma camada de saída, conforme pode ser visto na Figura 24. Os sinais de entrada são propagados camada a camada pela rede em uma direção positiva, ou seja, da camada de entrada para a camada de saída. A rede MLP possui treinamento do tipo supervisionado e utiliza o algoritmo de retro-propagação do erro (backpropagation). Este algoritmo é baseado em uma regra de aprendizagem que "corrige" o erro durante o treinamento (HAYKIN, 1998).

Figura 24 - Rede Neural MLP

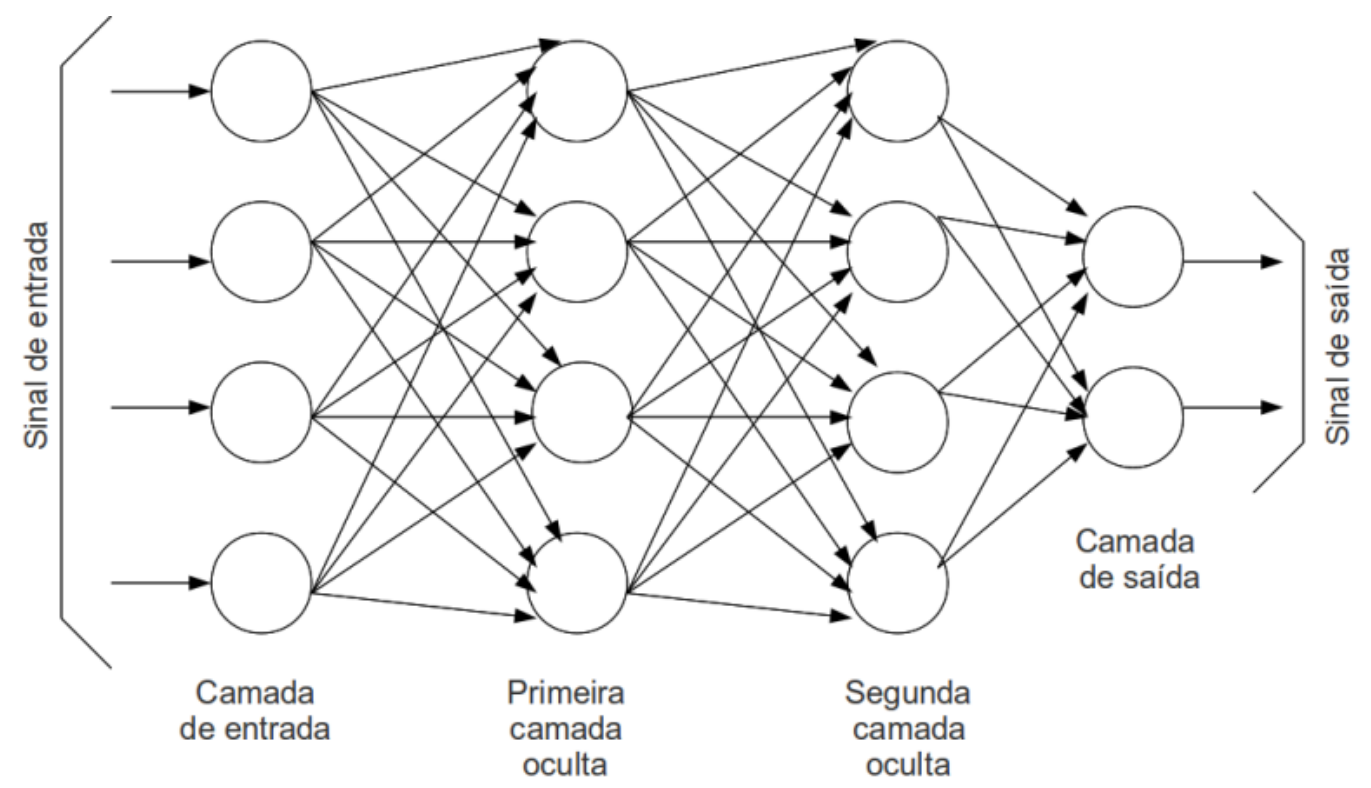

Fonte: Alexandre Volpi, 2010

Basicamente, o processo de backpropagation é constituido de duas fases: uma fase de propagação do sinal funcional, chamada de feedforward e uma de retro-propagação do erro, o backpropagation. Na fase positiva, os vetores de dados são aplicados às unidades de entrada, e seu efeito se propaga pela rede, camada a camada. Finalmente, um conjunto de saídas é produzido como resposta da rede. Durante a fase positiva, os pesos das conexões são mantidos fixos. Na retro-propagação do erro, por outro lado, os pesos são ajustados de acordo com uma regra de correção do erro. Especificamente, a resposta da rede em um instante de tempo é substituída da saída desejada (target) para produzir um sinal de erro. 
O sinal de erro é propagado da saída para a entrada, camada a camada, ajustando os pesos de modo que a distância entre a resposta da rede a resposta desejada seja reduzida. Por fim, a resposta da rede treinada é levada em consideração para a decisão. Neste ponto, a rede neural implementada tem peso 1 (peso total), na decisão, unindo as etapas de combinação e decisão em uma única tarefa. 


\section{Abordagem proposta}

\subsection{Resumo}

Neste capítulo é descrita a abordagem proposta desta dissertação, a qual foi baseada embasada em trabalhos publicados na literatura. Foi apresentada a motivação para a abordagem. Também foram apresentadas as etapas para o sistema multibiométrico, combinando técnicas de reconstrução no nível de extração de características, referenciando as técnicas já descritas nos capítulos anteriores, descrevendo como foi executa sua combinação.

\subsection{Introdução}

Conforme mencionado, o reconhecimento facial baseado em face ocluídas ainda não apresenta resultados satisfatórios, devido a dificuldade de extração de características discriminatórias para o reconhecimento biométrico. Uma possível solução para tal problema é a detecção e remoção da parte ocluída. No entanto, apenas remover a parte ocluída da face pode resultar em uma quantidade de características insuficiente, tornando a tarefa de reconhecimento bastante difícil. Na literatura podemos encontrar diversas técnicas quando nos deparamos com reconhecimento biométrico baseado em faces com oclusão. Por exemplo, alguns autores não tratam a oclusão e usam apenas imagens sem oclusão para gerar o modelo de classificação, ou seja, na fase de treinamento as imagens ocluídas são descartadas, diminuindo assim a quantidade de amostras (MARTÍNEZ, 2002). Existem também autores que treinam os modelos com as imagens ocluídas sem tratar a oclusão (ARYA; ANUKRITI, 2014), conforme ilustrado na Figura 25.

Figura 25 - Sistema de reconhecimento biométrico usando imagens de fase com oclusão no treinamento

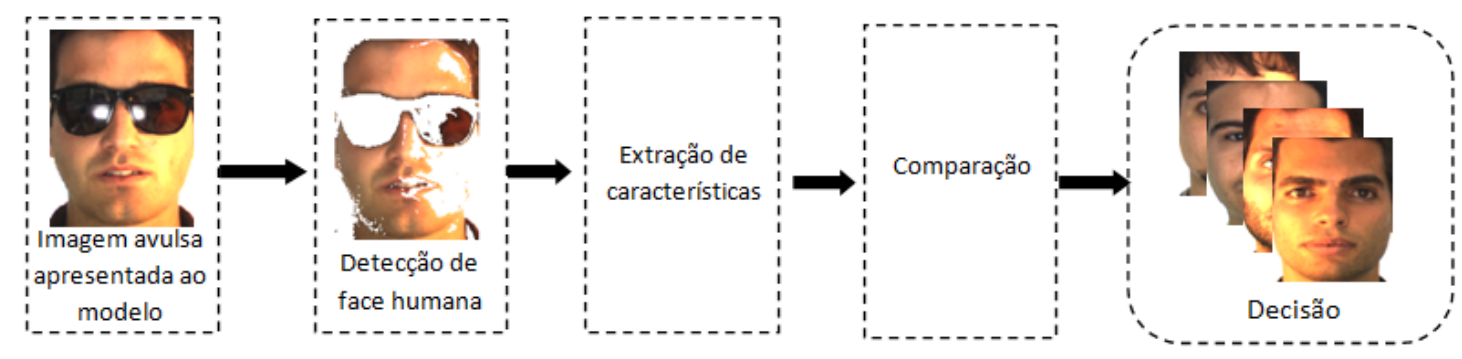


Os autores que tratam oclusão obtiveram os melhores resultados na literatura (BELLIL; BRAHIM; AMAR, 2016). A Figura 26 ilustra o processo de reconhecimento biométrico baseado em imagens de face com oclusão, sendo que a parte ocluída foi detectada e reconstruída.

Figura 26 - Sistema de reconhecimento biométrico baseado em imagens com oclusão, com reconstrução da parte ocluída

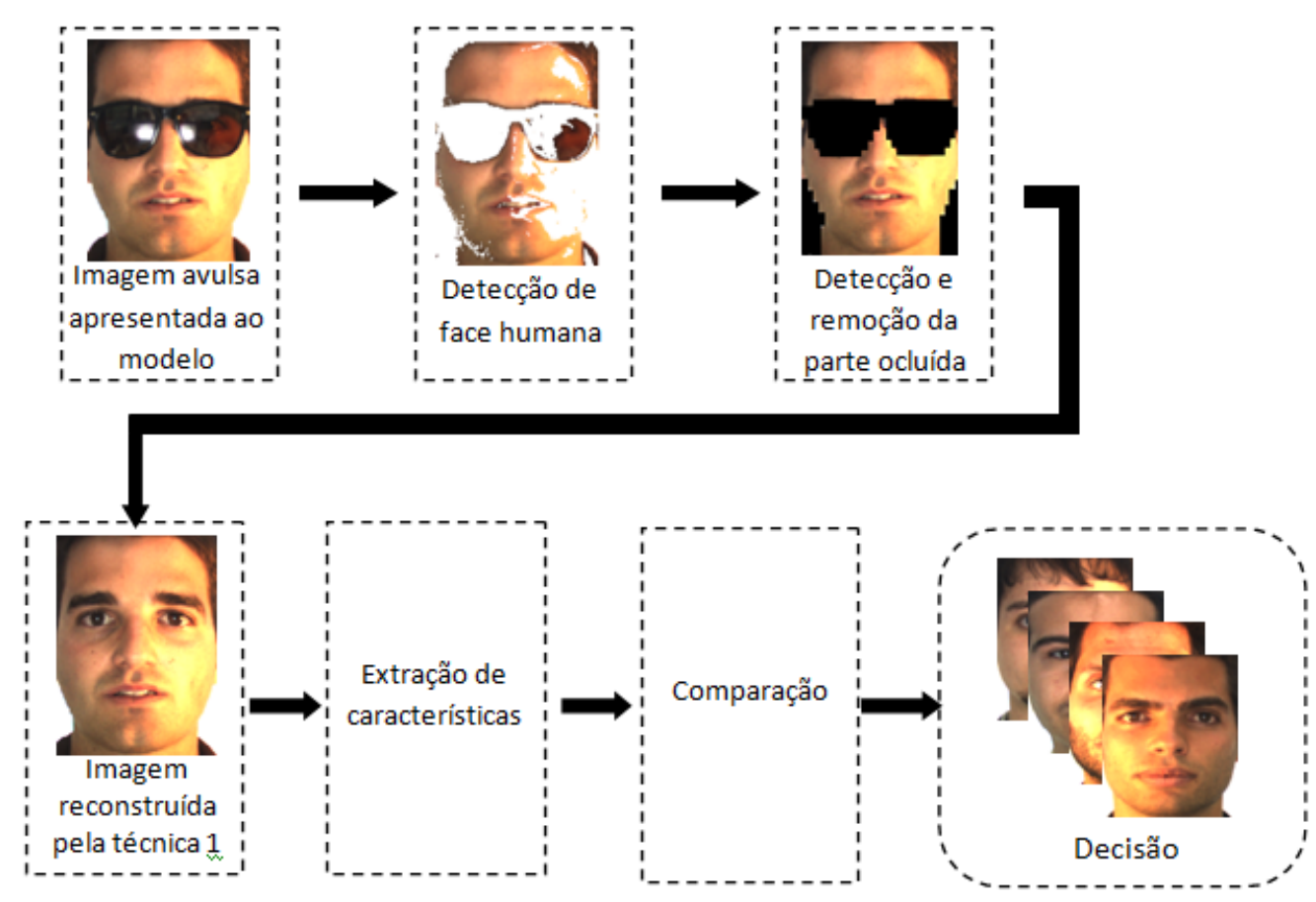

Fonte: Jozias Rolim, 2018

\subsection{Trabalhos relacionados}

Neste seção serão apresentados os trabalhos que motivaram a abordagem proposta. Em poucas palavras serão esboçadas suas estratégias e contribuições para a área e as diferentes formas de abordagem para atacar o problema de reconhecimento biométrico baseado em imagens de face ocluídas.

Há diversas abordagens para tratamento de oclusão em imagens, isso mostra que não existe um entendimento claro quanto a melhor forma de tratar imagens com oclusão para reconhecimento biométrico. Existem abordagens que tratam a parte ocluída da imagem como uma característica do indivíduo, outras utilizam apenas a parte não ocluída 
para identificar o indivíduo, enquanto, existem também, as que tratam a oclusão antes do processo de extração de característica.

Foi realizada uma pesquisa de forma exploratória, que levantou diversos trabalhos importantes da área, dentre os quais se podem citar:

- Sobottka e Pitas (SOBOTTKA; PITAS, 1998), apresentam um método para segmentação de faces baseado em extração e rastreamento de características, levando em consideração informações de cor e forma. O método é capaz também de extrair características internas da face, tais como: sobrancelhas, olhos, nariz, cova e queixo. O modelo ainda é capaz de segmentar faces com oclusão, ou falta de características. Entende-se como falta de característica a não possibilidade de extraí características tais como sobrancelha, olho, nariz, devido a oclusão.

- Wildan J. Hadi and Emad K. Jabbar (HADI; JABBAR, 2010), apresentam um método baseado em pigmentação de pele e modelo de olho para segmentar faces ocluídas. Os autores empregaram uma técnica de agrupamento, chamada Fuzzy K-means, para detectar oclusão. Por fim, recuperam as faces ocluídas, com base em simetria ou, utilizam a imagem na base que apresente maior semelhança com base em: informação sexo, idade e cor da pele. Foram apresentados resultados satisfatórios quando tratadas pequenas oclusões.

- Cheddad (CHEDDAD et al., 2009), também apresentaram um método baseado em pigmentação de pele. No entanto, empregaram a luminância, mostrando que esta pode ser útil na segmentação de pixels de pele ou não. A principal característica deste trabalho é que o espaço de imagem (3D, RGB) é reduzido para escala de cinza (1D).

- Kim (KIM et al., 2010), propôs um método para verificação de oclusão. O método consiste em três fases: (i) detecta uma forma da cabeça e do ombro aplicando contorno baseado em B-spline (função spline que tem o mínimo suporte em relação a um determinado grau, suavidade, e partição do domínio); (ii) a área da face é estimada ajustando uma elipse à forma da cabeça e ombros detectados; (iii) estima a oclusão baseada na taxa de cor de pele presente na área.

- Bellil (BELLIL; BRAHIM; AMAR, 2016), propõem um método baseado em Gappy Wavelet Neural Network (GWNNN) para identificação e reconhecimento de faces, o qual é capaz de fornecer uma melhor performance, quando tratando com faces 
ocluídas. Basicamente, a detecção de regiões ocluídas é realizada considerandoas como deformações locais de face, detectando-as por uma comparação entre os coeficientes wavelet da imagem de teste e os coeficientes wavelet de uma imagem de face genérica (formada pela média das faces da base de dados originalmente sem oclusão). Por fim, as regiões ocluídas são reconstruídas com base na GWNN.

- Min, Hadid e Dugelay (MIN; HADID; DUGELAY, 2011), propuseram uma abordagem na qual é extraída da imagem de face a oclusão e a parte não ocluída é usada no processo reconhecimento. Dada uma imagem de teste, o modelo procura por oclusões (óculos e cachecol) fazendo uso das técnicas de Gabor Wavelet, PCA (Análise de componentes principais) e SVM (Máquinas de Vetor Suporte). Após localizadas, as oclusões são removidas. Por fim, a imagem resultante sem oclusão é submetida para o reconhecimento.

- Jia H. e Martinez A. (JIA; MARTINEZ, 2008), apresentam um método de reconhecimento biométrico baseado em face, que leva em consideração imagens com oclusão no treinamento e no teste. Cada imagem de teste é descrita como uma combinação linear das amostras de treinamento em cada classe. Assim, as amostras de classe que fornecem a melhor reconstrução determinam o rótulo da classe. Para avaliar a melhor reconstrução foi utilizada uma medida chamada PSNR (Relação Sinal Ruído).

- Chaudhry (CHAUDHRY, 2012), propõem um método baseado no Asymmetrical Principal Component Analysis (APCA) para detecção e remoção de oclusão por óculos. O processo consiste em: (i) normalização da imagem da face, permitindo que as imagens apresentadas ao modelo tenham a mesma dimensão e sejam rotacionadas para posição frontal; (ii) reconstrução baseada no PCA para que através do erro de reconstrução e características de borda pode-se determina a área ocluída; (iii) reconstrói a parte ocluída baseado no APCA.

- Al-Naser e Soderstrom (AL-NASER; SODERSTROM, 2011), apresentam o uso do APCA para estimar regiões ocluídas com base nas áreas não ocluídas. Assim, realizam experimentos e os julgam de forma objetiva e subjetiva, mostrando que a partir de uma parte nítida e não ocluída, é possível reconstruir faces completas.

- Martinez (MARTÍNEZ, 2002), propuseram um método de particionamento de imagem para geração de subespaços independentes, que permite que seja possível compensar imagens de faces ocluídas. Assim, as imagens apresentadas ao modelo são divididas em $k$ sub-imagens e projetadas nos respectivos subespaços, de modo que através de 
uma análise probabilística é possível definir quão "bom"é a reconstrução para aquela sub-imagem, e levada em consideração apenas as melhores partes, removendo assim a oclusão, ou seja, as sub-imagens que apresentaram mais ruídos foram descartadas.

- Lee (LEE et al., 2006), com base na premissa de que existe um conjunto de características que são comuns a todas as faces humanas e que apresenta um alto poder discriminatório, propuseram um método, baseado em Adaboost, para selecionar o melhor conjunto de características para cada indivíduo e utilizar essas características pessoais distintas para aumentar o desempenho do reconhecimento, mesmos que as imagens de teste apresentem oclusão. As características são definidas com base em sub-imagens aplicadas ao PCA. Por fim, utiliza uma função para definir quão descriminante é a característica em relação as demais imagens na base de conhecimento.

- Arya e Anukriti (ARYA; ANUKRITI, 2014), apresentaram um sistema de reconhecimento facial baseado no Modelo Oculto de Markov (do inglês Hidden Markov Model - HMM), para tratar a oclusão. A imagem da face é representada por oito regiões isoladas: cabelos, testa, sobrancelhas, olhos, nariz, lábios superiores, boca e queixo. Assim, a região não ocluída na imagem da face de teste e treino é utilizada para o reconhecimento.

- Turk e Pentland (TURK; PENTLAND, 1991b), apresentaram o Eigenfaces, capaz de rastrear a face e reconhecer o indivíduo em tempo real. A abordagem trata o problema de reconhecimento facial projetando a face em um espaço que abrange as variações significativas entre a imagem de entrada e as imagens de face conhecidas. As características significativas são chamadas de autovetores (do inglês "eigenfaces") do conjunto de faces. A projeção caracteriza uma imagem de face pela soma ponderada dos eigenfaces, fazendo com que para o reconhecimento seja necessário apenas comparar seus pesos com o dos indivíduos conhecidos.

- Song, Yi e Sun (SONG; YIN; SUN, 2008), apresentaram um modelo para reconhecimento de faces ocluídas por óculos escuros. Neste caso, empregaram a técnica de eigenfaces, a qual foi utilizada para trata o óculos como uma característica da face. Com isso, tentam demonstrar que mesmo utilizando imagens com diferentes poses, iluminação e expressão, o sistema é capaz de reconhecer o indivíduo usando uma imagem de face ocluída. 
- Cornejo (CORNEJO, 2015), demonstra em seu trabalho um método, robusto a oclusão, para reconhecimento de expressões. Utilizando da estratégia de características insensíveis, utiliza os operadores de Padrões Binários Locais e Histograma de Gradientes Orientados para extração das mesmas. Realizando fusão a nível de características.

Um dos grandes problemas ao atacar a oclusão em face é escolher a técnica de detecção e reconstrução mais adequada. Há várias técnicas de detecção e reconstrução de oclusão, mas nenhuma delas é adequada para qualquer tipo de oclusão. Para solucionar este problema, nesta dissertação é proposta uma abordagem baseada na idéia de reconhecimento multibiométrico, a qual é descrita na seção seguinte.

\subsection{Combinação de técnicas de reconstrução em nível de extração de características}

Neste trabalho é proposta uma técnica de reconhecimento multibiométrico, na qual a partir de uma imagem de face ocluída é aplicado várias técnicas de detecção e reconstrução, gerando várias imagens de face. Em cada imagem gerada é aplicado uma técnica de extração de características. As características extraídas de todas as imagens são concatenadas e apresentada para um classificador. A Figura 27 ilustra a abordagem proposta. De forma detalhada, a abordagem proposta consiste de sete etapas:

- Na etapa 1, a imagem de face é captada no ambiente, sem tratamento e filtros. Nesta etapa a imagem não sofre nenhuma alteração ou pré-processamento, dizemos que nesse estado a imagem é original ou imagem avulsa;

- Na etapa 2, é aplicado uma técnica de segmentação da face na imagem original, conforme descrita na Seção 3.3, a qual visa delimitar a face e retirar a interferência do fundo. É necessário definir os parâmetros da técnica de detecção facial, de modo que esta seja capaz de detectar faces com oclusão, mais detalhes sobre valores dos parâmetros serão descritos no Capítulo 5.3. Nesta etapa, a face também é centralizada, redimensionada e rotacionada para a posição frontal. Esta etapa é chamada de pré-processamento. O pré-processamento é detalhado na Seção 5.3.3;

- Na etapa 3, é realizada a detecção e remoção da parte ocluída usando as técnicas que foram descritas na Seção 3.4;

- Na etapa 4, as imagens serão reconstruídas usando as técnicas descritas na Seção 3.5; 
- Na etapa 5, é realizada a extração de características de cada imagem reconstruídas. Para a extração de características das imagens de face foi aplicada a transformada Wavelet descrita na secção 3.7 .

- Na etapa 6, é realizada a fusão das características extraídas de cada imagem. A estratégia de fusão adotada será a concatenação das características extraídas.

- Na etapa 7, o vetor de características em conjunto com o rotulo do individuo é utilizado para treinar um classificador. Nesta dissertação foi utilizado uma Rede Neural Perceptron Multicamadas, a qual foi descrita na seção 3.8, como classificador. 
Figura 27 - Arquitetura da Abordagem proposta

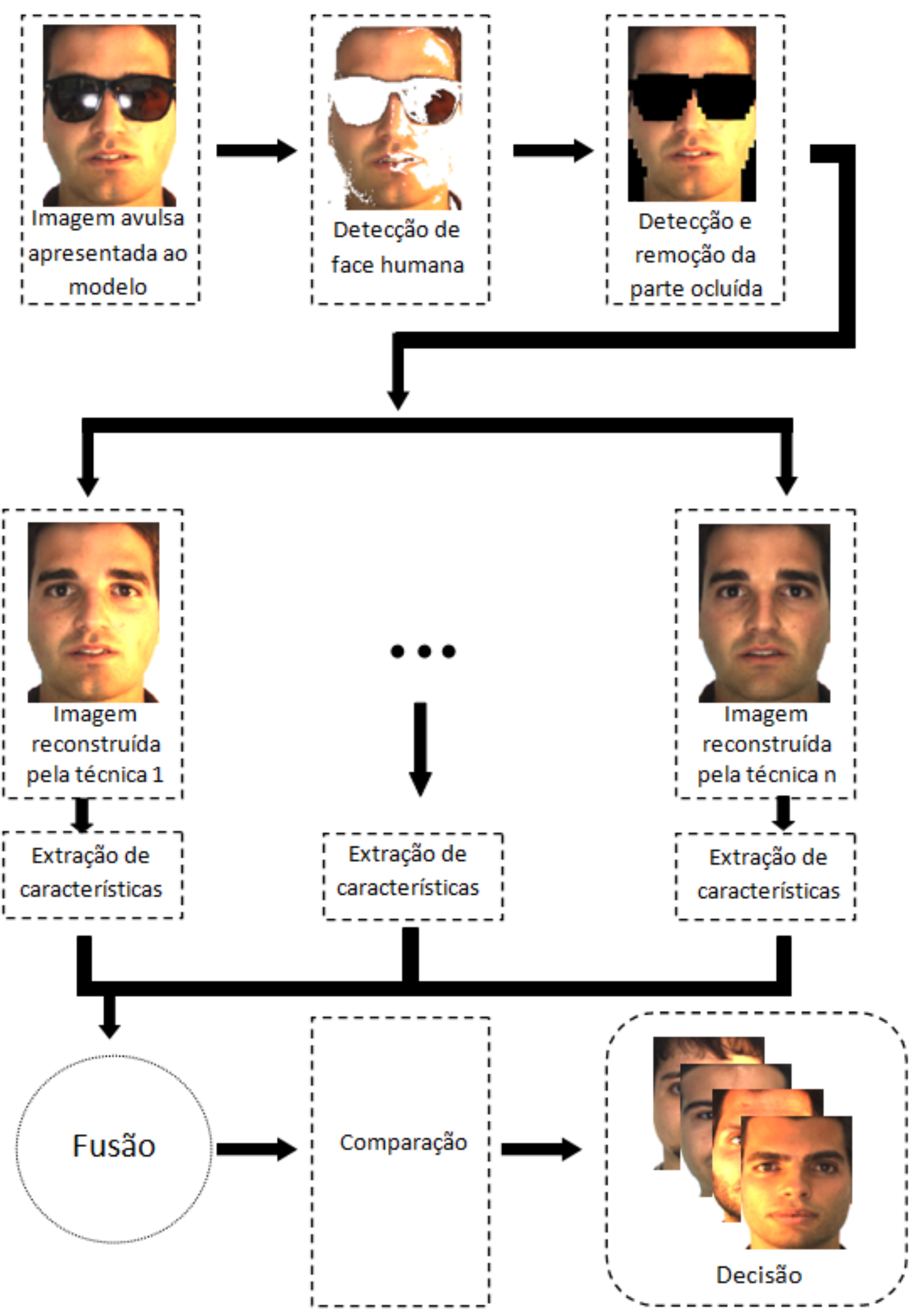

Fonte: Jozias Rolim, 2018 


\section{Resultados Experimentais}

\subsection{Resumo}

Neste capítulo, serão apresentados os resultados obtidos usando a abordagem proposta, assim como a configuração dos experimentos, parâmetros definidos e a metodologia de execução. Será apresentanto também, diversos experimentos envolvendo as técnicas de reconstrução facial descritas anteriormente e a abordagem proposta, com conjuntos de treinamento contendo imagens de face sem oclusão e conjuntos contendo imagens de face sem e com oclusão. Os resultados experimentais demonstram que a abordagem proposta é bastante promissora para atacar o problema de reconhecimento facial com oclusão.

\subsection{Introdução}

Neste capítulo, os três experimentos realizados e seus respectivos resultados são apresentados. Os experimentos são baseados em dois pressupostos bastante explorados na literatura: (i) o conjunto de treinamento foi formado apenas por imagens sem oclusão, enquanto para o conjunto de teste, as imagens podem ou nao ter oclusão; (ii) existem imagens ocluídas rotuladas no treinamento.

\subsection{Configurações dos experimentos}

Nesta seção serão apresentadas, de forma detalhada, as técnicas aplicadas neste trabalho, segmentadas por etapa do processo de reconhecimento biométrico. Também será apresentada a base de referência utilizada neste trabalho.

\subsubsection{Bases de dados utilizadas}

Nos experimentos realizados foi utilizado a base de dados AR Face Database que foi criada por Martinzer e Benavente (MARTÍNEZ; BENAVENTE, 1998). Esta base de dados é composta por 2.600 imagens de face no formato RGB e corresponde a 100 indivíduos, sendo 50 homens e 50 mulheres. As imagens de face apresentam variações de expressão, iluminação e oclusão. As oclusões são devidas a óculos escuros e cachecol. A resolução 
das imagens é de 768 x 576 pixels. As imagens são divididas em 13 categorias: expressão neutra, expressão de sorriso, expressão de raiva, expressão de grito, com luz a esquerda, com luz a direita, com luz em ambos os lados, ocluída com óculos de sol, ocluída com óculos de sol e luz a esquerda, ocluída com óculos de sol e luz a direita, ocluída com cachecol, ocluída com cachecol e luz a esquerda e ocluída com cachecol e luz a direita. As imagens foram capturadas em duas seções realizadas em dois dias diferentes, com duas semanas entre cada seção.

\subsubsection{Detecção de Face}

O primeiro passo de um sistema de reconhecimento biométrico consiste em identificar se na imagem apresentada há uma face de um indivíduo ou não. Para identificar a presença de imagens de face foi utilizada a técnica descrita na seção 3.3.2, a qual é baseada em texturas de pele humana. Apesar da base de dados utilizada ser formada apenas por imagem de faces e que em cada amostra existe uma face, a presença da oclusão pode impedir que as técnicas de segmentação encontre uma face na imagem, para evitar tal problema a base foi aplicada as técnicas de detecçãos definidas, para validar esse problema na base proposta. A estratégia foi aplicada a toda a base de dados AR Face Database e esta foi capaz de identificar todas as faces presentes nas imagens. A Figura 28 apresenta alguns exemplos de imagens de face identificadas.

\subsubsection{Pré-processamento das imagens}

A partir da identificação da face na imagem é necessário segmentá-la e redimensionála para que todas as imagens de face presentes na base de treinamento tenham o mesmo tamanho. Para segmentar as imagens de face foi utilizado o algoritmo Viola Jones, o qual foi treinado também para identificar imagens de face com oclusão. No treinamento do Viola Jones foram apresentadas imagens de face presentes na base e imagens de não face extraídas da internet. Após o treinamento, o algoritmo Viola Jones foi capaz de identificar e segmentar todas as imagens de face da base de dados. Logo após o processo de segmentação, a imagem de face obtida é alinhada com uma imagem base por meio de um processo de translação, onde uma imagem posicionada na posição $x_{1}, y_{1}$ é posicionada 
Figura 28 - Imagens de face detectadas na base de dados AR

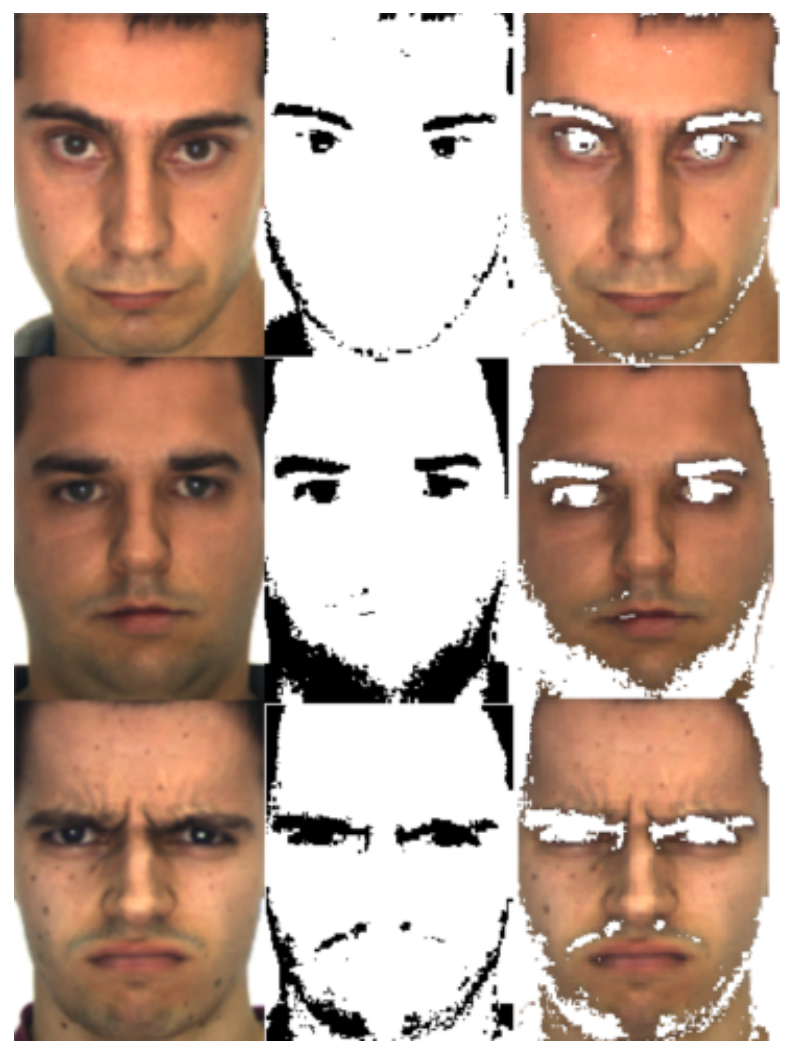

Fonte: Jozias Rolim, 2018

em $x_{2}, y_{2}$, conforme apresentado na equação 58 , onde $t_{x}, t_{y}$ são os valores de deslocamento horizontal e vertical, respectivamente.

$$
\left[\begin{array}{l}
x_{2} \\
y_{2}
\end{array}\right]=\left[\begin{array}{l}
x_{1} \\
y_{1}
\end{array}\right]+\left[\begin{array}{l}
t_{x} \\
t_{y}
\end{array}\right]
$$

Após o alinhamento é necessário alterar a escala da imagem para garantir que toda a imagem da face tenha o mesmo tamanho da imagem base. Neste caso foi aplicada uma transformação geométrica de escala apresentada na equação 60 , na qual $c_{x}, c_{y}$ são os coeficientes de escalar horizontal e vertical, respectivamente. Além disso, todas as imagens foram convertidas para a escala de cinza, de acordo com os seguintes pesos $0.2989,0.5870$ e 0.1140 para os pixels dos canais R, G e B, respectivamente, conforme pode ser visto na Equação 59. A Figura 29 ilustra o resultado obtido após a etapa de pré-processamento, aplicado as 2600 imagens da presentes na base AR Faces.

$$
G(r, g, b)=r * 0,2989+g * 0,5870+b * 0,1140
$$




$$
\left[\begin{array}{l}
x_{2} \\
y_{2}
\end{array}\right]=\left[\begin{array}{ll}
c_{x} & 0 \\
0 & c_{y}
\end{array}\right]+\left[\begin{array}{l}
x_{1} \\
y_{1}
\end{array}\right]
$$

Figura 29 - Preprocessamento das imagens

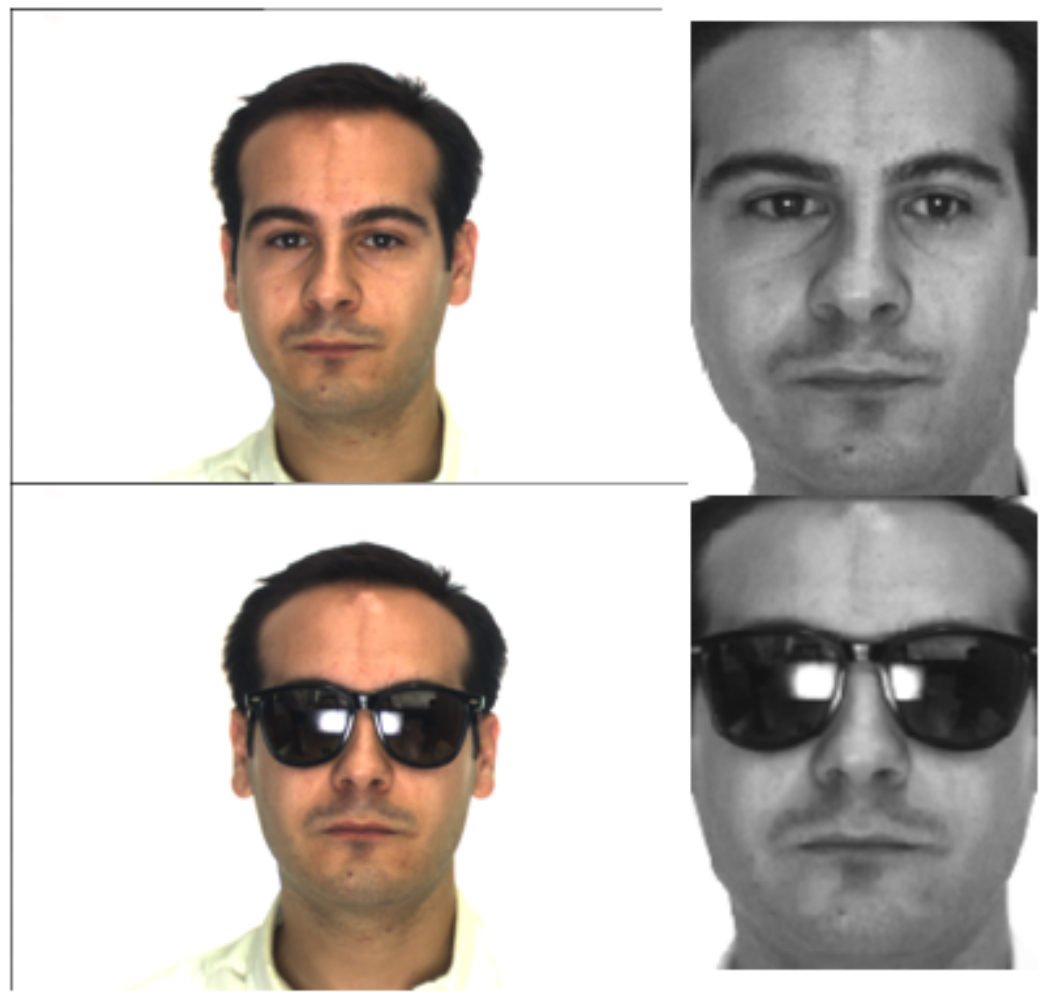

(i) imagem original, (ii) imagem tratada

Fonte: Jozias Rolim, 2018

\subsubsection{Detecção da oclusão e remoção da parte ocluída}

Para a detecção da parte ocluída foi utilizado o algoritmo Eigenfaces, descrito na Secção 3.5.1. Foi selecionado um subconjunto de imagens com oclusão e estas foram reconstruídas usando os Eigenfaces calculados com base nas imagens de faces sem oclusão do conjunto de treinamento. Após a reconstrução foi calculado o DFFS das imagens reconstruídas e foi observado que imagens com oclusão reconstruídas possuíam um DFFS acima de 100, enquanto que as imagens sem oclusão possuíam um DFFS inferior a 50. Assim, foi definido que imagens com um valor de DFFS maior que 100 possuíam oclusão, enquanto que imagens com DFFS menor foram consideradas sem oclusão (esses valores podem variar se aplicados a outras bases). 
Após constatado que uma imagem de face possuía oclusão, o próximo passo é realizar a remoção desta oclusão. Neste caso, a imagem reconstruída é comparada com a imagem original apresentada. Uma diferença em módulo entre a imagem original e a iamgem reconstruída é calculada em nível de pixel, e um limiar empírico foi definido igual a 45, ou seja, caso a diferença pixel a pixel das imagens, seja maior que 45, aquele pixel será considerado ocluído. A partir desse processo, é criada uma máscara de oclusão, capaz de remover a parte ocluída da imagem. Para cálculo da máscara de oclusão foram usados ainda um filtro morfológico de erosão e um filtro de dilatação. O filtro de dilatação foi aplicado usando a máscara $[[0,0,1],[1,1,1]]$, e no filtro de erosão foi utilizada a distância euclidiana (TURK; PENTLAND, 1991c), com o objetivo de maximizar a área ocluída e diminuir áreas com falsa ou mínima oclusão (apenas um pixel em uma grande região sem oclusão). De forma a diminuir a quantidade de pixel ocluídos isolados, foi utilizado uma janela de 4x4 na máscara de oclusão. Logo, a região será considerada ocluída se pelo menos $50 \%$ dos pixels na janela apresentarem oclusão. Na Figura 30 pode ser visto alguns exemplos de imagens com a parte ocluída removida.

\subsubsection{Reconstrução baseada em sub-espaços}

Para a reconstrução facial pode-se utilizar estratégias baseadas em subespaço, na qual o espaço de imagens é construído usando apenas imagens de face sem oclusão. Neste caso, foi realizado o cálculo do DFFS para definir se a imagem poderia ou não ser utilizada para gerar o espaço de imagens. O limiar definido para o PSNR foi definido igual a 50. A primeira imagem definida no espaço foi escolhida como sendo uma imagem com ausência de oclusão de forma empírica, as demais foram sendo aplicadas o processo descrito anteriormente. O espaço foi recalculado após cada nova iteração com a nova imagem sem oclusão. Após a formação dos espaço de face, as imagens foram projetadas e reconstruídas utilizando apenas $10 \%$ dos autovetores com maior representatividade, ou seja, ordenados pelos seus respectivos autovalores. 
Figura 30 - Remoção parte ocluída - Eigenfaces

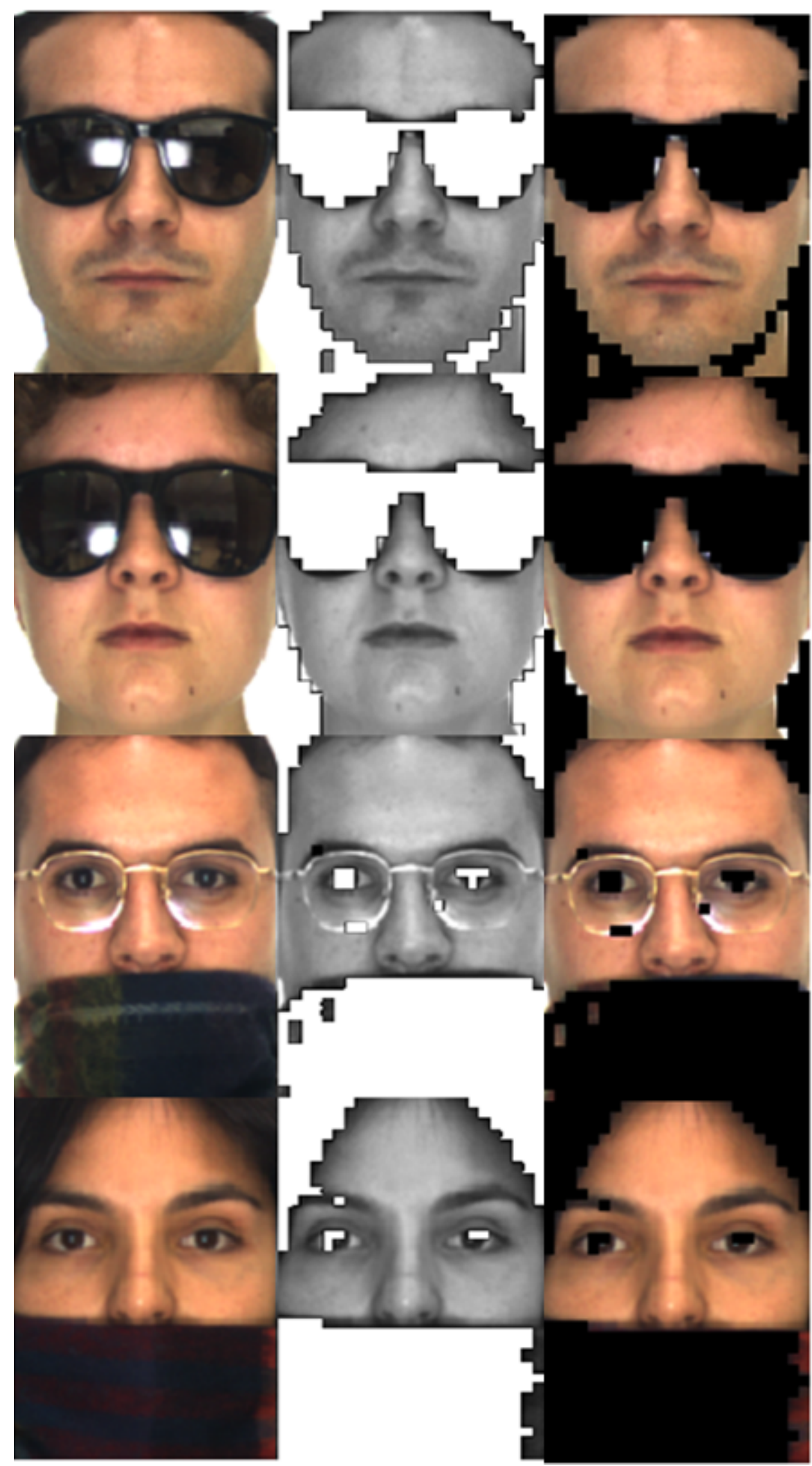

(i) Imagem original, (ii) Imagem com oclusão removida, (iii) Imagem colorida com oclusão em pixel 0 - preto 
5.3.6 Reconstrução facial baseada em regressões

Nesta etapa é treinado regressores para reconstruir a parte da imagem de face ocluída. Foram utilizadas quatro regressores, conforme descritos na secção 3.6. Cada um dos regressores possui parâmetros que devem ser definidos. Estes valores foram definidos com base no PSNR gerado pelas imagens reconstruídas. Seguem os valores definidos para cada parâmetro:

- Regressão com KNN - para a regressão com o KNN foram utilizados cinco vizinhos com pesos iguais, com base na distância euclidiana;

- Regressão com árvores de decisão aleatórias - com base em experimentos, os parâmetros foram definidos e os melhores valores foram definidos. Assim, foram utilizadas 10 árvores na floresta, com 32 características por iteração. O critério de qualidade de cada iteração foi calculado com base no erro quadrático médio ;

- Regressão Linear - Na regressão linear os valores da parte ocluída são preditos com base nos valores da região sem oclusão;

- Regressão Ridge - para a regressão ridge os valores de penalizações foram definidos iguais a $0.1,1$ e 10 , respectivamente;

\subsubsection{Avaliação das imagens reconstruídas}

Para avaliar a qualidade das imagens reconstruídas torna-se necessário definir uma medida de avaliação. Uma medida muito utilizada é a Relação Sinal-Ruído de Pico (do inglês Peak signal-to-noise ratio - PSNR), proposto por Ashin (ASHIN; MORIMOTO; VAILLANCOURT, 2005). Este é utilizado para definir uma taxa entre o valor máximo possível de um sinal e o poder do ruído de distorção que afeta a qualidade da imagem. O PSNR, geralmente é usado como um nível de referência para a semelhança entre a imagem reconstruída e a imagem original. Ele compara a imagem original com a imagem reconstruída para quantificar a qualidade dos dados de saída. Quanto maior o valor do PSNR, melhor é a qualidade da imagem reconstruída. A equação 61 é utilizada para calcular o PSNR.

$$
P S N R=10 \log _{10}\left(\frac{\max ^{2}}{M S E}\right)
$$


Onde max é o valor máximo possível do pixel na imagem e $M S E$ é o erro quadrático médio entre a imagem reconstruída e a imagem original. O calculo do MSE é dado pela equação 62 .

$$
M S E=\frac{\sum_{i=1}^{w} \sum_{j=1}^{h}\left[I_{1}(i, j)-I_{2}(i, j)\right]^{2}}{w h}
$$

Onde $I_{1}$ é a imagem original, $I_{2}$ é a imagem reconstruída e $w$ e $h$ são as quantidades de linhas e colunas respectivamente. Se o valor do PSNR for maior que 30, então a imagem reconstruída é considerada de boa qualidade, de acordo com Aishin (ASHIN; MORIMOTO; VAILLANCOURT, 2005).

\subsubsection{Extração de características}

Na etapa de extração de características foi utilizada a transformada wavelet, a qual decomponhe a imagem original em 4 sub-imagens (LL, LH, HL e HH). A função mãe utilizada foi a coiflet (ZHANG et al., 2016). A decomposição foi aplicada até o nível 3. Neste caso, a transformada wavelet foi aplicada a sub-imagem LL do primeiro nível de decomposição, gerando mais 4 sub-imagens (LL2, LH2, HL2 e HH2) e sobre LL2 a transformada wavelet foi reaplicada gerando mais 4 sub-imagens (LL3, LH3, HL3 e HH3). Este processo é ilustrado na Figura 31. As sub-imagens LH, HL, HH, LH2, HL2, HH2, LH3, HL3 e HH3 foram convertidas em matriz linha. Por fim, as sub-imagens geradas nível 3, foram transformadas em linhas e concatenadas, formando um vetor de características.

\subsubsection{Etapa de Fusão}

Na etapa de fusão, foram combinadas as características extraidas da função wavelet de diferentes técnicas. Os valores de LL3, HL3, LH3 e HH3 das imagens originais sem oclusão foram utilizados para treinar o classificador, enquanto a combinação deles extraídos das demais técnicas foram utilizados para a classificação. Assim, após combinadas, levando em consideração que as imagens possuem resolução 128x128 e que a decomposição wavelet em três níveis gera subimagens de tamanho 16x16, o vetor de características apresenta 1024 valores. 
Figura 31 - Decomposição em três níveis - Wavelet - Coiflet
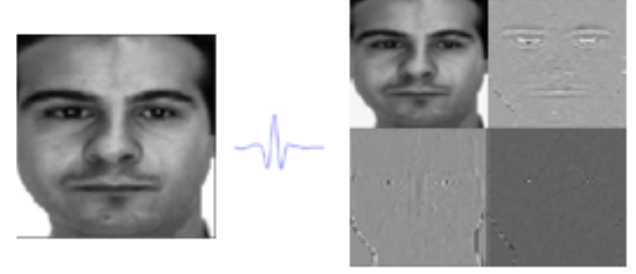

$\mathrm{HL}$
LH

$\mathrm{HH}$
LL2 LH2

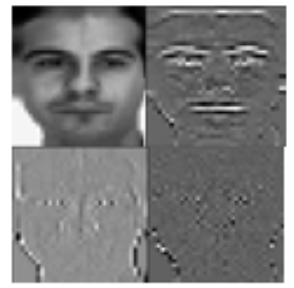

HL2

$\mathrm{HH} 2$$$
\mathrm{HH} 2
$$

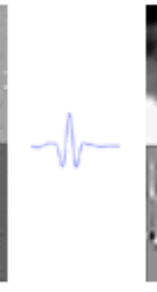

LL3 LH3

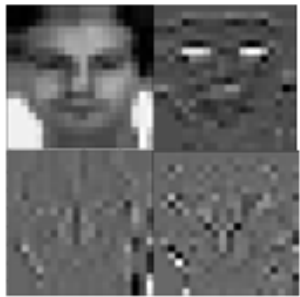

HL3

Fonte: Jozias Rolim, 2018

\subsubsection{Classificador}

Para realizar a tarefa de classificação foi utilizada uma Rede Neural Perceptron Multicamadas, a qual foi descrita na secção 3.8. Foram realizados experimentos preliminares para definir os parâmetros da Rede Neural, tais como, função de ativação dos neurônios e quantidade de neurônios na camada escondida. Neste caso, foi definido um range de valores para estes parâmetros. Foram utilizadas na avaliação dos parâmetros as imagens originalmente sem oclusão, que corresponde a 1400 imagens, sendo 14 imagens para cada indivíduo e as imagens originalmente com oclusão, que corresponde a 1200 imagens, sendo 12 imagens para cada indivíduo, para teste. Foi considerada uma rede MLP com apenas uma camada oculta, os valores avaliados para a quantidade de neurônios foram os seguintes $100,200,250,500,1000,1200,1250,1500$ e 2000, e para as funções de ativação foram às seguintes:

- Função identidade

$$
f(x)=x
$$

- Função logística

$$
f(x)=\frac{1}{1+\exp (-x)}
$$

- Função tangente hiperbólica

$$
f(x)=\frac{e^{t}-e^{-t}}{e^{t}+e^{-t}}
$$


- Função unidade linear retificada

$$
f(x)=\max (0, x)
$$

A atualização dos pesos da Rede Neural foi realizada via método do gradiente descendente. A Rede Neural foi treinada durante 10.000 épocas, ou até que de erro de validação não diminuísse mais que 0.0001 por duas épocas consecutivas, ou ainda, aumentasse por pelo menos duas épocas consecutivas. Foram utilizadas $10 \%$ das amostras do conjunto de treinamento para a validação. A Figura 32 apresenta a evolução da taxa de classificação para o range de valores utilizados. Analisando esta figura, pode-se dizer que a melhor configuração de parâmetros é dada por: função de ativação logística e quantidade de neurônios igual a 1250 .

Figura 32 - Evolução da taxa de reconhecimento variando os parãmetros da Rede Neural

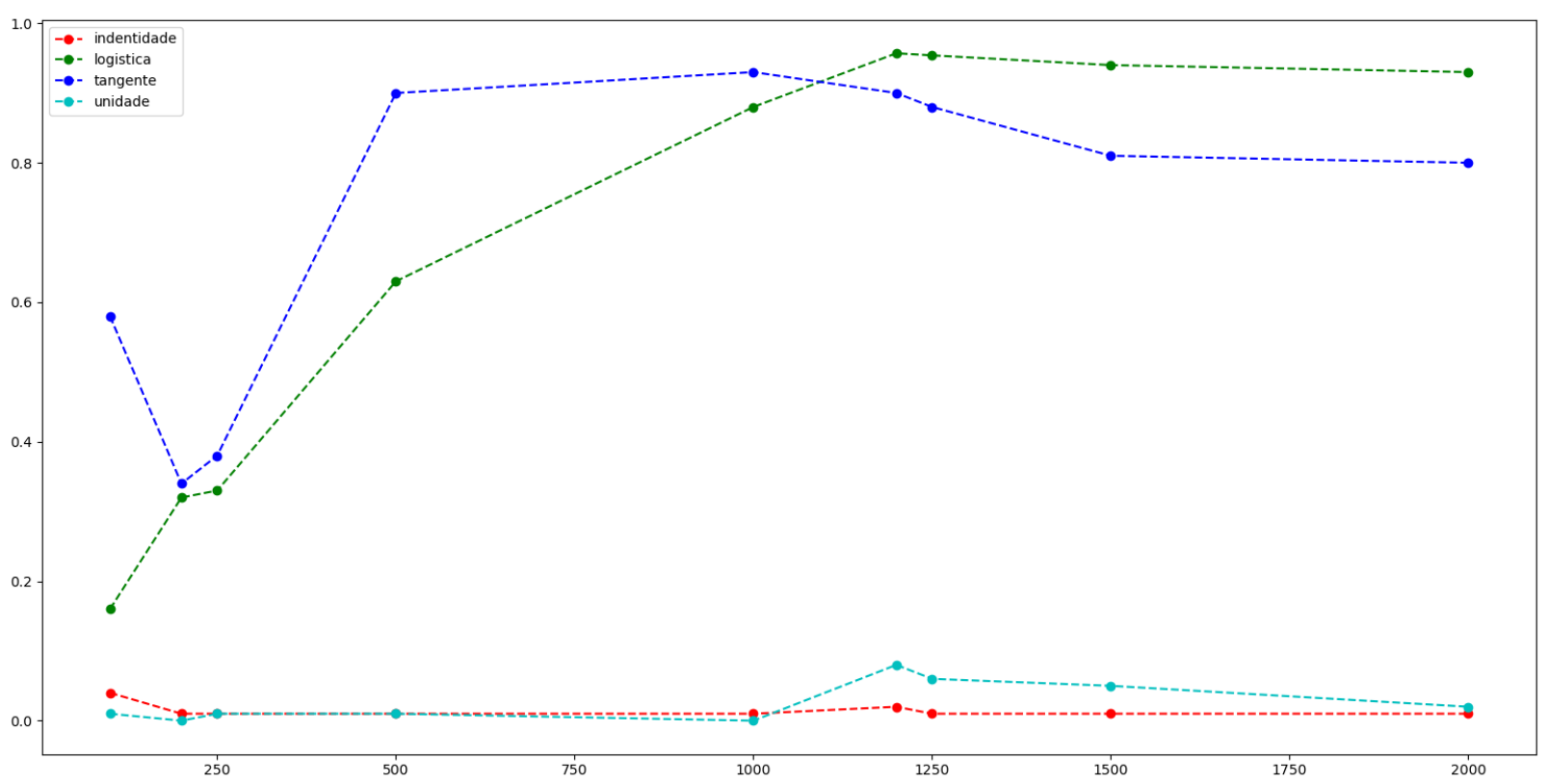

Legenda

Fonte: Jozias Rolim, 2018

5.3.11 Métricas de avalição usadas nos experimentos

Visando avaliar adequadamente performance do sistema de reconhecimento baseado na abordagem proposta foi utilizada algumas medidas, tais como, Precisão, Recall, F1 Score, Acurácia e matriz de confusão, as quais as definidas como: 
- Matriz confusão - representa em forma matricial a saída do experimento e as saídas esperadas para cada classe. A posição $i$ (linhas) da matriz apresentam os valores esperados para cada amostra, enquanto a posição $j$ (colunas), apresentam os valores preditos pelo modelo. Assim, cada posição $(i, j)$ da matriz apresenta a quantidade de amostras da classe $i$ que foram preditas pelo modelo como pertencendo a classe de valor $j$. Observe que quando $i=j$ o modelo prediz a classe correta. Para o problema de classificação binário, no qual a saída desejada por ser codificada como 0,1, a matriz de confusão pode ser vista conforme a Figura 33, onde os valores de VP, FN, FP e VN, representam respectivamente, verdadeiros positivos (quantidade de amostras que foram pedidas de forma correta pelo modelo para a classe 1), o valor de falso negativo (quantidade de amostras que foram preditas pelo modelo como não sendo da classe 1 - quando na verdade era), o valor de falsos positivos (quantidade de amostras que foram preditas como sendo da classe 1 , mas na verdade não é) e o valor de verdadeiros negativos (quantidade de amostras corretas que foram preditas pelo modelo como sendo da classe 0$)$.

Figura 33 - Matriz de confusão

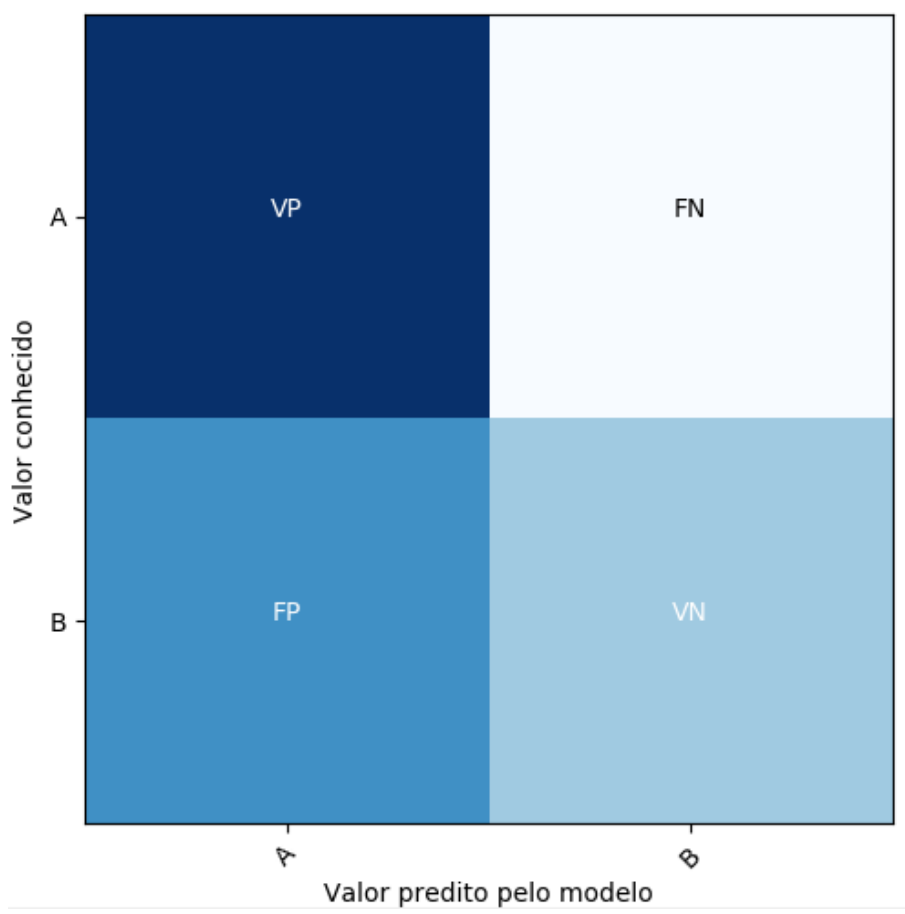

VP - Verdadeiro positivo, FN - Falso negativo, FP - Falso positivo e VN - Verdadeiro negativo 
No caso de problemas com múltiplas classes, os valores de FN, FP e VN são calculados de forma independente para cada classe. O valor de FN para a classe $i$, é dado pela soma dos demais valores da linha $i$ da matriz de confusão, dado por:

$$
F N_{i}=\sum_{j=1}^{n} c_{i j} a,\left\{\begin{array}{lll}
a=0 & \text { se } & i=j \\
a=1 & \text { se } & i \neq j
\end{array}\right.
$$

onde, $i$ representa a linha do valor conhecido e $j$ a coluna do valor predito pelo modelo, $c$ é a variável que representa o valor na posição $(i, j)$ e $a$ permite a eliminação do valor de VP, presente sempre na posição $c_{i, j}$ onde $i=j$. Para ilustrar o cálculo de FN, considere a matriz de confusão apresentada na Figura 34, com valores real, onde o valor de VP para a classe A é $3\left(c_{1,1}\right)$ e os demais valores da linha 1 são utilizados para calcular o $\mathrm{FN}$, são dado por $c_{1,2}+c_{1,3}=1+1=2$, sendo assim, o valor de $\mathrm{FN}$ é igual a 2 para a classe A.

Figura 34 - Exemplo de matriz de confusão

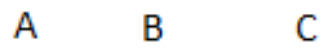

\begin{tabular}{|c|c|c|}
\hline 3 & 1 & 1 \\
\hline 0 & 4 & 1 \\
\hline 2 & 0 & 3 \\
\hline
\end{tabular}

Fonte: Jozias Rolim, 2018

Para calcular o valor de FP é necessário realizar o mesmo procedimento, no entanto o valor fixado é o de $j$ que representa o valor predito pelo modelo (fixa-se a coluna), o qual é dado por:

$$
F P_{j}=\sum_{i=1}^{n} c_{i j} a,\left\{\begin{array}{lll}
a=0 & \text { se } & i=j \\
a=1 & \text { se } & i \neq j
\end{array}\right.
$$

Usando a mtriz apresentada na Figura 34, pode-se calcular o valor de FP para a classe A como sendo, $c_{2,1}+c_{3,1}=0+2=2$, neste caso o valor de FP para a classe A é 2 . 
- Precisão - a medida de precisão é calculada conforme a Equação 69, onde $v p$ representa os valores verdadeiros positivos e $F P$ os valores falsos positivos. A Precisão basicamente mede a habilidade do classificador não rotular como positivo um exemplo que é negativo. $\mathrm{O}$ valor da precisão varia entre 0 e 1 , sendo 0 quando o valor de $V P=0$ e 1 quando o valor de $V P=1$, conseqüentemente o valor de $F P=0$.

$$
\text { precisao }=\frac{V P}{V P+F P}
$$

Para o problema de reconhecimento biométrico, por se tratar de um problema múltiplas classe, ou seja, o valor da precisão foi calculado para cada classe e a média é apresentada.

- Recall - o recall representa a capacidade do classificador de acertar todos os exemplos positivos. A taxa de recall varia entre 0 e 1 e pode ser calculado por:

$$
\text { recall }=\frac{V P}{V P+F N}
$$

onde, $V P$ é a taxa de verdadeiros positivos e $F N$ a taxa de falsos negativos. $\mathrm{O}$ valor recall apresentado nos experimentos representa a média de todos os resultados obtidos para cada classe separadamente.

- F1 Score - é interpretada como sendo a média ponderada entre a precisão e o recall. Neste caso, o valor de recall e precisão possui mesmo valor de peso, o qual pode ser obtida por:

$$
f 1 \text { score }=2 \frac{\text { precisao } * \text { recall }}{\text { precisao }+ \text { recall }}
$$

- Acurácia - pode ser definida como sendo a porcentagem entre o valor predido pelo modelo e o valor verdadeiro. O valor da acurácia pode variar entre 0 (nenhum resultado esperado foi predito corretamente pelo modelo) e 1 (todos os valores esperado foram preditos corretamente pelo modelo). Dado y representando as saídas esperadas e $\hat{y}$ as saídas predita, a acurácia é calculada usando a Equação 72.

$$
\operatorname{acuracia}(y, \hat{y})=\frac{1}{n} \sum_{i=1}^{n} 1 a,\left\{\begin{array}{lll}
a=0 & \text { se } & y \neq \hat{y} \\
a=1 & \text { se } & y=\hat{y}
\end{array}\right.
$$




\subsection{Experimento \#1}

Neste experimento, as imagens sem oclusão foram utilizadas para formar o conjunto de treinamento, enquanto as imagens com oclusão foram usadas para compor o conjunto de teste. Para detecção de face foi utilizado o algoritmo Viola Jones, para extração de características a tranformada Wavelet e a Rede Neural Perceptron Multicamadas como classificador. O modelo proposto pode ser visto na Figura 35, onde as partes grifadas foram ignoradas, as quais estão relacionadas com tratamento da oclusão. O objetivo deste experimento é demonstrar que é importante tratar a oclusão, caso isto não seja realizado o resultado pode ser muito ruim.

A base de treinamento foi formada por 1400 imagens (54\% das amostras), enquanto a base de teste era formada por 1200 imagens (46\% das amostras). O resultado obtido é apresentado na Tabela 1. A Figura 36, ilustra a matriz de confusão.

Figura 35 - Estrutura de um processo de reconhecimento facial sem tratamento da oclusão

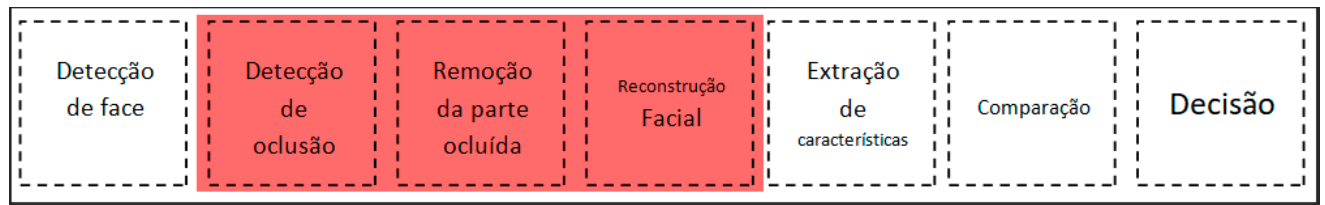

Fonte: Jozias Rolim, 2018

Tabela 1 - Métricas de desempenho para um sistema de reconhecimento biométrico sem treinamento da oclusão

\begin{tabular}{llll}
\hline Precisão & Recall & F1 - Score & Acurácia \\
\hline 0.588 & 0.486 & 0.499 & 0.486 \\
\hline \multicolumn{4}{c}{ Fonte: Jozias Rolim, 2018 }
\end{tabular}

\subsection{Experimento \#2}

O objetivo deste experimento é validar a hipótese de que técnicas de reconstrução facial produzem imagens de face distintas, logo as características extraídas também serão distintas, influenciando nas métricas de desempenho do sistema de reconhecimento biométrico. Cada estratégia de reconstrução facial foi aplicada individualmente. Para detecção da face foi utilizado o algoritmo Violas Jones, para detecção da oclusão e remoção da parte ocluída foi utilizada o algoritmo Skin color, para extração de características foi 
Figura 36 - Matriz de confusão para um sistema de reconhecimento biométrico sem treinamento da oclusão

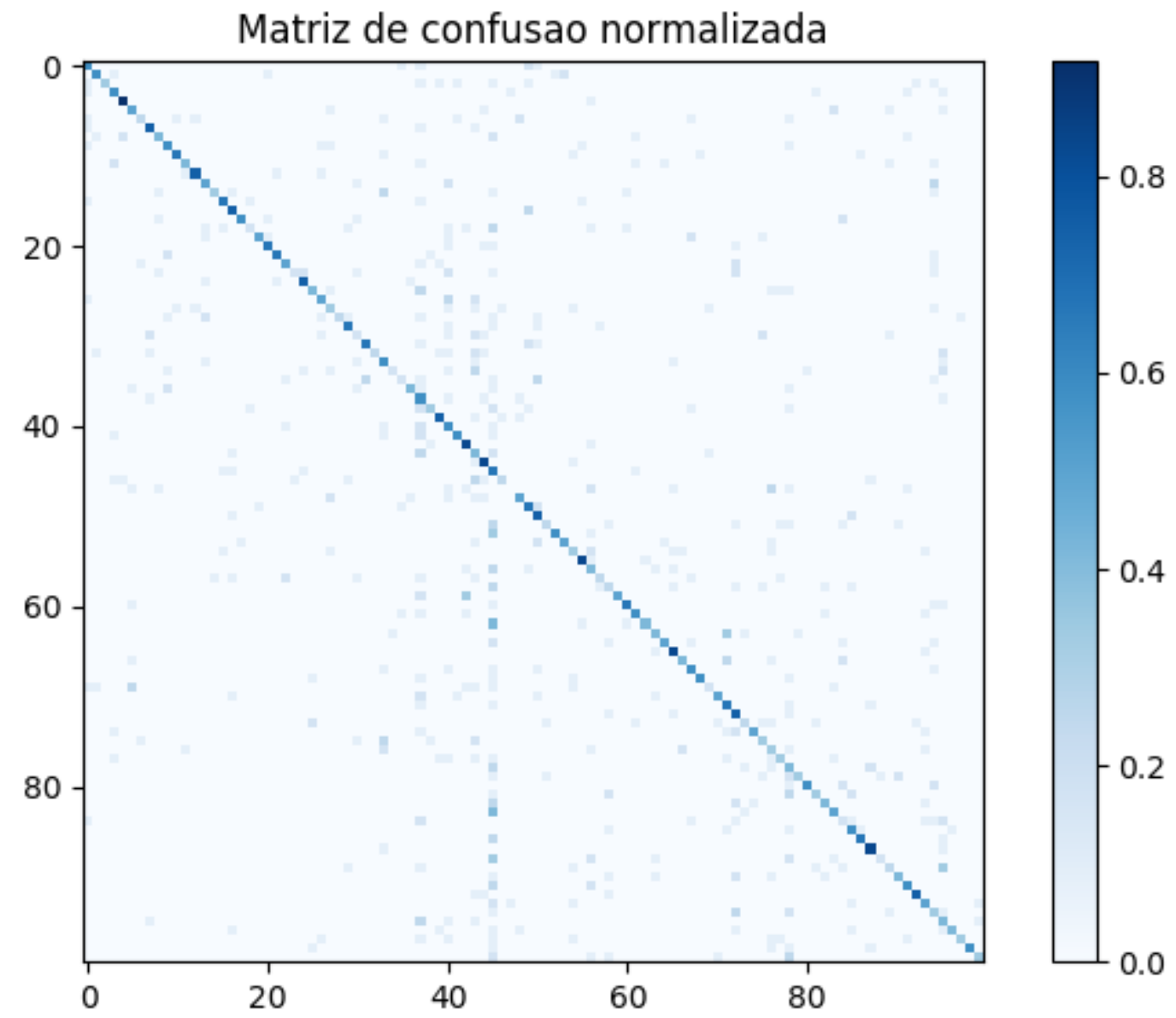

Fonte: Jozias Rolim, 2018

utilizado a transformada Wavelet e como classificador foi utilizado Rede Neural Perceptron Multicamadas. Conforme no Experimento I, descrito na secção 5.4, o sistema de reconhecimento proposto é apresentado na Figura 37.

Os resultados obtidos são descritos na Tabela 2. Na Figura 38 é apresentado a matriz de confusão para a ténica de reconstrução baseada em regressão com KNN. Nas Figuras 39, 40, 41, 42, 43 e 44, são apresentados alguns exemplos de reconstrução facial usando Eigenfaces, Fisherfaces, RPCA, FRPCA, APCA e GPCA, respectivamente, ambas baseadas em técnicas de subespaços. Nas Figuras 18, 20, 21 e 22, apresentam alguns exemplos de reconstrução facial usando técnicas baseadas em regressões, tais como, Regressão baseada em KNN, Regressão Linear, Regressão Ridge e Regressão baseada em árvores aleatórias, respectivamente. 
Figura 37 - Estrutura de um processo de reconhecimento facial com tratamento da oclusão

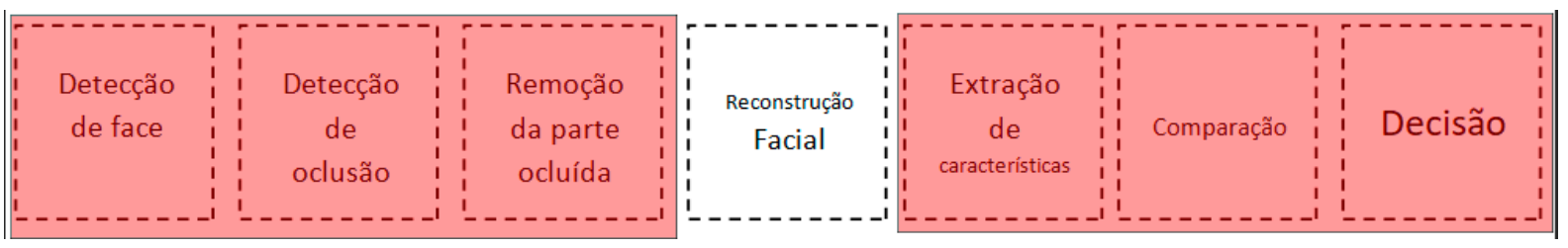

Fonte: Jozias Rolim, 2018

Tabela 2 - Métricas de desempenho para um sistema de reconhecimento biométrico com tratamento da oclusão

\begin{tabular}{lllll}
\hline Técnica & Precisão & Recall & F1 - Score & Acurácia \\
\hline Eigenfaces & 0.962 & 0.952 & 0.949 & 0.952 \\
Fisherfaces & 0.947 & 0.933 & 0.928 & 0.933 \\
RPCA & $\mathbf{0 . 9 7 4}$ & $\mathbf{0 . 9 6 5}$ & $\mathbf{0 . 9 6 4}$ & $\mathbf{0 . 9 6 5}$ \\
FRPCA & 0.928 & 0.912 & 0.906 & 0.912 \\
APCA & 0.925 & 0.915 & 0.906 & 0.915 \\
GPCA & 0.960 & 0.951 & 0.948 & 0.951 \\
Reg. Arvores & 0.771 & 0.752 & 0.735 & 0.752 \\
Reg. Knn & 0.774 & 0.760 & 0.742 & 0.760 \\
Reg. Linear & 0.679 & 0.669 & 0.649 & 0.669 \\
Reg. Ridge & 0.700 & 0.683 & 0.667 & 0.683 \\
\hline
\end{tabular}

Fonte: Jozias Rolim, 2018

\subsection{Experimento \#3}

Como ilustrado no experimento anterior, o desempenho de classificação sofre influência da técnica de reconstrução facial adotada. O objetivo deste experimento é mostrar que ao empregar uma estratégia de fusão das imagens geradas pelas técnicas de reconstrução facial, pode-se melhorar o desempenho do sistema de reconhecimento. Este experimento adota a mesma metodologia descrita no experimento da seção 5.5, no qual as imagens originalmente não ocluídas foram utilizadas para compor o treinamento, enquanto as imagens ocluídas reconstruídas pelas técnicas foram utilizadas para medir o desempenho de classificação. As seguintes combinações de técnicas foram adotadas: (i) Eigenfaces, GPCA, Fisherface e RPCA, usando as características de LH3, HL3, HH3 e LL3 respectivamente; (ii) GPCA, APCA, Fisherface e FRPCA, utilizando as características LL3, LH3, HL3 e HH3 respectivamente; (iii) GPCA, APCA, Fisherface e FRPCA, fazendo uso das características LH3, LL3, HL3 e HH3 respectivamente; (iv) GPCA, APCA, Fisherface e FRPCA, utilizando as características LH3, HL3, LL3 e HH3 respectivamente; (v) GPCA, 
Figura 38 - Matriz de confusão para um sistema de reconhecimento biométrico com reconstrução facial baseada em RPCA

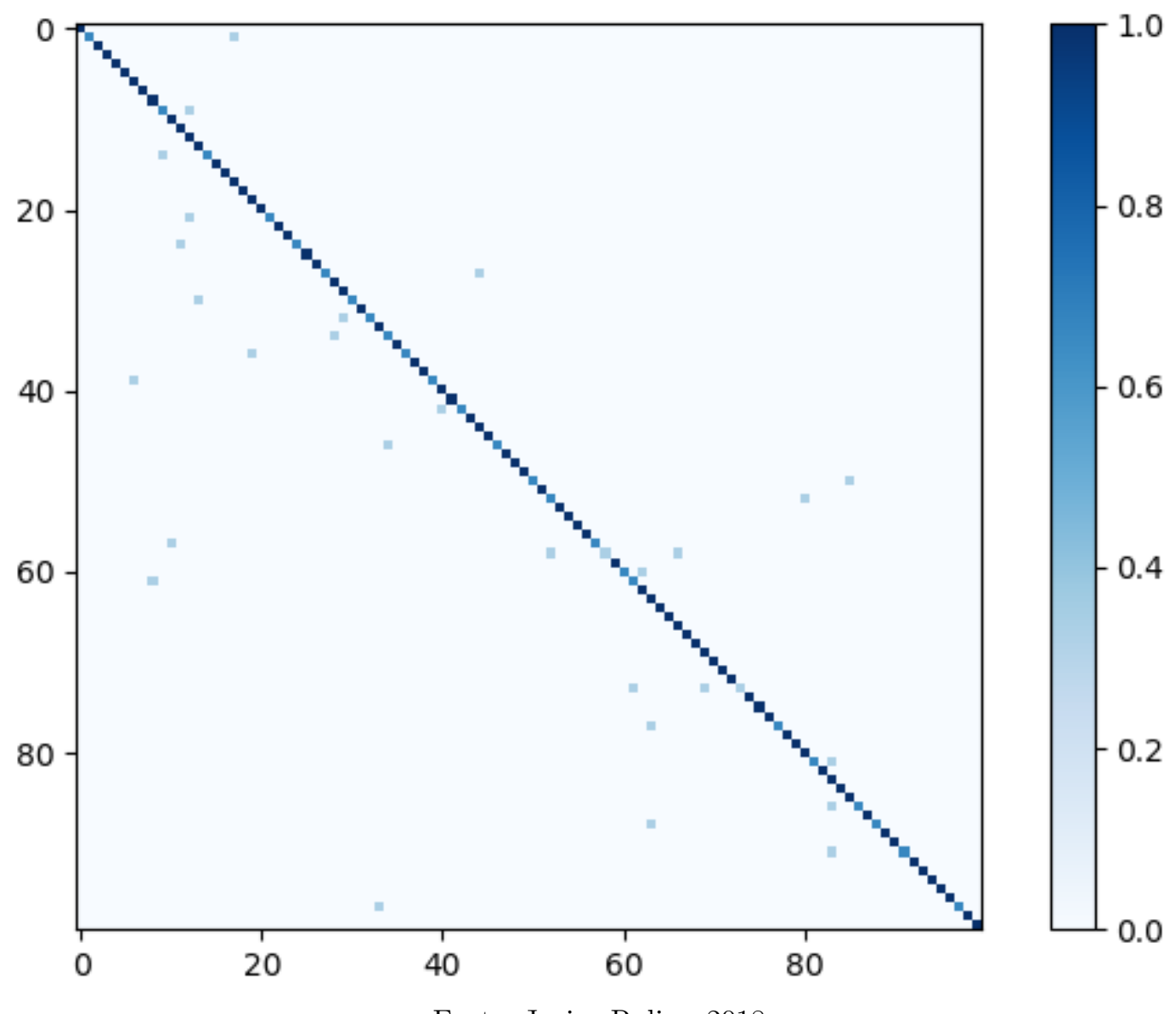

Fonte: Jozias Rolim, 2018

Figura 39 - Exemplos de reconstrução facial baseada em Eigenfaces

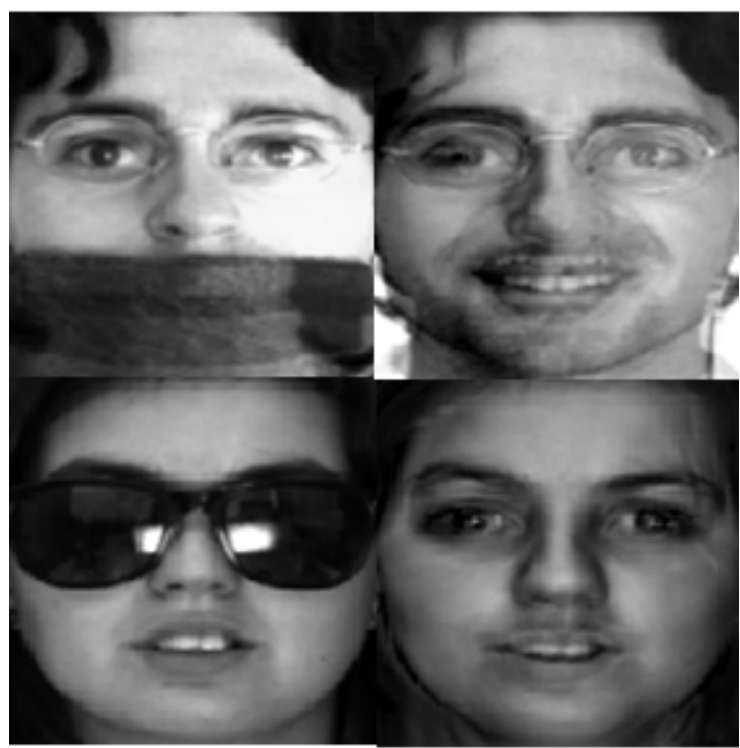

(i) Imagem original, (ii) Imagem reconstruída

Fonte: Jozias Rolim, 2018 
Figura 40 - Exemplos de reconstrução facial baseada em Fisherfaces

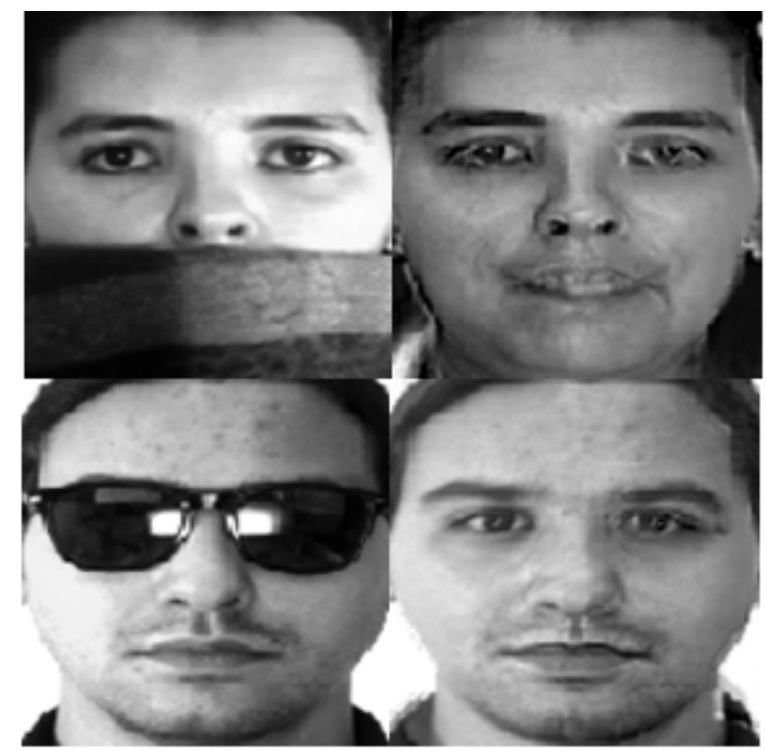

(i) Imagem original, (ii) Imagem reconstruída

Fonte: Jozias Rolim, 2018

Figura 41 - Exemplos de reconstrução facial baseada em RPCA

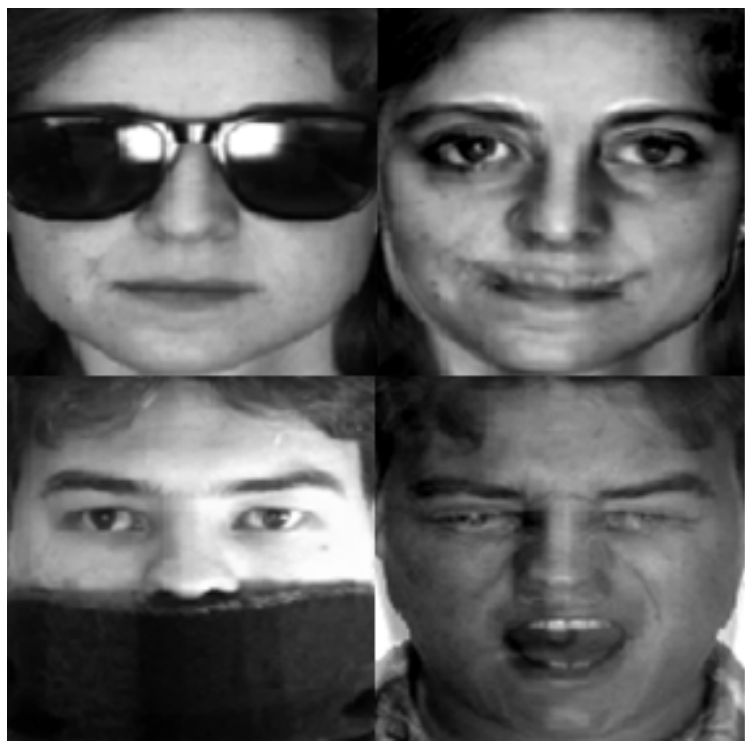

(i) Imagem original, (ii) Imagem reconstruída

Fonte: Jozias Rolim, 2018 
Figura 42 - Exemplos de reconstrução facial baseada em FRPCA

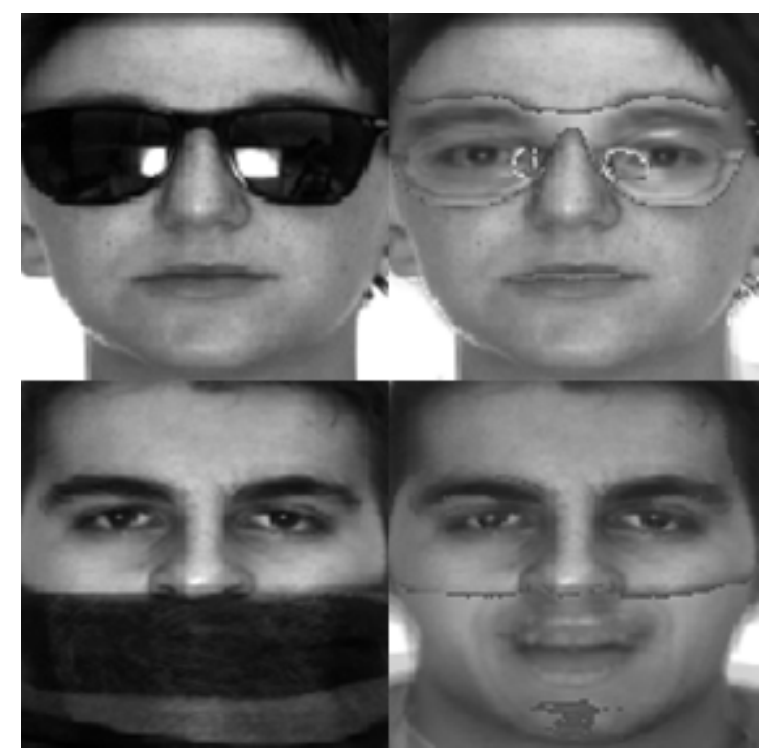

(i) Imagem original, (ii) Imagem reconstruída

Fonte: Jozias Rolim, 2018

Figura 43 - Exemplos de reconstrução facial baseada em APCA

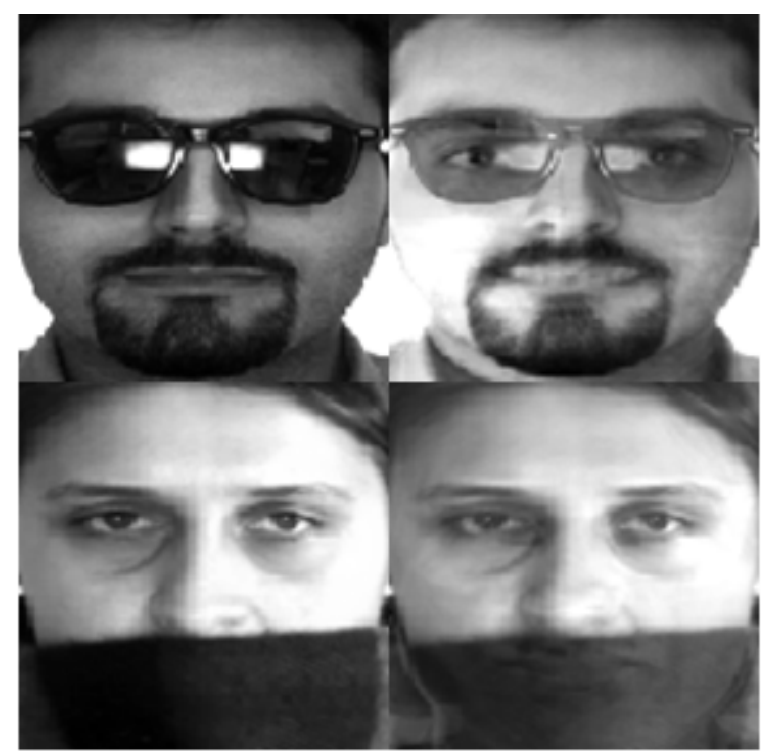

(i) Imagem original, (ii) Imagem reconstruída

Fonte: Jozias Rolim, 2018 
Figura 44 - Exemplos de reconstrução facial baseada em GPCA

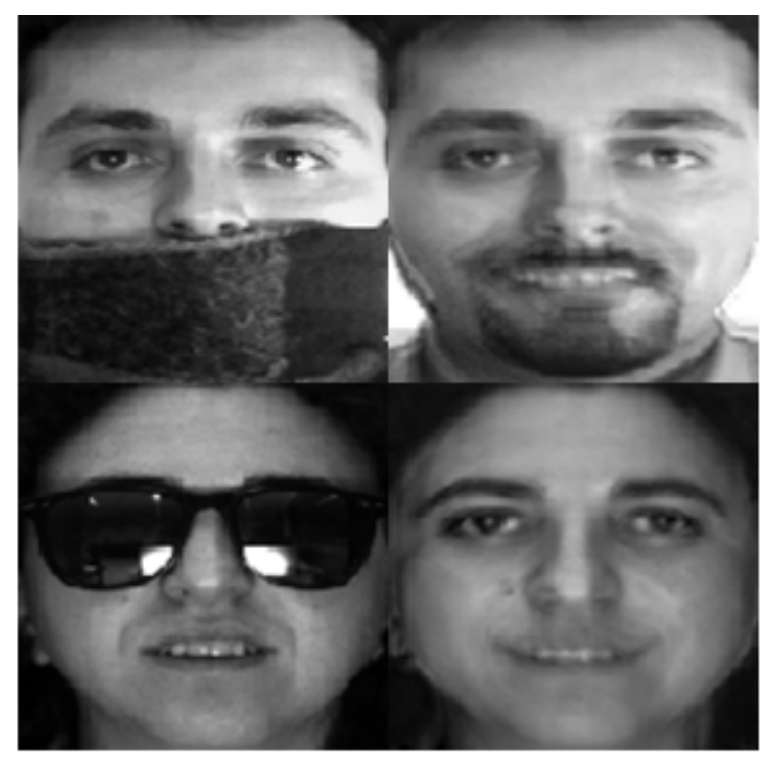

(i) Imagem original, (ii) Imagem reconstruída

Fonte: Jozias Rolim, 2018

APCA, Fisherface e FRPCA, utilizando-se das características LL3, HL3, LH3 e HH3 respectivamente; (vi) GPCA, APCA, Fisherface e FRPCA, com as características LL3, HL3, HH3 e LH3 respectivamente; (vii) GPCA, APCA, Fisherface, FRPCA, utilizando as características HL3, HH3, LH3 e LL3, respectivamente. Os resultados obtidos são descritos na tabela 3. A fusão foi realizada no nível de características, onde cada vetor de característica extraído de cada imagem reconstruída é concatenado para gerar o novo vetor de características, o qual é utilizado pelo classificador.

Tabela 3 - Métricas de desempenho para um sistema de reconhecimento multibiométrico com tratamento da oclusão

\begin{tabular}{lllll}
\hline Combinações & Precisão & Recall & F1 - Score & Acurácia \\
(i) & 0.970 & 0.961 & 0.959 & 0.961 \\
(ii) & $\mathbf{0 . 9 7 6}$ & $\mathbf{0 . 9 6 8}$ & $\mathbf{0 . 9 6 7}$ & $\mathbf{0 . 9 6 8}$ \\
(iii) & 0.945 & 0.936 & 0.930 & 0.936 \\
(iv) & 0.950 & 0.936 & 0.931 & 0.936 \\
(v) & 0.969 & 0.961 & 0.959 & 0.961 \\
(vi) & 0.969 & 0.960 & 0.958 & 0.960 \\
(vii) & 0.949 & 0.935 & 0.932 & 0.935 \\
\hline
\end{tabular}

Fonte: Jozias Rolim, 2018

As combinações foram selecionadas baseadas nos resultado de acurácia média individual de cada característica utilizada para classificação, os resultados médios individuais podem ser vistos na Tabela 4. 
Tabela 4 - Resultados médios individuais de acurácia por técnica

\begin{tabular}{lllll}
\hline Técnica & LL3 & HL3 & LH3 & HH3 \\
APCA & 0.935 & 0.833 & 0.811 & 0.811 \\
Fisherface & 0.952 & 0.850 & 0.852 & 0.852 \\
FRPCA & 0.941 & 0.812 & 0.802 & 0.802 \\
GPCA & 0.974 & 0.889 & 0.873 & 0.873 \\
Eigenfaces & 0.970 & 0.885 & 0.866 & 0.866 \\
RPCA & 0.976 & 0.878 & 0.875 & 0.875 \\
Árvore & 0.789 & 0.754 & 0.682 & 0.541 \\
KNN & 0.790 & 0.768 & 0.713 & 0.563 \\
Linear & 0.711 & 0.692 & 0.645 & 0.511 \\
Ridge & 0.728 & 0.690 & 0.642 & 0.500 \\
\hline
\end{tabular}

Fonte: Jozias Rolim, 2018

\subsection{Experimento \#4}

Este experimento assume que existem imagens ocluídas no treinamento. Essa suposição foi adotada por alguns autores, como por exemplo, Jia H. e Martinez A. (JIA; MARTINEZ, 2008). Neste caso, a imagem ocluída do conjunto de treinamento foi submetida a reconstrução usando uma das técnicas nesta dissertação antes de compor o conjunto de treinamento. O objetivo deste experimento é mostrar que se o conjunto de treinamento tiver alguma informação sobre a oclusão o desempenho pode melhorar. Neste experimento, foi utilizada a abordagem de validação cruzada com 10-fold. A validação cruzada permite que cada exemplo possa pertencer pelo menos uma vez ao conjunto de teste, permitindo assim que o sistema seja avaliado mais adequadamente.

\subsubsection{Técnicas baseadas em subespaço}

Neste experimento, as imagens de face ocluídas do conjunto de treinamento foram reconstruídas usando uma técnica baseada em subespaço, sendo que o espaço de imagens é formado pelas imagens não ocluídas. As Figuras 45, 46, 47, 48, 4950 apresentam a matriz de confusão calculada para o fold igual a 6 , no qual foi obtida menor acurácia para todas as técnicas baseadas em subespaço. Nas Tabelas 5, 6, 7, 8, 9, 10 são apresentados os resultados obtidos por cada técnica de subespaço para cada fold. 
Figura 45 - Matriz de confusão (para fold igual a 6) para um sistema de reconhecimento biométrico com reconstrução facial baseada Eigenfaces

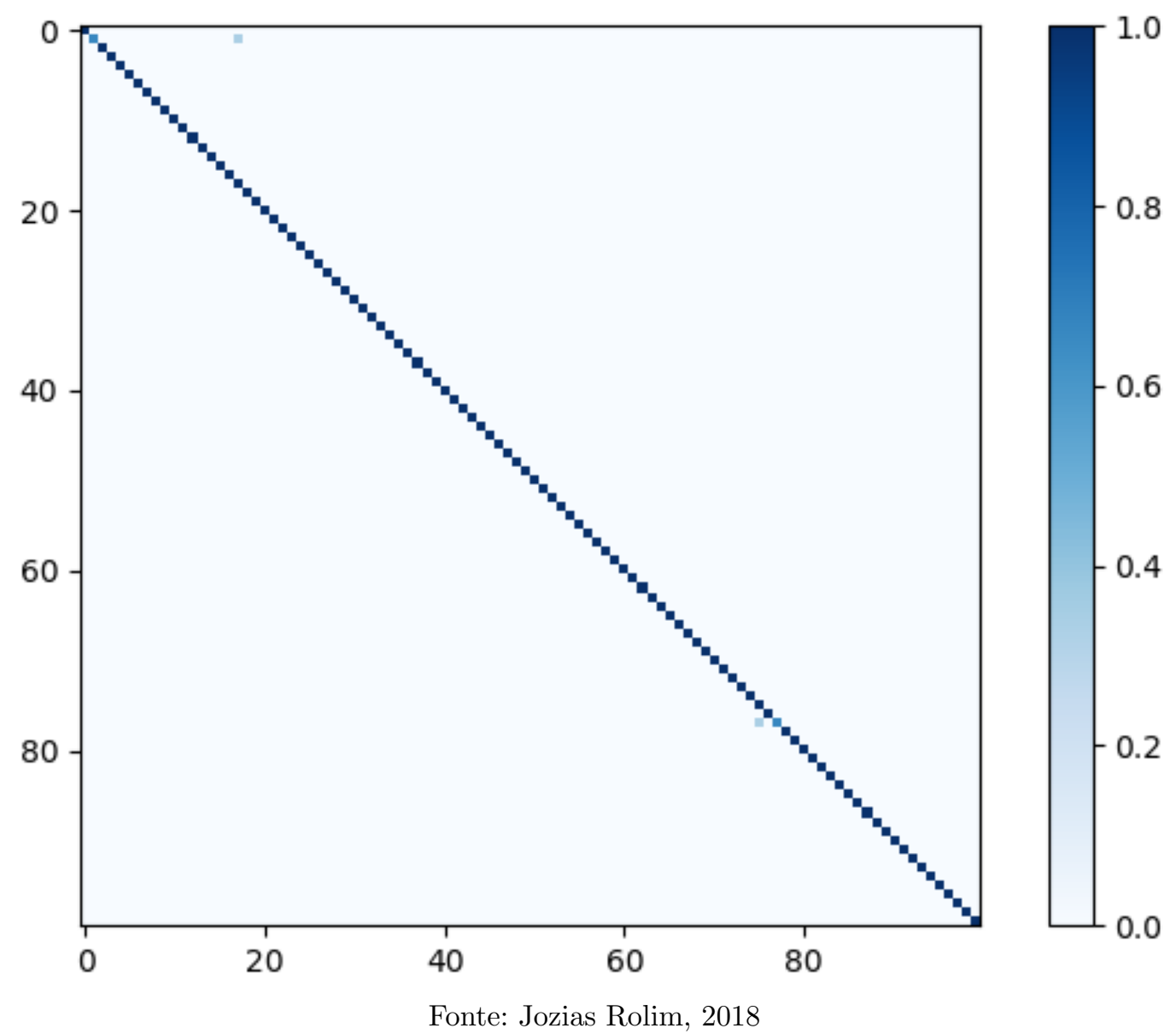

Tabela 5 - Métricas de desempenho para um sistema de reconhecimento biométrico com reconstrução facial via Eigenfaces com validação cruzada 10-folds

\begin{tabular}{lllll}
\hline fold & Precisão & Recall & F1 - Score & Acurácia \\
\hline 1 & 0.935 & 0.917 & 0.912 & 0.917 \\
2 & 0.913 & 0.890 & 0.889 & 0.890 \\
3 & 0.980 & 0.970 & 0.969 & 0.970 \\
4 & 0.948 & 0.930 & 0.929 & 0.930 \\
5 & 0.961 & 0.940 & 0.937 & 0.940 \\
6 & 0.995 & 0.993 & 0.993 & 0.993 \\
7 & 0.990 & 0.985 & 0.984 & 0.985 \\
8 & 0.909 & 0.915 & 0.900 & 0.915 \\
9 & 1.000 & 1.000 & 1.000 & 1.000 \\
10 & 0.987 & 0.980 & 0.979 & 0.980 \\
\hline Média & $\mathbf{0 . 9 6 2}$ & $\mathbf{0 . 9 5 2}$ & $\mathbf{0 . 9 4 9}$ & $\mathbf{0 . 9 5 2}$ \\
\hline
\end{tabular}

Fonte: Jozias Rolim, 2018 
Figura 46 - Matriz de confusão (para fold igual a 6) para um sistema de reconhecimento biométrico com reconstrução facial baseada em Fisherface

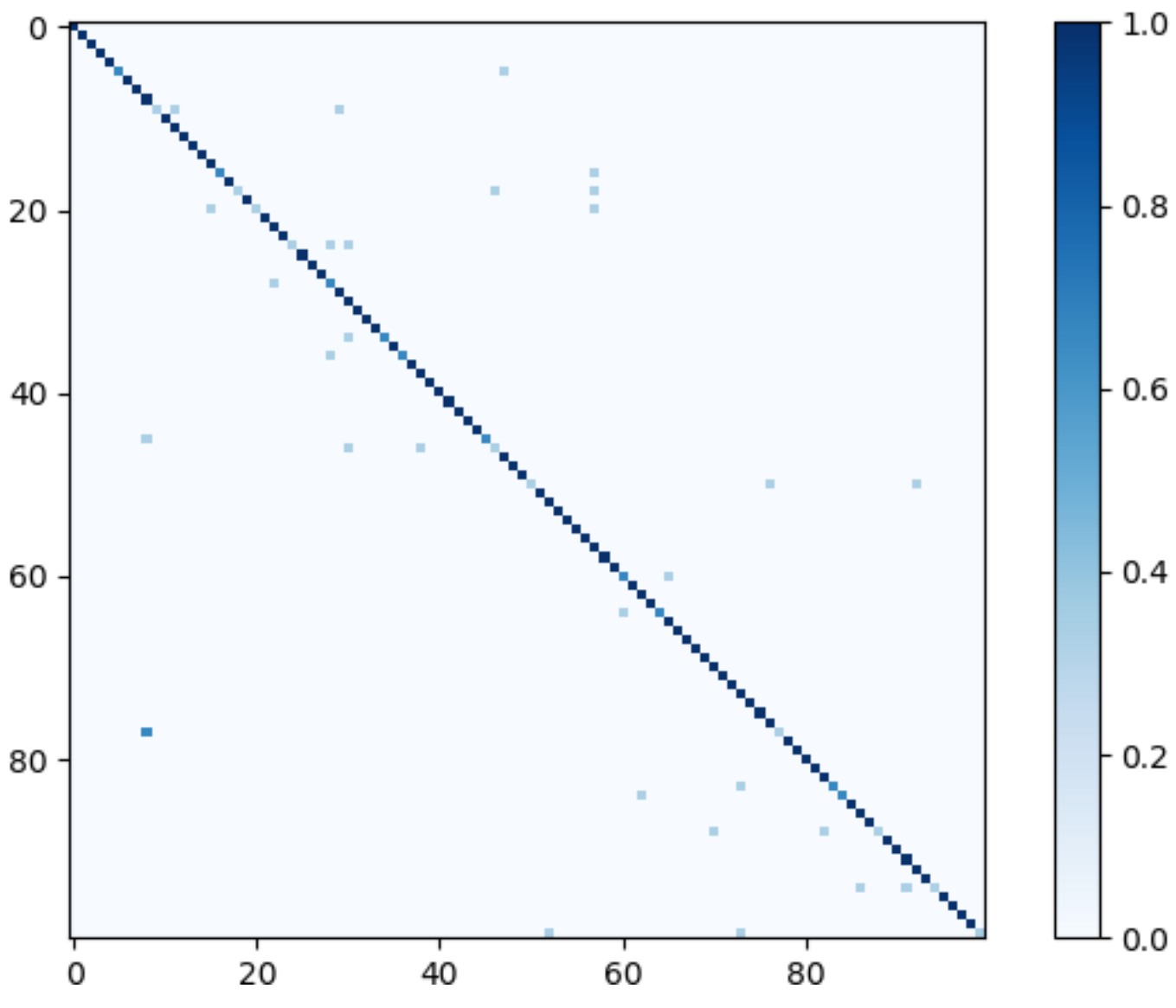

Fonte: Jozias Rolim, 2018

Tabela 6 - Métricas de desempenho para um sistema de reconhecimento biométrico com reconstrução facial via Fisherfaces com validação cruzada 10-folds

\begin{tabular}{lllll}
\hline fold & Precisão & Recall & F1 - Score & Acurácia \\
\hline 1 & 0.891 & 0.877 & 0.868 & 0.877 \\
2 & 0.938 & 0.927 & 0.925 & 0.927 \\
3 & 0.967 & 0.957 & 0.955 & 0.957 \\
4 & 0.938 & 0.917 & 0.911 & 0.917 \\
5 & 0.959 & 0.947 & 0.946 & 0.947 \\
6 & 0.930 & 0.900 & 0.891 & 0.900 \\
7 & 0.938 & 0.935 & 0.926 & 0.935 \\
8 & 0.968 & 0.950 & 0.947 & 0.950 \\
9 & 0.965 & 0.950 & 0.947 & 0.950 \\
10 & 0.977 & 0.965 & 0.963 & 0.965 \\
\hline Média & $\mathbf{0 . 9 4 7}$ & $\mathbf{0 . 9 3 3}$ & $\mathbf{0 . 9 2 8}$ & $\mathbf{0 . 9 3 3}$ \\
\hline
\end{tabular}

Fonte: Jozias Rolim, 2018 
Figura 47 - Matriz de confusão (para fold igual a 6) para um sistema de reconhecimento biométrico com reconstrução facial baseada em RPCA

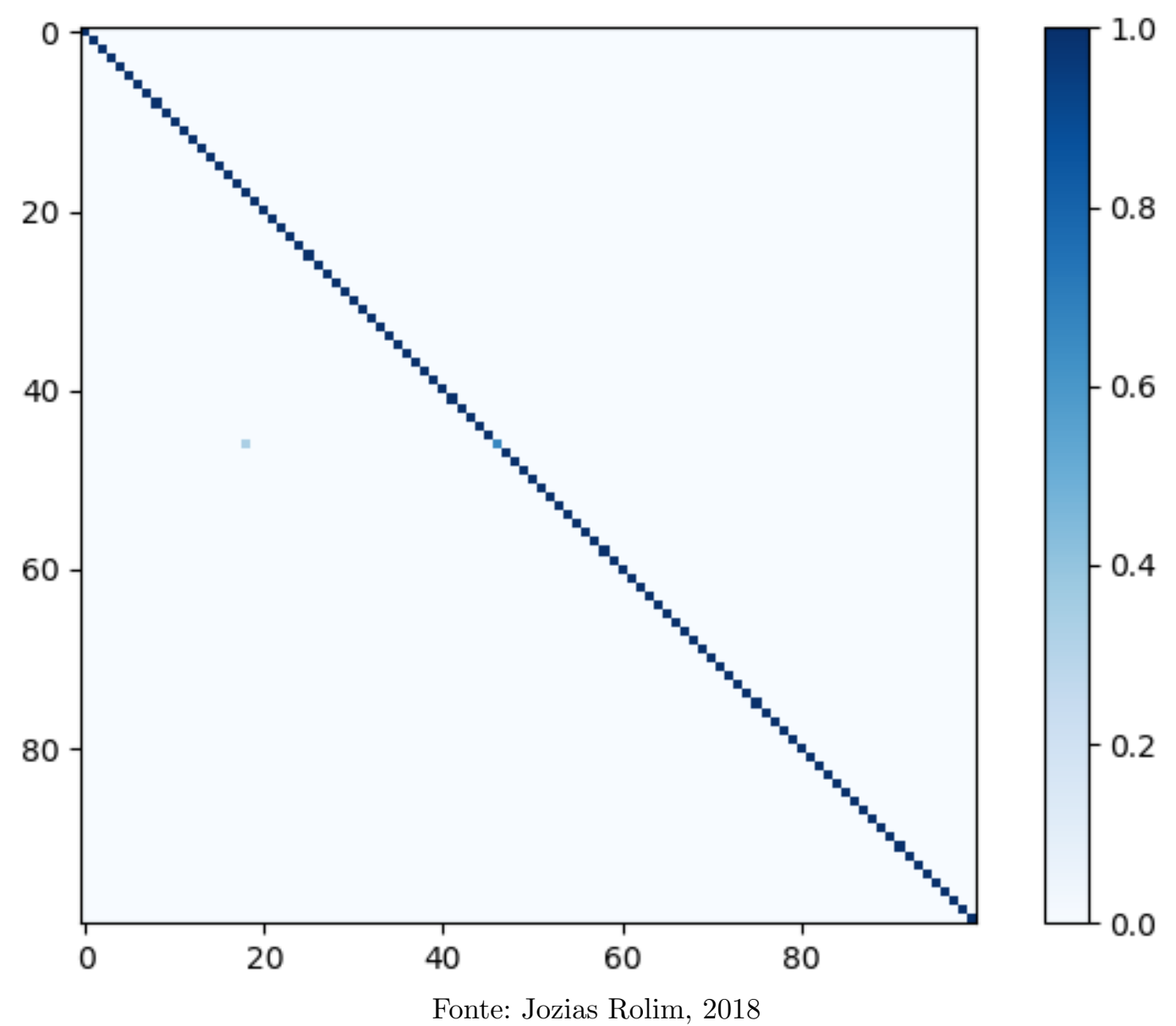

Tabela 7 - Métricas de desempenho para um sistema de reconhecimento biométrico com reconstrução facial via RPCA com validação cruzada 10-folds

\begin{tabular}{lllll}
\hline fold & Precisão & Recall & F1 - Score & Acurácia \\
\hline 1 & 0.958 & 0.943 & 0.940 & 0.943 \\
2 & 0.920 & 0.900 & 0.895 & 0.900 \\
3 & 0.983 & 0.977 & 0.974 & 0.977 \\
4 & 0.931 & 0.907 & 0.904 & 0.907 \\
5 & 0.964 & 0.953 & 0.951 & 0.953 \\
6 & 0.998 & 0.997 & 0.997 & 0.997 \\
7 & 0.997 & 0.995 & 0.995 & 0.995 \\
8 & 0.987 & 0.980 & 0.979 & 0.980 \\
9 & 1.000 & 1.000 & 1.000 & 1.000 \\
10 & 1.000 & 1.000 & 1.000 & 1.000 \\
\hline Média & $\mathbf{0 . 9 7 4}$ & $\mathbf{0 . 9 6 5}$ & $\mathbf{0 . 9 6 4}$ & $\mathbf{0 . 9 6 5}$ \\
\hline
\end{tabular}

Fonte: Jozias Rolim, 2018 
Figura 48 - Matriz de confusão (para fold igual a 6) para um sistema de reconhecimento biométrico com reconstrução facial baseada em FRPCA

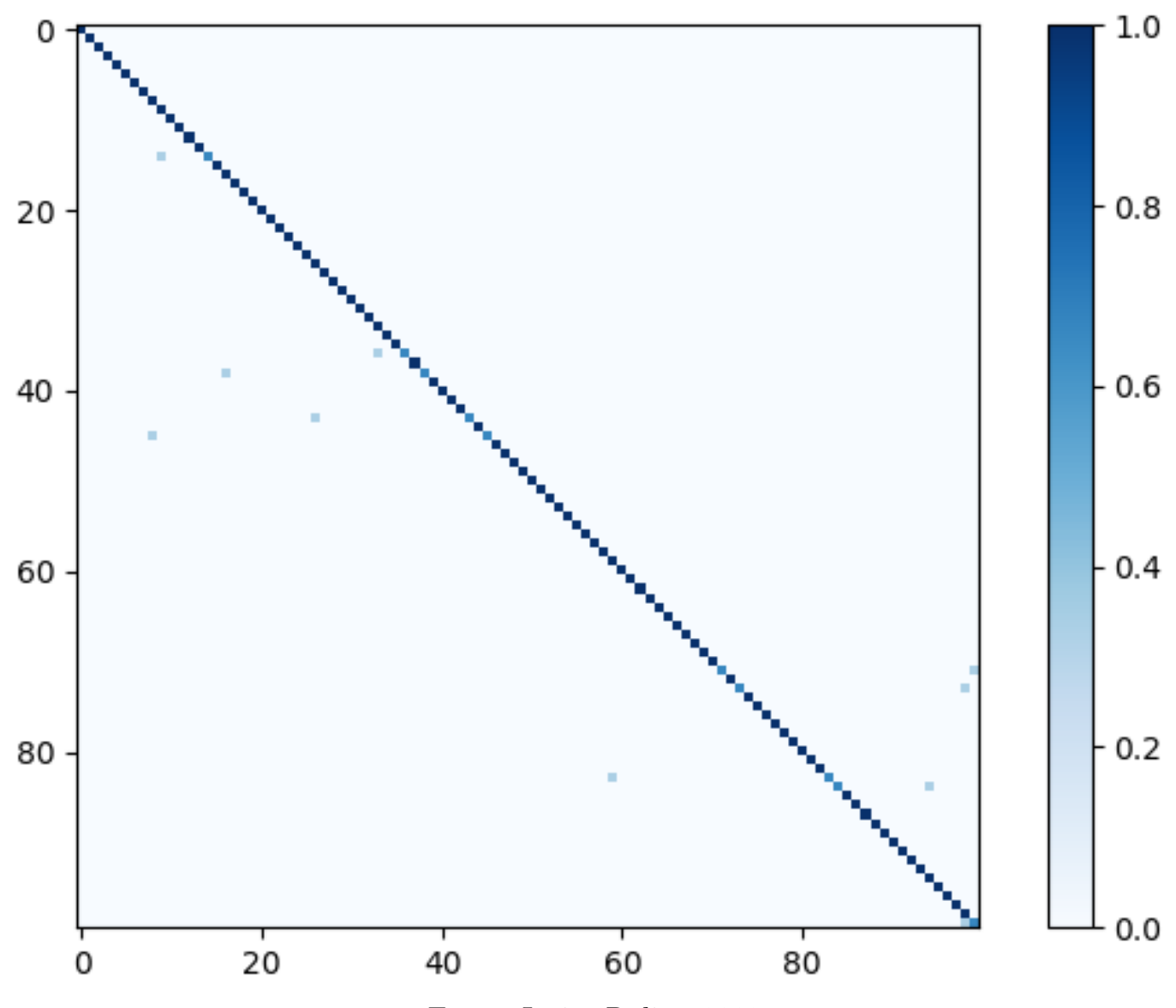

Fonte: Jozias Rolim, 2018

Tabela 8 - Métricas de desempenho para um sistema de reconhecimento biométrico com reconstrução facial via FRPCA com validação cruzada 10-folds

\begin{tabular}{lllll}
\hline fold & Precisão & Recall & F1 - Score & Acurácia \\
\hline 1 & 0.909 & 0.897 & 0.889 & 0.897 \\
2 & 0.944 & 0.927 & 0.926 & 0.927 \\
3 & 0.963 & 0.953 & 0.951 & 0.953 \\
4 & 0.900 & 0.873 & 0.868 & 0.873 \\
5 & 0.911 & 0.873 & 0.869 & 0.873 \\
6 & 0.975 & 0.967 & 0.966 & 0.967 \\
7 & 0.890 & 0.845 & 0.841 & 0.845 \\
8 & 0.893 & 0.905 & 0.888 & 0.905 \\
9 & 0.978 & 0.965 & 0.963 & 0.965 \\
10 & 0.915 & 0.910 & 0.896 & 0.910 \\
\hline Média & $\mathbf{0 . 9 2 8}$ & $\mathbf{0 . 9 1 2}$ & $\mathbf{0 . 9 0 6}$ & $\mathbf{0 . 9 1 2}$
\end{tabular}

Fonte: Jozias Rolim, 2018 
Figura 49 - Matriz de confusão (para fold igual a 6) para um sistema de reconhecimento biométrico com reconstrução facial baseada em APCA

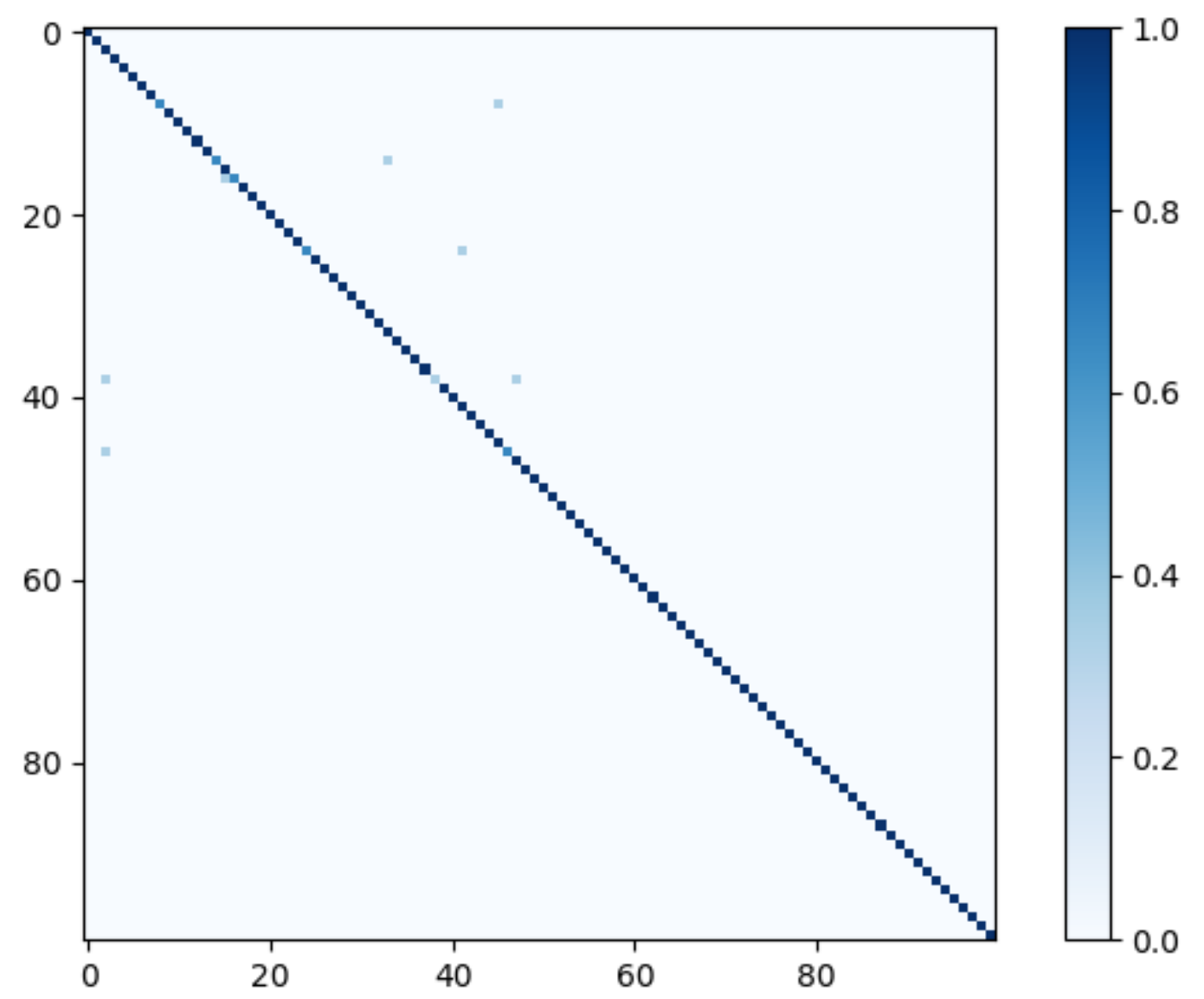

Fonte: Jozias Rolim, 2018

Tabela 9 - Métricas de desempenho para um sistema de reconhecimento biométrico com reconstrução facial via APCA e validação cruzada 10-folds

\begin{tabular}{lllll}
\hline fold & Precisão & Recall & F1 - Score & Acurácia \\
\hline 1 & 0.932 & 0.910 & 0.902 & 0.910 \\
2 & 0.966 & 0.950 & 0.950 & 0.950 \\
3 & 0.973 & 0.963 & 0.961 & 0.963 \\
4 & 0.925 & 0.893 & 0.888 & 0.893 \\
5 & 0.953 & 0.930 & 0.927 & 0.930 \\
6 & 0.983 & 0.977 & 0.975 & 0.977 \\
7 & 0.851 & 0.840 & 0.824 & 0.840 \\
8 & 0.888 & 0.910 & 0.888 & 0.910 \\
9 & 0.983 & 0.975 & 0.973 & 0.975 \\
10 & 0.799 & 0.800 & 0.774 & 0.800 \\
\hline Média & $\mathbf{0 . 9 2 5}$ & $\mathbf{0 . 9 1 5}$ & $\mathbf{0 . 9 0 6}$ & $\mathbf{0 . 9 1 5}$ \\
\hline
\end{tabular}

Fonte: Jozias Rolim, 2018 
Figura 50 - Matriz de confusão (para fold igual a 6) para um sistema de reconhecimento biométrico com reconstrução facial baseada em GPCA

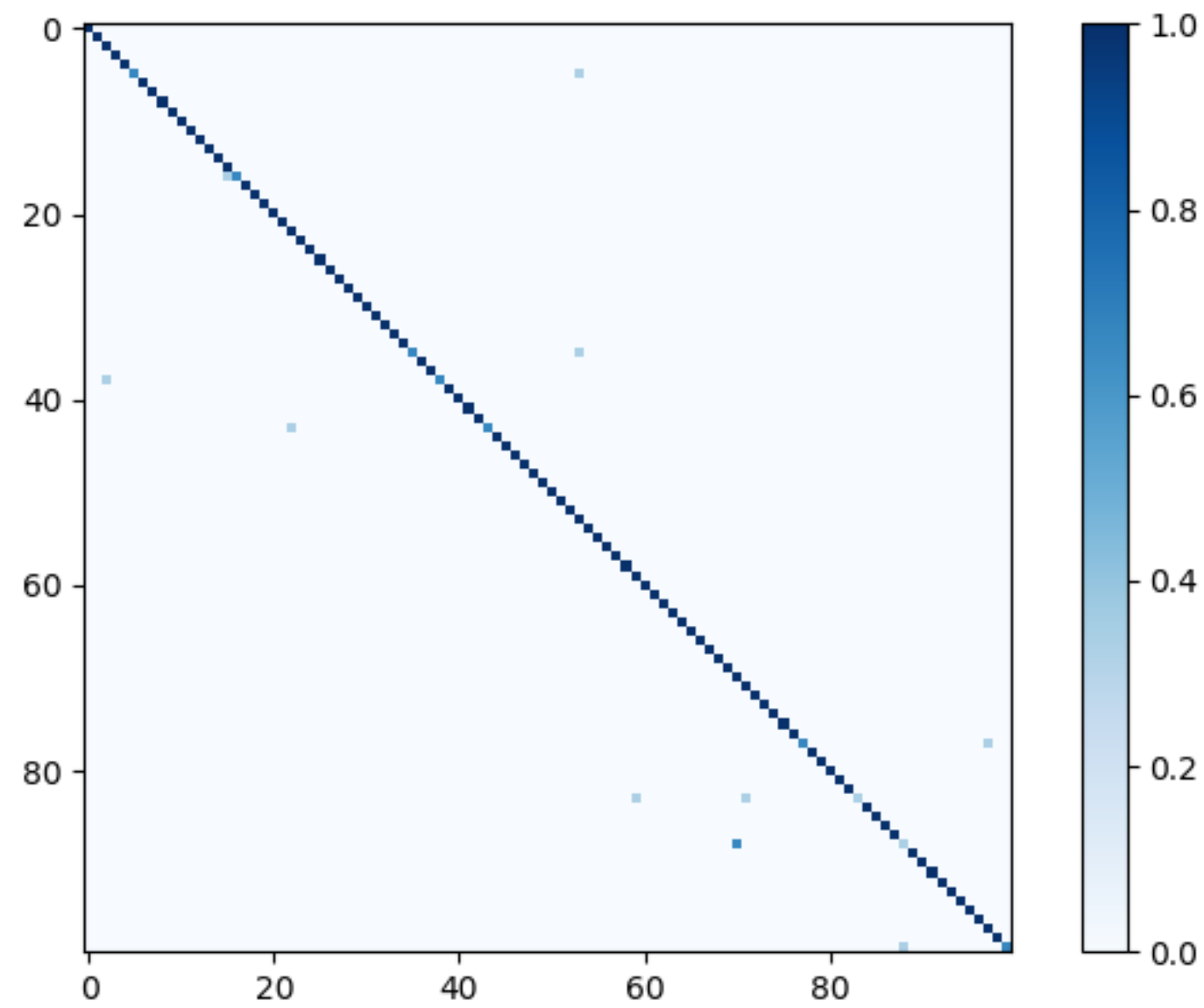

Fonte: Jozias Rolim, 2018

Tabela 10 - Métricas de desempenho para um sistema de reconhecimento biométrico com reconstrução facial via GPCA com validação cruzada 10-folds

\begin{tabular}{lllll}
\hline Valor de k & Precisão & Recall & F1 - Score & Acurácia \\
\hline 1 & 0.933 & 0.913 & 0.907 & 0.913 \\
2 & 0.939 & 0.927 & 0.922 & 0.927 \\
3 & 0.978 & 0.970 & 0.968 & 0.970 \\
4 & 0.882 & 0.847 & 0.841 & 0.847 \\
5 & 0.964 & 0.953 & 0.953 & 0.953 \\
6 & 0.972 & 0.963 & 0.961 & 0.963 \\
7 & 1.000 & 1.000 & 1.000 & 1.000 \\
8 & 0.932 & 0.935 & 0.923 & 0.935 \\
9 & 1.000 & 1.000 & 1.000 & 1.000 \\
10 & 1.000 & 1.000 & 1.000 & 1.000 \\
\hline Média & $\mathbf{0 . 9 6 0}$ & $\mathbf{0 . 9 5 1}$ & $\mathbf{0 . 9 4 8}$ & $\mathbf{0 . 9 5 1}$ \\
\hline
\end{tabular}

Fonte: Jozias Rolim, 2018 


\subsubsection{Técnicas baseadas em regressão}

Neste experimento, as imagens de face ocluídas do conjunto de treinamento foram reconstruídas usando uma técnica baseada em regressões. Nas Tabelas 11, 12, 13, 14 são apresentados os resultados obtidos por cada técnica de baseada em regressão para cada fold.

Tabela 11 - Métricas de desempenho para um sistema de reconhecimento biométrico com reconstrução facial via árvore extremamente aleatórias com validação cruzada 10-folds

\begin{tabular}{lllll}
\hline fold & Precisão & Recall & F1 - Score & Acurácia \\
\hline 1 & 0.884 & 0.883 & 0.870 & 0.883 \\
2 & 0.843 & 0.803 & 0.798 & 0.803 \\
3 & 0.975 & 0.963 & 0.961 & 0.963 \\
4 & 0.912 & 0.883 & 0.880 & 0.883 \\
5 & 0.899 & 0.870 & 0.867 & 0.870 \\
6 & 0.643 & 0.600 & 0.573 & 0.600 \\
7 & 0.607 & 0.600 & 0.576 & 0.600 \\
8 & 0.558 & 0.585 & 0.542 & 0.585 \\
9 & 0.743 & 0.700 & 0.684 & 0.700 \\
10 & 0.646 & 0.630 & 0.601 & 0.630 \\
\hline Média & $\mathbf{0 . 7 7 1}$ & $\mathbf{0 . 7 5 2}$ & $\mathbf{0 . 7 3 5}$ & $\mathbf{0 . 7 5 2}$ \\
\hline
\end{tabular}

Fonte: Jozias Rolim, 2018

Tabela 12 - Métricas de desempenho para um sistema de reconhecimento biométrico com reconstrução facial via regressão linear e validação cruzada 10-folds

\begin{tabular}{lllll}
\hline fold & Precisão & Recall & F1 - Score & Acurácia \\
\hline 1 & 0.913 & 0.893 & 0.888 & 0.893 \\
2 & 0.897 & 0.860 & 0.858 & 0.860 \\
3 & 0.961 & 0.950 & 0.946 & 0.950 \\
4 & 0.837 & 0.793 & 0.786 & 0.793 \\
5 & 0.796 & 0.753 & 0.746 & 0.753 \\
6 & 0.480 & 0.457 & 0.435 & 0.457 \\
7 & 0.415 & 0.440 & 0.408 & 0.440 \\
8 & 0.419 & 0.450 & 0.405 & 0.450 \\
9 & 0.625 & 0.605 & 0.579 & 0.605 \\
10 & 0.451 & 0.490 & 0.442 & 0.490 \\
\hline Média & $\mathbf{0 . 6 7 9}$ & $\mathbf{0 . 6 6 9}$ & $\mathbf{0 . 6 4 9}$ & $\mathbf{0 . 6 6 9}$ \\
\hline
\end{tabular}


Tabela 13 - Métricas de desempenho para um sistema de reconhecimento biométrico com reconstrução facial via regressão ridge com validação cruzada 10-folds

\begin{tabular}{lllll}
\hline fold & Precisão & Recall & F1 - Score & Acurácia \\
\hline 1 & 0.863 & 0.827 & 0.822 & 0.827 \\
2 & 0.882 & 0.857 & 0.852 & 0.857 \\
3 & 0.988 & 0.983 & 0.983 & 0.983 \\
4 & 0.892 & 0.853 & 0.849 & 0.853 \\
5 & 0.872 & 0.833 & 0.830 & 0.833 \\
6 & 0.563 & 0.507 & 0.492 & 0.507 \\
7 & 0.376 & 0.405 & 0.369 & 0.405 \\
8 & 0.446 & 0.440 & 0.408 & 0.440 \\
9 & 0.608 & 0.610 & 0.576 & 0.610 \\
10 & 0.514 & 0.515 & 0.486 & 0.515 \\
\hline Média & $\mathbf{0 . 7 0 0}$ & $\mathbf{0 . 6 8 3}$ & $\mathbf{0 . 6 6 7}$ & $\mathbf{0 . 6 8 3}$ \\
\hline
\end{tabular}

Fonte: Jozias Rolim, 2018

Tabela 14 - Métricas de desempenho para um sistema de reconhecimento biométrico com reconstrução facial via regressão com KNN com validação cruzada 10-folds

\begin{tabular}{lllll}
\hline Valor de k & Precisão & Recall & F1 - Score & Acurácia \\
\hline 1 & 0.914 & 0.897 & 0.889 & 0.897 \\
2 & 0.915 & 0.890 & 0.885 & 0.890 \\
3 & 0.981 & 0.973 & 0.972 & 0.973 \\
4 & 0.913 & 0.883 & 0.876 & 0.883 \\
5 & 0.886 & 0.860 & 0.853 & 0.860 \\
6 & 0.707 & 0.660 & 0.647 & 0.660 \\
7 & 0.477 & 0.510 & 0.464 & 0.510 \\
8 & 0.625 & 0.645 & 0.602 & 0.645 \\
9 & 0.733 & 0.715 & 0.689 & 0.715 \\
10 & 0.588 & 0.565 & 0.540 & 0.565 \\
\hline Média & $\mathbf{0 . 7 7 4}$ & $\mathbf{0 . 7 6 0}$ & $\mathbf{0 . 7 4 2}$ & $\mathbf{0 . 7 6 0}$ \\
\hline
\end{tabular}

Fonte: Jozias Rolim, 2018

\subsubsection{Reconhecimento sem tratamento da oclusão}

Similar ao experimento \#1, neste experimento as imagens de face com oclusão no conjunto de treinamento e teste não sofreram nenhum tratamento. Na Tabela 15 é apresentado os resultados obtidos usando validação cruzada 10-fold. Neste caso, foi obtido uma acurácia média de $\mathbf{0 . 8 3 0}$ com desvio padrão igual a $\mathbf{0 . 0 7}$. 
Tabela 15 - Métricas de desempenho para um sistema de reconhecimento biométrico sem reconstrução facial com validação cruzada 10-folds

\begin{tabular}{lllll}
\hline fold & Precisão & Recall & F1 - Score & Acurácia \\
\hline 1 & 0.830 & 0.790 & 0.781 & 0.790 \\
2 & 0.815 & 0.747 & 0.756 & 0.747 \\
3 & 0.910 & 0.880 & 0.874 & 0.880 \\
4 & 0.887 & 0.867 & 0.858 & 0.867 \\
5 & 0.931 & 0.907 & 0.906 & 0.907 \\
6 & 0.785 & 0.700 & 0.704 & 0.700 \\
7 & 0.947 & 0.955 & 0.946 & 0.955 \\
8 & 0.784 & 0.790 & 0.761 & 0.790 \\
9 & 0.870 & 0.850 & 0.837 & 0.850 \\
10 & 0.819 & 0.820 & 0.795 & 0.820 \\
\hline Média & $\mathbf{0 . 8 5 5}$ & $\mathbf{0 . 8 3 0}$ & $\mathbf{0 . 8 2 1}$ & $\mathbf{0 . 8 3 0}$ \\
\hline
\end{tabular}

Fonte: Jozias Rolim, 2018

5.7.4 Fusão de técnicas de reconstrução baseadas em subespaço

A única diferença deste experimento para o experimento \#3 reside no conjunto de treinamento. Enquanto no experimento \#3, o conjunto treinamento era formado apenas por imagens não ocluídas, neste experimento o conjunto de treinamento contém imagens não ocluídas e imagens ocluídas reconstruídas por alguma técnica baseada em subespaço. Os resultados obtidos são apresentados na Tabela 16. Neste caso, foi obtido uma acurácia média de $\mathbf{0 . 9 1 1}$ com desvio padrão igual a $\mathbf{0 . 1 0}$.

Tabela 16 - Métricas de desempenho para um sistema de reconhecimento multibiométrico com reconstrução facial baseada em subespaço com validação cruzada 10-folds

\begin{tabular}{lllll}
\hline Valor de k & Precisão & Recall & F1 - Score & Acurácia \\
\hline 1 & 0.824 & 0.793 & 0.777 & 0.793 \\
2 & 0.852 & 0.777 & 0.784 & 0.777 \\
3 & 0.951 & 0.930 & 0.926 & 0.930 \\
4 & 0.811 & 0.730 & 0.733 & 0.730 \\
5 & 0.973 & 0.963 & 0.962 & 0.963 \\
6 & 0.980 & 0.973 & 0.973 & 0.973 \\
7 & 0.980 & 0.985 & 0.981 & 0.985 \\
8 & 1.000 & 1.000 & 1.000 & 1.000 \\
9 & 0.982 & 0.975 & 0.974 & 0.975 \\
10 & 0.993 & 0.990 & 0.989 & 0.990 \\
\hline Média & $\mathbf{0 . 9 3 4}$ & $\mathbf{0 . 9 1 1}$ & $\mathbf{0 . 9 0 9}$ & $\mathbf{0 . 9 1 1}$ \\
\hline
\end{tabular}

Fonte: Jozias Rolim, 2018 
5.7.5 Fusão de técnicas de reconstrução baseadas em subespaço e baseadas em regressões

Neste experimento, o conjunto treinamento é formado por imagens não ocluídas e ocluídas reconstruídas por técnicas baseadas em subespaço ou baseadas em regressões. Os resultados obtidos são apresentados na Tabela 17. Neste caso, foi obtido uma acurácia média de $\mathbf{0 . 9 1 8}$, com desvio padrão de $\mathbf{0 . 0 7}$.

Tabela 17 - Métricas de desempenho para um sistema de reconhecimento multibiométrico com reconstrução facial baseada em subespaço e baseadas em regressões e validação cruzada 10 -folds

\begin{tabular}{lllll}
\hline Valor de k & Precisão & Recall & F1 - Score & Acurácia \\
\hline 1 & 0.861 & 0.820 & 0.812 & 0.820 \\
2 & 0.842 & 0.773 & 0.781 & 0.773 \\
3 & 0.959 & 0.940 & 0.939 & 0.940 \\
4 & 0.823 & 0.750 & 0.750 & 0.750 \\
5 & 0.978 & 0.970 & 0.968 & 0.970 \\
6 & 0.990 & 0.987 & 0.986 & 0.987 \\
7 & 0.982 & 0.975 & 0.974 & 0.975 \\
8 & 0.997 & 0.995 & 0.995 & 0.995 \\
9 & 0.980 & 0.975 & 0.974 & 0.975 \\
10 & 0.997 & 0.995 & 0.995 & 0.995 \\
\hline Média & $\mathbf{0 . 9 4 0}$ & $\mathbf{0 . 9 1 8}$ & $\mathbf{0 . 9 1 7}$ & $\mathbf{0 . 9 1 8}$ \\
\hline
\end{tabular}

Fonte: Jozias Rolim, 2018

\subsection{Discussão dos Resultados}

No experimento \#1, descrito na secção 5.4, foi utilizado imagens com oclusão no teste, mas que não sofreram nenhum tratamentos, cujo objetivo era mostrar que a não utilização de técnicas de reconstrução facial pode resultar em desempenho ruim. No experimento \#2, descrito na secção 5.5, cada técnica de reconstrução facial foi avaliada isoladamente. Já no experimento \#3, descrito na secção 5.6, foi realizado a fusão no nível de característica das imagens geradas por cada técnica de reconstrução facial. A Tabela 18 apresenta um resumos dos resultados obtidos nestes experimentos.

Analisando a Tabela 18, pode-se perceber que para alguns casos ao tratar a oclusão houve um ganho em termos de acurácia média. Esse resultado valida a hipótese de que diferentes técnicas de reconstrução facial produzem diferentes imagens de face, que influenciam na taxa de reconhecimento. Conseqüentemente, se as imagens reconstruídas forem combinadas, pode-se gerar um conjunto de característica mais discriminante. Sabe-se 
Tabela 18 - Resumo das Métricas de desempenho alcançadas no Experimento \#1, \#2 e $\# 3$

\begin{tabular}{lllll}
\hline Técnica & $\begin{array}{l}\text { Precisão } \\
\text { média }\end{array}$ & Recall médio & F1score médio & $\begin{array}{l}\text { Acurácia } \\
\text { média }\end{array}$ \\
\hline NTOT & 0.588 & 0.486 & 0.499 & 0.486 \\
Eigenfaces & 0.428 & 0.438 & 0.407 & 0.438 \\
Fisherfaces & 0.261 & 0.219 & 0.204 & 0.219 \\
RPCA & 0.508 & 0.526 & 0.488 & 0.526 \\
FRPCA & 0.435 & 0.526 & 0.402 & 0.426 \\
APCA & 0.411 & 0.363 & 0.352 & 0.363 \\
GPCA & 0.590 & 0.597 & 0.565 & 0.597 \\
Reg. Arvores & 0.763 & 0.752 & 0.740 & 0.752 \\
Reg. Knn & 0.797 & 0.765 & 0.756 & 0.765 \\
Reg. Linear & 0.735 & 0.712 & 0.703 & 0.712 \\
Reg. Ridge & 0.736 & 0.711 & 0.702 & 0.711 \\
APCA +Ei- & 0.409 & 0.374 & 0.355 & 0.374 \\
gen +Fisher & & & & \\
Árvore & 0.554 & 0.507 & 0.481 & 0.507 \\
+GPCA & & & & \\
Todas & 0.584 & 0.565 & 0.536 & 0.565 \\
Todas Regres- & 0.402 & 0.376 & 0.355 & 0.376 \\
sores & & & & 0.537 \\
Todas & 0.541 & 0.537 & 0.513 & \\
bespaço & & & & \\
\hline
\end{tabular}

NTOT - Não trata a oclusão e não utiliza imagens ocluídas no treinamento

Fonte: Jozias Rolim, 2018

que uma grande variação intraclasse, pode levar a um espalhamento dos autovetores no espaço de imagens, os quais podem gerar imagens reconstruídas com um nível elevado de ruído que pode ser prejudicial para o reconhecimento. Isto pode justificar o desempenho ruim alcançado pelas técnicas de reconstrução Fisherface, Eigenface e APCA. Por outro lado, as técnicas baseadas em regressores alcançaram um ganho considerável ao ser aplicada em imagens com oclusão.

O experimento IV levou em consideração há existência de imagens ocluídas no conjunto de treinamento. Para que estas imagens fossem utilizadas no treinamento, as oclusões foram detectadas e a imagem de face foi reconstruída. Um resumos dos resultados obtidos pelas técnicas é apresentado na Tabela 19.

Analisando a 19, pode-se validar a hipótese de que a fusão das imagens de face no nível características pode gerar um conjunto de novas características com maior poder discriminatório, visto que a fusão realizada neste experimento produziu uma melhora 
Tabela 19 - Resumo das Métricas de desempenho alcançadas no Experimento \#4

\begin{tabular}{lllll}
\hline Técnica & $\begin{array}{l}\text { Precisão } \\
\text { média }\end{array}$ & Recall médio & F1score médio & $\begin{array}{l}\text { Acurácia } \\
\text { média }\end{array}$ \\
\hline NTOT & 0.855 & 0.830 & 0.821 & 0.830 \\
Eigenfaces & 0.920 & 0.903 & 0.900 & 0.903 \\
Fisherfaces & 0.894 & 0.862 & 0.859 & 0.862 \\
RPCA & 0.929 & 0.907 & 0.905 & 0.907 \\
FRPCA & 0.871 & 0.842 & 0.834 & 0.842 \\
APCA & 0.881 & 0.857 & 0.849 & 0.857 \\
GPCA & 0.924 & 0.898 & 0.897 & 0.898 \\
Reg. Arvores & 0.871 & 0.844 & 0.836 & 0.844 \\
Reg. Knn & 0.852 & 0.839 & 0.820 & 0.848 \\
Reg. Linear & 0.842 & 0.830 & 0.820 & 0.830 \\
Reg. Ridge & 0.852 & 0.830 & 0.820 & 0.830 \\
Todas & $\mathbf{0 . 9 4 0}$ & $\mathbf{0 . 9 1 8}$ & $\mathbf{0 . 9 1 7}$ & $\mathbf{0 . 9 1 8}$ \\
Todas & 0.934 & 0.911 & 0.909 & 0.911 \\
bespaço & & & & \\
\hline
\end{tabular}

NTOT - Não tratando oclusão e utilizando imagens ocluídas no treinamento Fonte: Jozias Rolim, 2018

considerável nas métricas de desempenho. Além disso, todas as técnicas isoladamente produziram um resultado melhor quando comparada com o não tratamento da oclusão. Este fato pode justificar o desempenho ruim alcançado pela fusão das técnicas no nível de característica no experimento \#3. Como as técnicas de reconstrução no experimento \#3 produziram imagens de face com um alto nível de ruído, a fusão no nível de característica não foi capaz de reduzir a interferência do ruído no desempenho de reconhecimento.

\subsection{Considerações Finais}

As técnicas de deteç̧ão e remoção de oclusão apresentam algumas limitações no que diz respeito a detecção da parte ocluída. Na detecção de oclusão baseada em pigmentação da pele, apenas oclusões por objetos são encontradas, enquanto a oclusão por mão na face não é detectada. Esta apresenta bons resultados para indivíduos caucasianos e asiáticos, no entanto para pessoas de pele negra, não é possível a deteç̧ão da face, pois as cores mais escuras são tratadas como oclusão. Cabelo, sobrancelha e barba também são identificados como oclusão.

A técnica de Eigenfaces obteve bons resultados em termos de detecção e reconstrução para a maioria das faces que apresentaram pouca oclusão. No entanto, quando 
a porcentagem de oclusão na face é aproxima-se ou superior a 30\%, os resultados não são satisfatórios. As técnicas baseadas em regressão demonstraram resultados melhores quando no treinamento são levadas em consideração apenas imagens sem oclusão.

A estratégia de fusão adotada nesse trabalho foi realizada apenas no nível de características, o qual foi útil apenas no experimento \#4. No experimento \#3 as imagens reconstruídas apresentaram um alto nível de ruído, ao realizar a concatenação este ruído era inserido no classificador, prejudicando a performance do reconhecimento. Apesar disso, as hipóteses levantadas no início do trabalho foram validas, a saber, i) diferentes técnicas de reconstrução de face produzem diferentes imagens de face, ii) a extração de características a partir de diferentes imagens pode gerar um conjunto de característica com alto poder discriminatório.

Existem diversas técnicas de detecção de face, extração de características, remoção da parte ocluída, reconstrução da parte ocluída, extração de características, estratégias de fusão, algoritmos de classificação e técnicas para decisão, que não foram exploradas neste trabalho, que se combinadas e estudadas podem tornar o sistema robusto e mais assertivo.

Os experimentos realizados foram executados em ambiente Linux com uma máquina com 24 CPUs e 120 GB de memória. Nessas configurações, por exemplo, o tempo de treinamento (detecção de face, detecção de oclusão, remoção da parte ocluída, reconstrução da parte ocluída, extração de características, fusão das características e treinamento do modelo baseado em rede neural) durou em torno de 32 minutos. O qual pode ser considerado relativamente alto, no entanto, para o experimento \#4 o ganho em performance pode justificar no futuro o emprego desta abordagem.

Todos códigos gerados, imagens reconstruídas, gráficos, logs de execução e dados originais utilizados pelos modelos foram disponibilizados no repositório remoto do GitHub no link "https://github.com/mocotinha/reconhecimento-facial-oclusao". Levando em consideração que os dados da base AR Face são de uso público para professores e pesquisadores e os trabalhos que fazem uso do mesmo devem citá-lo, e que sua permissão para download é necessária via processo estipulado pelo criador, descrito na página "http://www2.ece.ohiostate.edu/ aleix/ARdatabase.html", optou-se por não disponibilizar os dados originais da base. No entanto foi criado um tutorial para direcionar os interessados para a página de aquisição da base de dados. Os códigos foram desenvolvidos, em sua maioria, na linguaguem Python 2.7, contendo também alguns códigos em MatLab. 


\section{Conclusão e Perspectivas Futuras}

\subsection{O enfoque da pesquisa}

A abordagem proposta ao longo desta dissertação, dentre outras potencialidades, mostraram-se eficientes no tratamento de vários aspectos, dentre eles, destaca-se i) detecção da oclusão facial, ii) reconstrução da face ocluída, iii) reconhecimento biométrico. Comparado com as abordagens tradicionais, as quais não tratam a oclusão e emprega apenas a parte não ocluída no reconhecimento, como por exemplo, no trabalho de Yi e Sun (SONG; YIN; SUN, 2008), ou tratam a oclusão antes do processo de extração de características, como nos trabalhos Arya e Anukriti (ARYA; ANUKRITI, 2014) e Min, Hadid e Dugelay (MIN; HADID; DUGELAY, 2011), a abordagem proposta obteve um ganho em termos de taxa de reconhecimento de pelo menos $1.21 \%$ em relação as demais técnicas estudadas de forma isolada (apresentado no experimento IV), em comparação com a técnica RPCA que apresentou valor de acurácia média de 0.907 , enquanto a combinação de todas as técnicas apresentou o valor de 0.918. Quando comparado o resultado com o menor obtido, não tratando a oclusão, o ganho foi de $10.6 \%$.

Ao empregar diversas técnicas para reconstrução das imagens de faces ocluídas foi possível levantar os prós e contras de cada uma. As técnicas baseadas em subespaço levam em consideração, sempre, o subespaço de imagens gerado pelas imagens de treinamento, o que tornam elas, as técnicas baseadas em subespaços, sensíveis a imagens com oclusão no treinamento, ou seja, caso existam imagens ocluídas conhecidas no treinamento, as mesmas precisam ser descartadas. As técnicas baseadas em regressões, por outro lado, baseiam no treinamento de técnicas que permitem que seja possível prever valores com base no treinamento, assim, caso existam imagens ocluídas conhecidas, mesmo a reconstrução tendendo para a oclusão é possível obter a similaridade entre o indivíduo cadastrado no treinamento e a imagem submetida para teste.

A combinação das técnicas de reconstrução facial pode ocorrer de diversas formas. Inúmeras técnicas para extração de características permitem diversas visões da imagem. Imagens reconstruídas, principalmente por técnicas baseadas em subespaços, apresentam grande nível de ruído e deformação, pois estas atuam em toda em face, enquanto uma pequena parte da face está ocluída. Além disso, dependendo da variação intraclasse pode ocorrer um espalhamento dos autovetores que pode levar a geração de imagens de face 
altamente ruidosas. A fusão no nível de característica permitiu que fosse gerado um modelo de reconhecimento biométrico, que dependendo da performance individual de cada técnica de reconstrução, produzisse um ganho no desempenho.

\subsection{Contribuições e resultados obtidos}

As contribuições originais deste trabalho estão basicamente concentradas nos seguintes itens:

- Apresenta uma descrição detalhada de todas as etapas do reconhecimento biométrico baseado em faces com oclusão, o qual é capaz de tratar tanto imagens ocluídas quanto imagens sem oclusão;

- Foi realizada uma comparação entre dez técnicas de reconstrução facial e cinco combinações diferentes destas, apresentando diversas métricas de avaliação, como recall, f1score e acurácia;

- Todas as técnicas de reconstrução foram descritas detalhadamente e disponibilizado seu código fonte, servindo como nova fonte para desenvolvimento de pesquisa na área de reconhecimento biométrico baseado em faces com oclusão;

- Foi demonstrando experimentalmente que uma abordagem capaz de tratar a oclusão pode alcançar melhor performance quando comparada com uma que trata a oclusão;

- Experimentalmente foi demonstrado que diferentes técnicas de reconstrução de face produzem diferentes imagens de face, o que possibilita a extração de características distintas, garantindo uma maior completude no que diz respeito ao espaço de características.

- A fusão das imagens reconstruídas no nível de extração de característica pode ser capaz de gerar um vetor de característica com maior poder discriminatório.

- A abordagem proposta pode ser empregada em aplicações reais de reconhecimento biométrico que emprega outras modalidades biométricas com oclusão ou não; 


\subsection{Perspectivas Futuras}

As perspectivas futuras incluem tanto aqueles tópicos que não foram devidamente abordados ao longo deste trabalho, pelas mais variadas razões, quanto tópicos que ganham importância a partir dos resultados alcançados com este trabalho. São elas:

- Utilizar outras técnicas de detecção e remoção de oclusão para avaliar o impacto destas no desempenho das técnicas de reconstrução analisadas nesta dissertação;

- Empregar a abordagem proposta em outras bases de dados, de modo a verificar seu comportamento para difentes tipos oclusões, visto que a base de dados utilizada apresenta apenas oclusões de óculos escuros e cachecol;

- Investigar o impacto de outras funções mãe na transformada wavelet para extração de característica, dado que as sub-imagens formadas por outras funções podem conter características que sejam mais discriminatórias. Além disso, investigar qual melhor nível de decomposição e quais coeficientes utilizarem (LL, HL, LH, HH);

- Empregar outros classificadores, tais como, Florestas de caminhos ótimos e Máquina de vetores de suporte na tarefa de classificação, dado que na literatura estes têm apresentando bons resultados;

- Um dos pontos questionáveis na abordagem proposta diz respeito a estratégia de fusão. A concatenação produz um vetor de característica de alta dimensionalidade e não reduz o nivél ruído presente em cada vetor de característica. Outras estratégias, tais como, média ou média ponderada pode produzir uma vetor de característica de baixa dimensionalidade e com menor nível de ruído;

- Validar experimentos partindo do pressuposto que existem imagens com oclusão rotuladas, de modo a preparar o modelo de classificação para possíveis reconstruções, adicionando amostras reconstruídas pelas técnicas no treinamento. 


\section{Referências $^{1}$}

AKHTAR, Z.; MICHELONI, C.; FORESTI, G. L. Biometric liveness detection: challenges and research opportunities. IEEE Security 85 Privacy, IEEE, v. 13, n. 5, p. 63-72, 2015. Citado na página 46.

AL-NASER, M.; SODERSTROM, U. Reconstruction of occluded facial images using asymmetrical principal component analysis. In: Systems, Signals and Image Processing (IWSSIP), 2011 18th International Conference on. [S.l.: s.n.], 2011. p. 1-4. ISSN 2157-8672. Citado na página 74.

AL-RAISI, A. N.; AL-KHOURI, A. M. Iris recognition and the challenge of homeland and border control security in uae. Telematics and Informatics, Elsevier, v. 25, n. 2, p. 117-132, 2008. Citado na página 23.

ARYA, K. V.; ANUKRITI. Face recognition under partial occlusion using hmm and face edge length model. In: 2014 9th International Conference on Industrial and Information Systems (ICIIS). [S.l.: s.n.], 2014. p. 1-6. ISSN 2164-7011. Citado 3 vezes nas páginas 71, 75 e 113.

ASHIN, R.; MORIMOTO, A.; VAILLANCOURT, R. Image compression with multiresolution singular value decomposition and other methods. Mathematical and Computer Modelling, v. 41, n. 6, p. 773 - 790, 2005. ISSN 0895-7177. Disponível em: 〈http://www.sciencedirect.com/science/article/pii/S0895717705001329〉. Citado 2 vezes nas páginas 85 e 86.

BALA, D. Biometrics and information security. In: Proceedings of the 5th Annual Conference on Information Security Curriculum Development. New York, NY, USA: ACM, 2008. (InfoSecCD '08), p. 64-66. ISBN 978-1-60558-333-4. Disponível em: 〈http://doi.acm.org/10.1145/1456625.1456644〉. Citado na página 27.

BELLIL, W.; BRAHIM, H.; AMAR, C. B. Gappy wavelet neural network for 3d occluded faces: detection and recognition. Multimedia Tools and Applications, v. 75, n. 1, p. 365-380, 2016. ISSN 1573-7721. Disponível em: 〈http://dx.doi.org/10.1007/s11042-014-2294-6〉. Citado 2 vezes nas páginas 72 e 73.

BUREL, G.; CAREL, D. Detection and localization of faces on digital images. Pattern Recognition Letters, v. 15, n. 10, p. 963 - 967, 1994. ISSN 0167-8655. Disponível em: 〈http://www.sciencedirect.com/science/article/pii/0167865594900272〉. Citado na página 23.

BURRAGE, K. et al. A deflation technique for linear systems of equations. SIAM Journal on Scientific Computing, v. 19, n. 4, p. 1245-1260, 1998. Disponível em: 〈https://doi.org/10.1137/S1064827595294721〉. Citado na página 55.

CHANG, K. I. et al. Comparison and combination of ear and face images in appearancebased biometrics. IEEE Trans. Pattern Anal. Mach. Intell., v. 25, n. 9, p. 1160-1165, 2003. Disponível em: 〈http://dblp.uni-trier.de/db/journals/pami/pami25.html\#ChangBSV03〉. Citado na página 38.

1 De acordo com a Associação Brasileira de Normas Técnicas. NBR 6023. 
CHAUDHRY, N. A. Automatic facial occlusion detection and removal. 2012. Citado na página 74 .

CHEDDAD, A. et al. A skin tone detection algorithm for an adaptive approach to steganography. Signal Process., Elsevier North-Holland, Inc., Amsterdam, The Netherlands, The Netherlands, v. 89, n. 12, p. 2465-2478, dez. 2009. ISSN 0165-1684. Disponível em: 〈http://dx.doi.org/10.1016/j.sigpro.2009.04.022〉. Citado 2 vezes nas páginas 46 e 73.

CHELlAPPA, R.; WILSON, C. L.; SIROHEY, S. Human and machine recognition of faces: a survey. Proceedings of the IEEE, v. 83, n. 5, p. 705-741, May 1995. ISSN 0018-9219. Citado na página 23.

CORNEJO, J. Y. R. Reconhecimento de emoções baseado em expressões faciais robusto a oclusões. Repositório da Produção Científica e Intelectual da Unicamp, 2015. Citado na página 76.

DAUGMAN, J. Face and gesture recognition: overview. IEEE Transactions on Pattern Analysis and Machine Intelligence, v. 19, n. 7, p. 675-676, Jul 1997. ISSN 0162-8828. Citado na página 23.

DHARAVATH, K.; TALUKDAR, F.; LASKAR, R. Study on biometric authentication systems, challenges and future trends: A review. In: IEEE. Computational Intelligence and Computing Research (ICCIC), 2013 IEEE International Conference on. [S.1.], 2013. p. 1-7. Citado na página 46.

ERDOGMUS, D. et al. Recursive principal components analysis using eigenvector matrix perturbation. EURASIP Journal on Advances in Signal Processing, v. 2004, n. 13, p. 263984, Oct 2004. ISSN 1687-6180. Disponível em: 〈https://doi.org/10.1155/S1110865704404120〉. Citado 3 vezes nas páginas 12, 55 e 58 .

FISHER, R. A. The statistical utilization of multiple measurements. Annals of Eugenics, Blackwell Publishing Ltd, v. 8, n. 4, p. 376-386, 1938. ISSN 2050-1439. Disponível em: 〈http://dx.doi.org/10.1111/j.1469-1809.1938.tb02189.x〉. Citado na página 51.

FREUND, Y.; SCHAPIRE, R.; ABE, N. A short introduction to boosting. JournalJapanese Society For Artificial Intelligence, JAPANESE SOC ARTIFICIAL INTELL, v. 14, n. 771-780, p. 1612, 1999. Citado na página 44.

GEURTS, P.; ERNST, D.; WEHENKEL, L. Extremely randomized trees. Machine Learning, v. 63, n. 1, p. 3-42, Apr 2006. ISSN 1573-0565. Disponível em: 〈https://doi.org/10.1007/s10994-006-6226-1〉. Citado na página 65.

GOLUB, G. H.; LOAN, C. F. van. Matrix Computations. [S.1.]: The Johns Hopkins University Press, 1989. (Johns Hopkins Series in the Mathematical Sciences, 3). Citado na página 56.

HAARA, A.; KANGAS, A. Comparing k nearest neighbours methods and linear regression-is there reason to select one over the other? v. 4, 02 2012. Citado na página 62.

HADI, W. J.; JABBAR, E. K. Face occlusion detection and recovery using fuzzy c-means. Engineering; Technology Journal, v. 28, n. 18, p. 5744-5756, 2010. Citado na página 73. 
HAYKIN, S. Neural Networks: A Comprehensive Foundation. 2nd. ed. Upper Saddle River, NJ, USA: Prentice Hall PTR, 1998. ISBN 0132733501. Citado 2 vezes nas páginas 68 e 69.

HEGDE, A. et al. Perturbation-based eigenvector updates for on-line principal components analysis and canonical correlation analysis. Journal of VLSI signal processing systems for signal, image and video technology, v. 45, n. 1, p. 85-95, Nov 2006. ISSN 1573-109X. Disponível em: 〈https://doi.org/10.1007/s11265-006-9773-6〉. Citado na página 55.

HOERL, A. E.; KENNARD, R. W. Ridge regression: Biased estimation for nonorthogonal problems. Technometrics, v. 12, n. 1, p. 55-67, 1970. Disponível em: $\langle$ http://www.tandfonline.com/doi/abs/10.1080/00401706.1970.10488634〉. Citado na página 64.

JAIN, A.; FLYNN, P.; ROSS, A. A. Handbook of biometrics. [S.1.]: Springer Science \& Business Media, 2007. Citado na página 23.

JIA, H.; MARTINEZ, A. M. Face recognition with occlusions in the training and testing sets. In: Automatic Face Gesture Recognition, 2008. FG '08. 8th IEEE International Conference on. [S.l.: s.n.], 2008. p. 1-6. Citado 2 vezes nas páginas 74 e 99.

JOLLIFFE, I. Principal Component Analysis. Springer, 2002. (Springer Series in Statistics). ISBN 9780387954424. Disponível em: 〈https://books.google.com.br/books?id= $\backslash$ \olByCrhjwIC〉. Citado na página 53.

KIM, G. et al. Face occlusion detection by using b-spline active contour and skin color information. In: Control Automation Robotics Vision (ICARCV), 2010 11th International Conference on. [S.l.: s.n.], 2010. p. 627-632. Citado na página 73.

KINNUNEN, T.; HAUTAMäKI, V.; FRäNTI, P. Fusion of Spectral Feature Sets for Accurate Speaker Identification. In: Proceeding of International Conference Speech and Computer. [S.1.: s.n.], 2004. p. 361-365. Citado na página 40.

KUNG, S. Y.; DIAMANTARAS, K. I.; TAUR, J. S. Adaptive principal component extraction (apex) and applications. IEEE Transactions on Signal Processing, v. 42, n. 5, p. 1202-1217, May 1994. ISSN 1053-587X. Citado na página 55.

LARRABEE, B.; SCOTT, H. M.; BELLO, N. M. Ordinary least squares regression of ordered categorical data: Inferential implications for practice. Journal of Agricultural, Biological, and Environmental Statistics, v. 19, n. 3, p. 373-386, Sep 2014. ISSN 1537-2693. Disponível em: 〈https://doi.org/10.1007/s13253-014-0176-z〉. Citado na página 63.

LEE, P. H. et al. Distinctive personal traits for face recognition under occlusion. In: 2006 IEEE International Conference on Systems, Man and Cybernetics. [S.l.: s.n.], 2006. v. 5, p. 4202-4207. ISSN 1062-922X. Citado na página 75.

LI, S. Z.; JAIN, A. K. Handbook of Face Recognition. 2nd. ed. [S.1.]: Springer Publishing Company, Incorporated, 2011. ISBN 085729931X, 9780857299314. Citado na página 23.

MALLAT, S. A Wavelet Tour of Signal Processing, Third Edition: The Sparse Way. 3rd. ed. [S.1.]: Academic Press, 2008. ISBN 0123743702, 9780123743701. Citado 2 vezes nas páginas 67 e 68 . 
MAO, J.; JAIN, A. K. Artificial neural networks for feature extraction and multivariate data projection. Trans. Neur. Netw., IEEE Press, Piscataway, NJ, USA, v. 6, n. 2, p. 296317, mar. 1995. ISSN 1045-9227. Disponível em: 〈http://dx.doi.org/10.1109/72.363467〉. Citado na página 55.

MARCIALIS, G. L.; ROLI, F. Fingerprint verification by fusion of optical and capacitive sensors. Pattern Recogn. Lett., Elsevier Science Inc., New York, NY, USA, v. 25, n. 11, p. 1315-1322, ago. 2004. ISSN 0167-8655. Disponível em: 〈http://dx.doi.org/10.1016/j.patrec.2004.05.011〉. Citado na página 38.

MARTÍnEZ, A.; BENAVENTE, R. The AR Face Database. Bellatera: [s.n.], 1998. Cites in Scholar Google: http://scholar.google.com/scholar?hl=en\&lr=\&client=firefoxa\&cites $=1504264687621469812$. Disponível em: 〈http://www.cat.uab.cat/Public/ Publications/1998/MaB1998〉. Citado na página 79.

MARTÍNEZ, A. M. Recognizing imprecisely localized, partially occluded, and expression variant faces from a single sample per class. IEEE Trans. Pattern Anal. Mach. Intell., IEEE Computer Society, Washington, DC, USA, v. 24, n. 6, p. 748-763, jun. 2002. ISSN 0162-8828. Disponível em: 〈http://dx.doi.org/10.1109/TPAMI.2002.1008382〉. Citado 2 vezes nas páginas 71 e 74 .

MIN, R.; HADID, A.; DUGELAY, J. L. Improving the recognition of faces occluded by facial accessories. In: Automatic Face Gesture Recognition and Workshops (FG 2011), 2011 IEEE International Conference on. [S.l.: s.n.], 2011. p. 442-447. Citado 2 vezes nas páginas 74 e 113.

MONWAR, M.; GAVRILOVA, M. Multimodal biometric system using rank-level fusion approach. Systems, Man, and Cybernetics, Part B: Cybernetics, IEEE Transactions on, v. 39, n. 4, p. 867-878, 2009. ISSN 1083-4419. Citado na página 36.

OJA, E. Book; Book/Illustrated. Subspace methods of pattern recognition. [S.l.]: Letchworth, Hertfordshire, England : Research Studies Press ; New York : Wiley, 1983. Includes index. ISBN 0863800106. Citado na página 55.

PHILLIPS, P. J. et al. The feret evaluation methodology for face-recognition algorithms. IEEE Transactions on pattern analysis and machine intelligence, IEEE, v. 22, n. 10, p. 1090-1104, 2000. Citado na página 23.

RAGHAVENDRA, R.; RAO, A.; KUMAR, G. H. Multisensor biometric evidence fusion of face and palmprint for person authentication using particle swarm optimisation ;. Int. J. Biometrics, Inderscience Publishers, Inderscience Publishers, Geneva, SWITZERLAND, v. 2, n. 1, p. 19-33, dez. 2010. ISSN 1755-8301. Disponível em: 〈http://dx.doi.org/10.1504/IJBM.2010.030414〉. Citado na página 37.

RAO, Y. N.; PRINCIPE, J. C. Robust on-line principal component analysis based on a fixed-point approach. In: 2002 IEEE International Conference on Acoustics, Speech, and Signal Processing. [S.1.: s.n.], 2002. v. 1, p. I-981-I-984. ISSN 1520-6149. Citado na página 55.

RAO, Y. N.; PRINCIPE, J. C.; WONG, T. F. Fast rls-like algorithm for generalized eigendecomposition and its applications. Journal of VLSI signal processing systems for signal, image and video technology, v. 37, n. 2, p. 333-344, Jun 2004. ISSN 0922-5773. 
Disponível em: 〈https://doi.org/10.1023/B:VLSI.0000027495.79266.ad〉. Citado na página 55 .

ROSS, A.; GOVINDARAJAN, R. Feature Level Fusion Using Hand and Face Biometrics. 2005. Citado na página 38.

ROSS, A.; JAIN, A. Information fusion in biometrics. Pattern Recognition Letters, v. 24, p. 2115-2125, 2003. Citado 2 vezes nas páginas 39 e 40.

ROSS, A.; JAIN, A. K. Multimodal biometrics: an overview. In: . [S.l.: s.n.], 2004. p. 1221-1224. Citado na página 35.

SOBOTTKA, K.; PITAS, I. A novel method for automatic face segmentation, facial feature extraction and tracking. Signal Processing: Image Communication, v. 12, n. 3, p. 263 - 281, 1998. ISSN 0923-5965. Disponível em: 〈http://www.sciencedirect.com/science/ article/pii/S0923596597000428〉. Citado na página 73.

SÖDERSTRÖM, U.; LI, H. Asymmetrical principal component analysis theory and its applications to facial video coding. [S.l.]: INTECH Open Access Publisher, 2011. Citado na página 54.

SONG, C.; YIN, B.; SUN, Y. Eyeglasses eigenface based glasses-face recognition. In: Networking, Sensing and Control, 2008. ICNSC 2008. IEEE International Conference on. [S.l.: s.n.], 2008. p. 1385-1390. Citado 2 vezes nas páginas 75 e 113.

TURK, M.; PENTLAND, A. Eigenfaces for recognition. Journal of cognitive neuroscience, v. 3, n. 1, p. 71-86, 1991. Citado na página 48.

TURK, M.; PENTLAND, A. Eigenfaces for recognition. J. Cognitive Neuroscience, MIT Press, Cambridge, MA, USA, v. 3, n. 1, p. 71-86, jan. 1991. ISSN 0898-929X. Disponível em: 〈http://dx.doi.org/10.1162/jocn.1991.3.1.71〉. Citado 2 vezes nas páginas 49 e 75.

TURK, M.; PENTLAND, A. Eigenfaces for recognition. J. Cognitive Neuroscience, MIT Press, Cambridge, MA, USA, v. 3, n. 1, p. 71-86, jan. 1991. ISSN 0898-929X. Disponível em: 〈http://dx.doi.org/10.1162/jocn.1991.3.1.71〉. Citado na página 83.

VIOLA, P.; JONES, M. J. Robust real-time face detection. International journal of computer vision, Springer, v. 57, n. 2, p. 137-154, 2004. Citado 3 vezes nas páginas 42, 44 e 45.

WANG, C. et al. Matrix perturbation based approach for sensitivity analysis of eigen-solutions in a microgrid. Science China Technological Sciences, v. 56, n. 1, p. 237-244, Jan 2013. ISSN 1869-1900. Disponível em: 〈https://doi.org/10.1007/s11431-012-5067-3〉. Citado na página 56.

WANG, Z. M.; TAO, J. H. Reconstruction of partially occluded face by fast recursive pca. In: 2007 International Conference on Computational Intelligence and Security Workshops (CISW 2007). [S.l.: s.n.], 2007. p. 304-307. Citado na página 58.

YANG, B. Projection approximation subspace tracking. Trans. Sig. Proc., IEEE Press, Piscataway, NJ, USA, v. 43, n. 1, p. 95-107, jan. 1995. ISSN 1053-587X. Disponível em: 〈http://dx.doi.org/10.1109/78.365290〉. Citado na página 55. 
ZHANG, Z. et al. Choosing wavelet methods, filters, and lengths for functional brain network construction. PLOS ONE, Public Library of Science, v. 11, n. 6, p. 1-24, 062016. Disponível em: 〈https://doi.org/10.1371/journal.pone.0157243〉. Citado na página 86.

ZIAUDDIN, S.; DAILEY, M. N. A robust hybrid iris localization technique. In: IEEE. Electrical Engineering/Electronics, Computer, Telecommunications and Information Technology, 2009. ECTI-CON 2009. 6th International Conference on. [S.1.], 2009. v. 2, p. 1058-1061. Citado na página 23. 